1

2 Elsevier required licence: (c) <2017>. This manuscript version is made available under the 3 CC-BY-NC-ND 4.0 license http://creativecommons.org/licenses/by-nc-nd/4.0/
4

5

6

7

8

9

10

11

12

13

14

15

16

17

18

19

20

21

22

23

24

25

26

27

28

29

30

31

32

33

34

35

36

37

38

39

40

41

42

43

44

45

46

47

48

49

50

51

52

530 


\title{
Design and Synthesis of Short Amphiphilic Cationic Peptidomimetics Based on Biphenyl Backbone as Antibacterial Agents
}

\author{
Naresh Kumar*1 \\ ${ }^{1}$ School of Chemistry, UNSW Australia, Sydney, NSW 2052, Australia. \\ ${ }^{2}$ School of Optometry and Vision Science, UNSW Australia, Sydney, NSW 2052, Australia \\ ${ }^{3}$ School of Life Sciences, University of Technology Sydney, PO Box 123, Ultimo 2007, Australia. \\ ${ }^{4}$ School of Civil and Environmental Engineering, UNSW, Sydney, NSW 2052 Australia \\ ${ }^{5}$ SDx Tethered Membranes Pty Ltd, 30-32 Barcoo St, Roseville 2069, Australia. \\ *E-mail: n.kumar@unsw.edu.au* Tel: +61 29385 4698; Fax: +61 293856141.
}

Rajesh Kuppusamy ${ }^{1}$, Muhammad Yasir ${ }^{2}$, Thomas Berry ${ }^{3}$, Charles G. Cranfield ${ }^{3}$, Shashidhar Nizalapur ${ }^{1}$, Eugene Yee ${ }^{1}$, Onder Kimyon ${ }^{4}$, Aditi Taunk ${ }^{1}$, Kitty K. K. Ho ${ }^{1}$, Bruce Cornell ${ }^{5}$, Mike Manefield ${ }^{4}$, Mark Willcox ${ }^{2}$, David StC Black ${ }^{1}$, and

\section{ABSTRACT}

Antimicrobial peptides (AMPs) and their synthetic mimics have received recent interest as new alternatives to traditional antibiotics in attempts to overcome the rise of antibiotic resistance in many microbes. AMPs are part of the natural defenses of most living organisms and also they have a unique mechanism of action against bacteria. Herein, a new series of short amphiphilic cationic peptidomimetics were synthesized by incorporating the 3'-amino-[1,1'-biphenyl]-3-carboxylic acid backbone to mimic the essential properties of natural AMPs. By altering hydrophobicity and charge, we identified the most potent analogue $\mathbf{2 5 g}$ that was active against both Gram-positive Staphylococcus aureus $(\mathrm{MIC}=15.6 \mu \mathrm{M})$ and Gram-negative Escherichia coli $(\mathrm{MIC}=7.8 \mu \mathrm{M})$ bacteria. Cytoplasmic permeability assay results revealed that $\mathbf{2 5 \mathrm { g }}$ acts primarily by depolarization of lipids in cytoplasmic membranes. The active compounds were also investigated for their cytotoxicity to human cells, lysis of lipid bilayers using tethered bilayer lipid membranes (tBLMs) and their activity against pre-established biofilms of S. aureus and E. coli.

Keywords: antimicrobial peptide, peptidomimetics, membrane disruption, antibiofilm activity.

\section{Introduction}

Antibiotic resistance in bacteria is a major concern facing global public health. Multidrug resistant strains of Gram-positive bacteria such as methicillin-resistant Staphylococcus aureus (MRSA), methicillin-resistant Staphylococcus epidermidis (MRSE), and vancomycin-resistant Enterococci faecalis (VRE), and Gram-negative bacteria such as Escherichia coli, Klebsiella pneumoniae, and Pseudomonas aeruginosa, have emerged as major causes of hospital and community-acquired infections [1]. Particularly, Gram-positive bacteria such as MRSA account for a high percentage of hospital-acquired infections [1,2]. Due to the increasing resistance of bacterial strains against conventional antibiotics, efforts have been made to investigate naturally-occurring antimicrobial peptides (AMPs) and their derivatives as alternative antimicrobial agents [3-5]. AMPs such as PMX30063 and LTX109 are currently in clinical trials [6-8]. Although some promising AMPs are in the pipeline, there is still an urgent need for the development of new antibiotic scaffolds.

AMPs are widespread in nature and serve as the first-line of defense against microbial attack in insects, plants, amphibians, and mammals [9-12]. Unlike conventional antibiotics, AMPs act via non-receptor interactions, which make it difficult for bacteria to develop resistance to AMPs. Most cationic antimicrobial peptides possess a rigid secondary structure and adopt an amphipathic conformation such that their positively-charged face interacts electrostatically with the negatively-charged membrane surface, while their hydrophobic face inserts into the lipophilic interior of the membrane [13, 14]. The broad-spectrum antimicrobial peptide pexiganan, which acts via disruption of bacterial cell membranes, has reached phase III clinical trials [15]. Only a few naturally-occurring AMPs have been used clinically, including polymyxin B and colistin (polymyxin E), due to their in vivo toxicity, susceptibility to proteolytic degradation, poor activity in the presence of salts and cytotoxicity to the host cells [16]. Produced through solid-phase synthesis, AMPs also have high manufacturing costs [17].

The drawbacks of conventional AMPs have stimulated the development of peptidomimetics [18], which are synthetic nonpeptidic molecules designed to mimic the properties of peptides. The various kinds of peptidomimetics include $\alpha$-peptides [19], $\beta$-peptides [20], peptoids [21-23], $\beta$-turn mimetics [24], cationic $\beta^{3 R 3}$-peptides [25] and lipopeptides [26]. In particular, a number of structurally simple, cationic peptidomimetics possessing natural or unnatural amino acids and with amphipathic character have been investigated as antibacterial agents [27, 28]. Svendsen and co-workers have synthesized a range of peptides of variable length utilizing arginine and tryptophan aminoacids, and showed good minimal inhibitory concentration (MIC) of $2.5 \mu \mathrm{g} \mathrm{mL}$ against Staphylococcus aureus and $5 \mu \mathrm{g} \mathrm{mL}^{-1}$ against Escherichia coli [29]. An ultra-short pyrazole-based peptidomimetics showed a MIC of $4 \mu \mathrm{g} \mathrm{mL}^{-1}$ against MRSA and was four times more potent than melittin [30]. Pyne and co-workers have developed $C 2$-symmetric binaphthyl-containing peptidomimetics that showed excellent antimicrobial activity against both Grampositive and Gram-negative bacterial pathogens [31]. Haldar and co-workers designed aryl-alkyl-lysine-based peptide mimics that mimicked the membrane-active properties of natural AMPs [32]. Their group also investigated cationic small molecules with spatial control of hydrophobicity to minimize toxicity against human erythrocytes while still maintaining antibacterial activity [33].

Our research group has recently synthesized short glyoxamide-based peptidomimetics via the ring-opening reaction of $\mathrm{N}$ naphthoylisatins with amines and amino acids $[34,35]$. As part of an ongoing program to develop short antimicrobial peptidomimetics, we were interested in utilizing the biphenyl backbone due to its frequent presence in medicinal chemistry [36, 37]. In an analysis of scaffolds of pharmacologically active molecules, biphenyl was found to be present in $2.1 \%$ of reference drug molecules [38,39]. Furthermore, the importance of the biphenyl unit is shown by their presence in several natural products [38- 
40], such as the antibacterial compounds MC21-A (1) and MC21-B (2) isolated from marine bacterium Pseudoalteromonas phenolica [41, 42]. The biphenyl-containing antibacterial compounds biphenomycin A (3) and B (4) were isolated from the cultured broth of Streptomyces griseorubiginosus 43608 [43-45]. Antibiotics such as arylomycin A2 (5), arylomycin B2 (6) and vancomycin also contain biphenyl moieties.<smiles>Oc1c(Br)cc(Br)cc1-c1cc(Br)cc(Br)c1O</smiles><smiles>O=C(O)c1ccc(-c2ccc(C(=O)O)c(Br)c2Br)c(Br)c1</smiles>
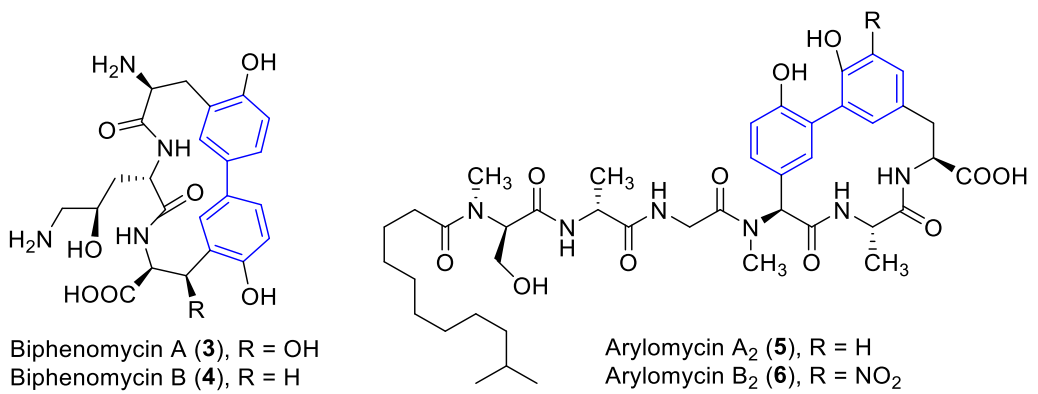

Fig. 1 Biphenyl-containing antibacterial compounds, with the biphenyl motif highlighted in blue.

In this work, we designed a unique scaffold for developing short antimicrobial peptidomimetics by utilizing a 3, 3'-substituted biphenyl unit as the key hydrophobic backbone to mimic the structural and biological properties of many AMPs. The segregation of hydrophobic $\left(\mathrm{R}^{1}\right)$ and cationic $\left(\mathrm{R}^{2}\right)$ groups via the biphenyl core confers amphipathic character to the entire molecule (Fig. 2). Importantly, the modular design of this scaffold allows for ready optimization of the biphenyl-based peptidomimetics simply by varying the nature of the hydrophobic $\left(\mathrm{R}^{1}\right)$ and cationic $\left(\mathrm{R}^{2}\right)$ groups.
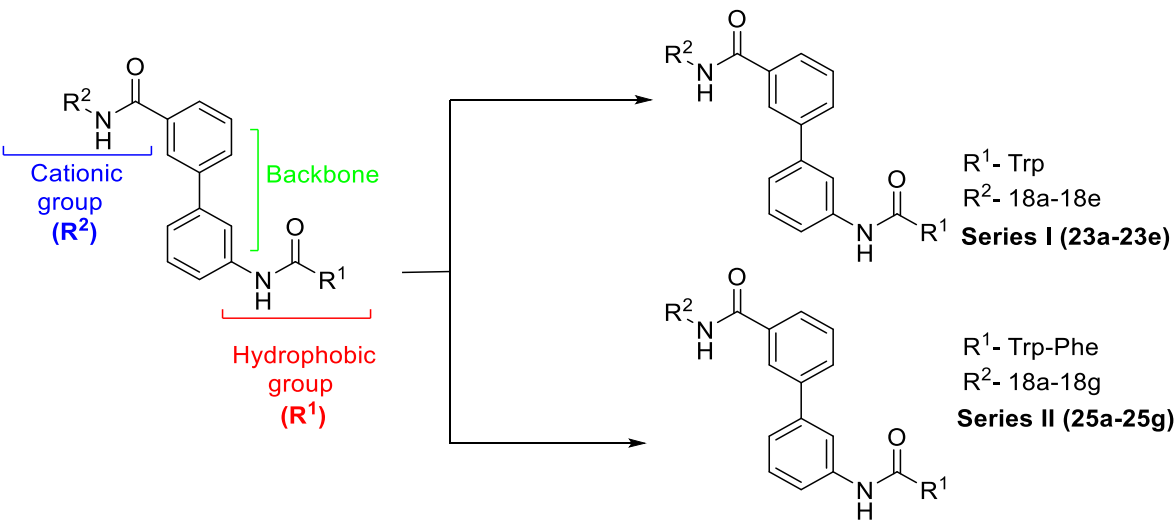

Fig. 2 General structure of biphenyl based peptidomimetics

The biphenyl-based peptidomimetics synthesized in this work were classified into two series based on the length of the hydrophobic group $\left(\mathrm{R}^{1}\right)$ attached to the molecule. Series I (23a-23e) incorporated a single tryptophan (Trp) group at the 3-position of biphenyl, whereas series II (25a-25g) incorporated a tryptophan-phenylalanine (Trp-Phe) dipeptide at the same position. The selection of Trp was based on its ability to interact with the interfacial region of the bacterial membranes, thereby anchoring the biphenyl derivatives to lipid bilayers [46]. The cationic groups $\left(\mathrm{R}^{2}\right)$ were incorporated at the 3'-position of biphenyl, and they included 1,2-diaminoethane, 1-(2-aminoethyl)guanidine, and amino acids such as arginine and lysine. This demonstrated the importance of short non-natural amine and guanidine groups over cationic amino acids. Arginine and 1-(2-aminoethyl)guanidine were chosen because the guanidine group exhibits a stronger electrostatic interaction and more extensive hydrogen bonding with the negatively-charged phospholipids of the bacterial cell membrane [47].

The synthesized compounds were evaluated for biological activity against Gram-positive and Gram-negative bacterial strains. In addition, cytotoxicity was also investigated for selected potent antimicrobial compounds. To study how the active compounds interacted with lipid membranes, tethered bilayer lipid membranes (tBLMs) in association with electrical impedance spectroscopy was employed. In addition, the ability of the compounds to alter cytoplasmic permeability was assessed by using the membrane potential-sensitive cyanine dye diSC3-5. Finally, the ability of the compounds to inhibit the biofilm formation of $S$. aureus and $E$. coli was also evaluated.

\section{Results and discussion}

\subsection{Design and synthesis of biphenyl derived peptidomimetics}

The acid 17 was synthesized by deprotecting the Boc group of $\mathbf{1 2}$ with TFA, followed by amide formation with $\mathbf{1 5}$ and subsequent ester hydrolysis using aqueous sodium hydroxide. On coupling 17 with different amines (18a-18g) respective amides 24a-24g were yielded and the deprotection of $\mathbf{2 4 a - 2 4 g}$ gave the series II compounds (25a-25g). The synthesis of amines $\mathbf{1 8 b}$, and $\mathbf{1 8 d}-\mathbf{1 8 g}$ were shown in scheme2. The guanylation reaction using $N, N^{\prime}$-Di-Boc- $1 H$-pyrazole-1-carboxamidine provides the corresponding amine 18b. The amino ester $\mathbf{1 8 d}$ was prepared from $\mathrm{NH}_{2}-\mathrm{Arg}(\mathrm{Mtr})-\mathrm{OH}$ using thionyl chloride and methanol. The acids $\mathbf{2 1}\left(\mathbf{X}^{\prime}\right)$, 21(X'), 20(Y') were used to synthesize the amides 21a, 20b, 21b using $\mathrm{PyBOP} / \mathrm{CH}_{2} \mathrm{Cl}_{2}$ coupling agent, and subsequent Fmoc cleavage using piperidine/DMF to afford $\mathbf{1 8 e - 1 8 g}$. 


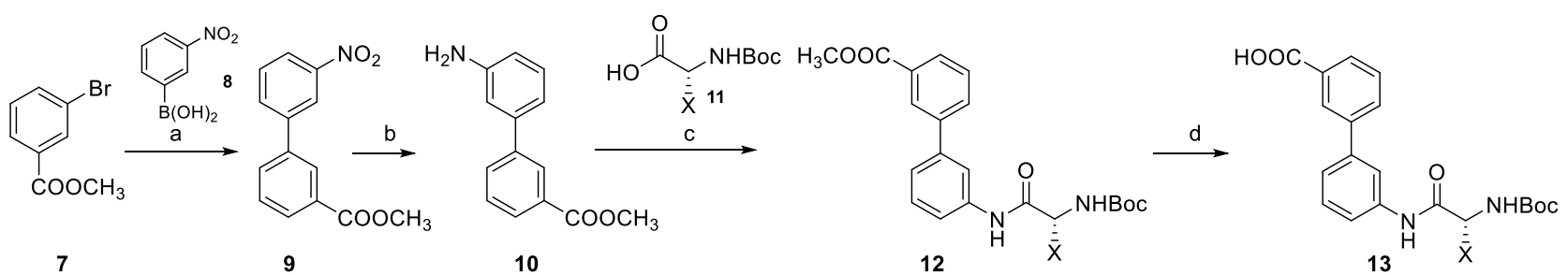

9

13

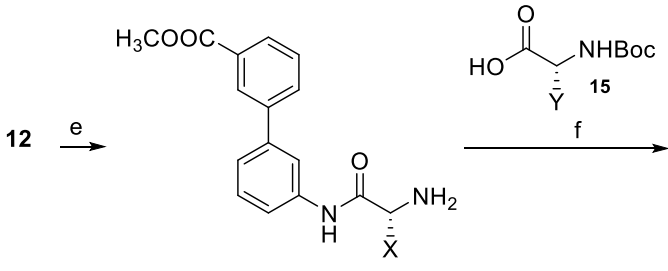

14
$\mathrm{H}_{3} \mathrm{COOC}$<smiles>[Y]C(NC(=O)OCC)C(=O)NC([Y])C(=O)Nc1cccc(-c2cccc(C)c2)c1</smiles>

(n)OC

17

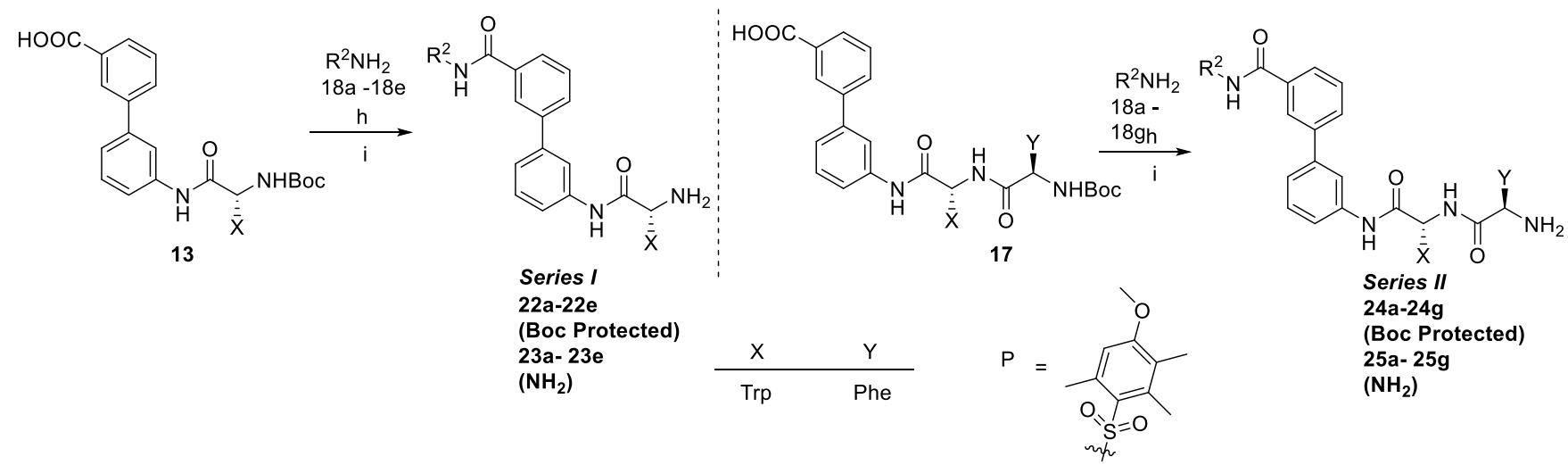

18a

$18 b$

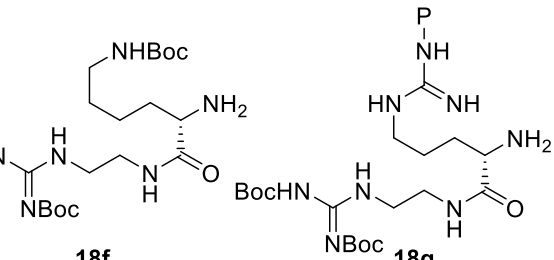

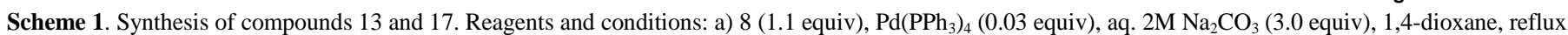
overnight, $65 \%$; b) $10 \% \mathrm{Pd} / \mathrm{C}, \mathrm{H}_{2}$ balloon, THF, rt, overnight, $90 \%$; c) EDCI (1.2 equiv), HOBt (1.0 equiv), DIEA (2.5 equiv), DMF, rt, 8 h, $63 \%$; d) aq. $1 \mathrm{~N}$ $\mathrm{NaOH}\left(2.0\right.$ equiv), THF, MeOH, rt, overnight, 90\% e) TFA, $\mathrm{CH}_{2} \mathrm{Cl}_{2}$, RT, 4h, 89\%; f) EDCI (1.2 equiv), HOBt (1.0 equiv), DIEA (2.5 equiv), DMF, rt, 8h, 54\%; g) aq. $1 \mathrm{~N} \mathrm{NaOH}$ (2.0 equiv), THF, MeOH, rt, overnight, 89\%; h) EDCI (1.2 equiv), HOBt (1.0 equiv), DIEA (2.5 equiv), DMF, rt, 8 h-overnight, 52-84\%; i) TFA, $\mathrm{CH}_{2} \mathrm{Cl}_{2}, \mathrm{RT}, 4$ h-overnight, $49-89 \%$.<smiles>NCCNC(=NC(=O)OCc1ccccc1)C(=O)O</smiles>

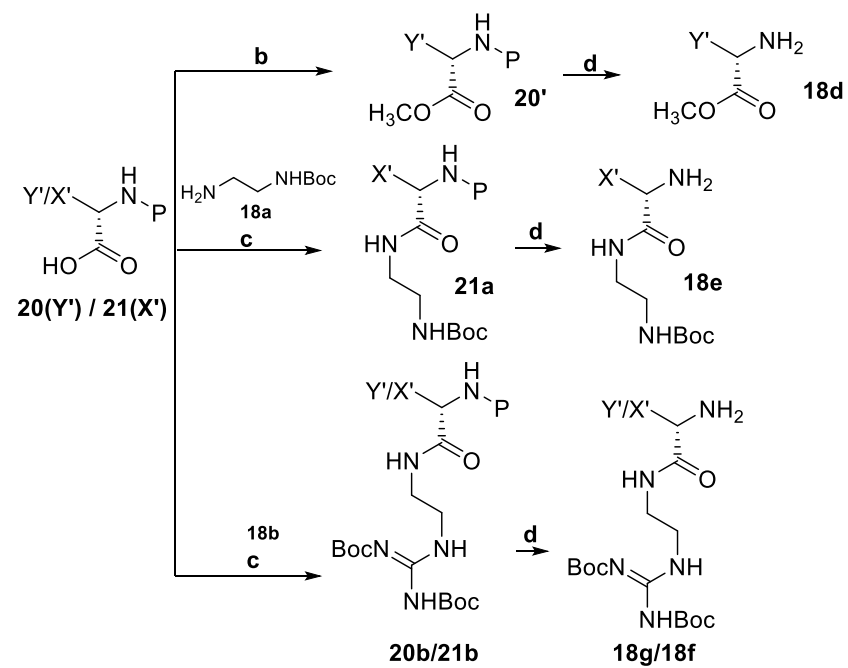

\begin{tabular}{rrrrr} 
& $X^{\prime}$ & $Y^{\prime}$ & $P$ & \% Yield \\
\hline 20' & & Arg & Fmoc & 90 \\
21a & Lys & & Fmoc & 54 \\
20b & & Arg & Fmoc & 34 \\
21b & Lys & & Fmoc & 41 \\
& & & & \\
& $X^{\prime}$ & $Y^{\prime}$ & \% Yield & \\
\hline 18d & & Arg & 85 & \\
18e & Lys & & 89 & \\
18g & & Arg & 78 & \\
18f & Lys & & 79 &
\end{tabular}

Scheme 2. Synthesis of $\mathbf{1 8 b}, \mathbf{1 8 d - 1 8 g}$. Reagents and conditions: a) $N, N^{\prime}$-Di-Boc- $1 H$-pyrazole-1-carboxamidine ( 0.1 equiv), THF, rt, 30 min, crude; b) SOCl 2 (1.5 equiv), $\mathrm{MeOH}$, rt, overnight; c) PyBOP (1.1 equiv), $\mathrm{HOBt}$ (1.0 equiv), DIEA (3.0 equiv), $\mathrm{CH}_{2} \mathrm{Cl}_{2}$, rt, overnight; d) Piperidine (2.0 equiv), DMF, RT, overnight. 
The biphenyl derivative $\mathbf{2 9}$ attached with guanidine without any hydrophobic group was synthesized as shown in scheme3. The biphenyl ester 9 was hydrolyzed to acid $\mathbf{2 6}$ and coupling with $\mathbf{1 8 b}$ to afford the amide $\mathbf{2 7}$ and, subsequent deprotection with TFA gave 29. Finally, 35 without the biphenyl backbone but intact with hydrophobic and cationic group was synthesized from LTryptophan 30. The acid $\mathbf{3 3}$ was obtained by the sequential formation of dipeptide $\mathbf{3 2}$ from 30, followed by ester hydrolysis. The amide 34 was obtained on coupling 33 with $\mathbf{1 8 b}$, and it was deprotected with TFA to yield 35 (Scheme 4).

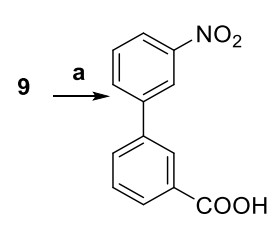

26

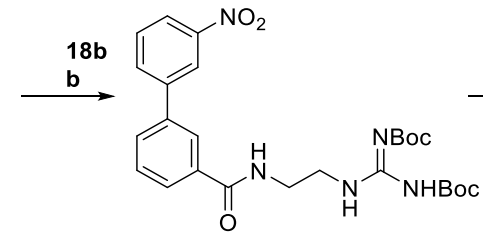

27

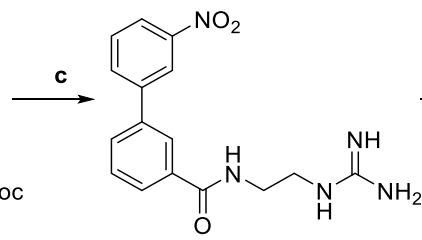

28

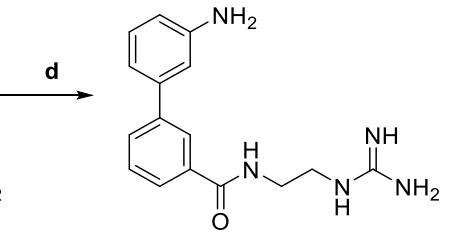

29

Scheme 3. Synthesis of compound 29. Reagents and conditions: a) aq. 1N NaOH (2.0 equiv), THF, MeOH, rt, overnight, $90 \%$; b) EDCI (1.2 equiv), HOBt (1.0 equiv), DIEA (2.5 equiv), DMF, rt, overnight, $80 \%$; c) TFA, $\mathrm{CH}_{2} \mathrm{Cl}_{2}, \mathrm{rt}$, 4h-overnight, $90 \%$; d) $N, N^{\prime}$-Di-Boc- $1 H$-pyrazole- 1 -carboxamidine (1.0 equiv), Et ${ }_{3} \mathrm{~N}$ (2.0 equiv), THF, RT, $6 \mathrm{~h}, 85 \%$ e) $10 \% \mathrm{Pd} / \mathrm{C}, \mathrm{H}_{2}$ balloon, rt, $5 \mathrm{~h}, 40 \%$.<smiles>COC(=O)[C@H](N)Cc1c[nH]c2ccc(CC(C)C)cc12</smiles><smiles>CC(C)(C)OC(=O)N=C(NCCNC(=O)[C@H](Cc1c[nH]c2ccccc12)NC(=O)[C@@H](N)Cc1ccccc1C[C@@H](N)C(C)(C)C)NC(=O)OC(C)(C)C</smiles>

Scheme 4. Synthesis of compound 35. Reagents and conditions: a) $\mathrm{SOCl}_{2}$ (1.5 equiv), MeOH, RT, overnight, $90 \%$; b) EDCI (1.2 equiv), HOBt (1.0 equiv), DIEA (2.5 equiv), DMF, rt, overnight, $65 \%$; c) $1 \mathrm{~N} \mathrm{NaOH}_{(\mathrm{aq})}(2.0$ equiv), THF, MeOH, rt, overnight, $91 \%$; d) EDCI (1.2 equiv), HOBt (1.0 equiv), DIEA (2.5 equiv), DMF, rt, overnight, $45 \%$; e) TFA, $\mathrm{CH}_{2} \mathrm{Cl}_{2}$, RT, overnight, $47 \%$.

\subsection{Antimicrobial activity study}

The antimicrobial activities of the newly synthesized peptidomimetics were assessed against the Gram-positive bacterium Staphylococcus aureus [SA38], and two Gram-negative bacteria, Pseudomonas aeruginosa [PA01], and Escherichia coli [K12] are summarized in table1.

The series I compounds 23a-23e were tested against Gram-positive bacterium Staphylococcus aureus [SA38]. The compound 23b $(\mathrm{MIC}=62.5 \mu \mathrm{M})$ in which the biphenyl group segregated with tryptophan hydrophobic group and simple guanidine cationic group showed more activity compared to simple amine cationic group 23a $(\mathrm{MIC}=125 \mu \mathrm{M})$. The compound $\mathbf{2 3 b}$ containing simple guanidium cationic moiety which mimic the ariginine amino acid found in natural AMPs displayed the good activity. The MIC values of 23c $(31.2 \mu \mathrm{M})$ and $23 d(62.5 \mu \mathrm{M})$ attached with the Lys-ester and Arg-ester cationic groups are compared with 23a and 23b by maintaining the total net charge and hydrophobicity of the compounds. We noticed that the amine containing cationic group of lysine methyl ester $\mathbf{2 3 d}$ showed four-fold increase in antibacterial activity compared to the 23a. Interestingly, the similar antibacterial activity of $\mathbf{2 3 b}$ and $\mathbf{2 3 d}$ revealed that the simple guanidine cationic group is enough to mimic the arginine. The antibacterial activity of compound $\mathbf{2 3 e}(\mathrm{MIC}=31.2 \mu \mathrm{M})$, and $\mathbf{2 3 c}$ remains same even though the net cationic charge is increased. This could be due to the imbalance of the peptide hydrophobicity and charge distribution. Although, the series I compounds 23a-23e found to be active against $S$. aureus, these compounds did not have significant activity against the two Gramnegative bacteria, Pseudomonas aeruginosa [PA01], and Escherichia coli [K12]. Based on the results from series I, increase in the net cationic charge did not show any profound antibacterial effect against Gram-positive and Gram-negative bacterial strains.

The series II compounds 25a-25g were made on hypothesis that the increase in hydrophobicity will enhance the antibacterial activity and to understand the effect of hydrophobicity along with the cationic character against the Gram-negative pathogens. All the compounds 25a-25g were tested against the Gram-positive bacterium Staphylococcus aureus [SA38]. As expected 25a (MIC $=62.5 \mu \mathrm{M})$ and $25 \mathrm{~b}(\mathrm{MIC}=15.6 \mu \mathrm{M})$ containing excess hydrophobic phenylalanine group showed excellent activity compared to less hydrophobic compounds $23 \mathbf{a}(\mathrm{MIC}=125 \mu \mathrm{M})$ and $\mathbf{2 3 b}(\mathrm{MIC}=62.5 \mu \mathrm{M})$. The increase in hydrophobicity of $23 \mathbf{c}(31.2 \mu \mathrm{M})$ did not improve the MIC of 25c. Whereas, in compound $25 \mathbf{d}(31.2 \mu \mathrm{M})$ the activity increased two-fold compared to $23 \mathbf{d}(62.5$ $\mu \mathrm{M})$. This may be resulted due to the increase in hydrophobic bulkiness along with the extensive hydrogen bonding of guanidine group. 25e (MIC $=31.2 \mu \mathrm{M})$ retained the same activity compared to $23 \mathrm{e}(\mathrm{MIC}=31.2 \mu \mathrm{M})$ though the hydrophobicity is increased may be due to the net positive charge equals with the number of hydrophobic group. We hypothesized that if the net positive charge is important in the activity of $\mathbf{2 5 e}$ and if the amine groups are replaced with guanidine groups, the activity should increase. 
$25 f(31.2 \mu \mathrm{M})$ showed same activity after replacing with one guanidine of $\mathbf{2 5 e}$. As anticipated the compound $\mathbf{2 5 g}(\mathrm{MIC}=15.6$ $\mu \mathrm{M})$ replaced with the two-guanidine by attaching arginine in place of lysine group in $\mathbf{2 5 f}$ showed excellent activity compared to 25e $(\mathrm{MIC}=31.2 \mu \mathrm{M})$ probably due to the strong hydrogen bonding with the negatively charged phospholipids of bacterial cell membrane.

25a-25g were also tested against Gram-negative bacteria Escherichia coli [K12]. Compounds 25a, 25c, 25d did not show notable antibacterial activity. The compound $\mathbf{2 5 b}(\mathrm{MIC}=31.2 \mu \mathrm{M}$ ), with the increased hydrophobicity compared to $\mathbf{2 3 e}$ (MIC $=>125$ $\mu \mathrm{M})$ showed dramatically four-fold improvement against $E$. coli. The antibacterial activity of cationic peptides on Gram-negative bacteria is influenced by two steps to overcome the outer-membrane barrier. The high membrane bound concentration of the cationic peptides facilitates the outer-membrane permeabilization and in the final step the inner membrane damage causes the cell lysis [48]. In this step, the hydrophobic interactions become dominant. This clearly suggests the importance of activity of $\mathbf{2 5 b}$ compared to 23e. The compounds $25 \mathrm{f}(\mathrm{MIC}=15.6 \mu \mathrm{M})$, and $25 \mathrm{~g}(\mathrm{MIC}=7.8 \mu \mathrm{M})$ containing guanidine cationic groups displayed good activity against $E$. coli compared to $25 \mathrm{c}(\mathrm{MIC}=125 \mu \mathrm{M})$ and $25 \mathrm{e}(\mathrm{MIC}=31.2 \mu \mathrm{M})$ containing the amine cationic groups. These results evidently showed that the electrostatic attraction played the decisive role for the excellent activity against the E. coli. The compound $29(62.5 \mu \mathrm{M})$ retains the biphenyl backbone showed the similar activity of $\mathbf{2 3 b}$ against $S$. aureus and E. coli even though the hydrophobic tryptophan group was removed. This could be due to the hydrophobicity of the biphenyl backbone.

Finally, the MIC results of $\mathbf{3 5}$ without the biphenyl backbone ( $>250 \mu \mathrm{M})$ compared with $\mathbf{2 3 b}(62.5 \mu \mathrm{M})$ against Staphylococcus aureus [SA38]. The antibacterial activity is totally lost after the removal of biphenyl backbone from the active compound $\mathbf{2 3 \mathbf { b }}$. The MIC results confirms the biphenyl backbone plays a major role in balancing the hydrophobicity and amphipathicity which are considered as the key parameters for the antibacterial activity against Gram-positive and Gram-negative bacterial strains.

Overall, the structure activity relationship (SAR) draw the inference regarding the antibacterial activity of the biphenyl backbone peptidomimetic derivatives against $S$. aureus and E. coli. Firstly, the series II compounds with excess hydrophobic group showed good to excellent antimicrobial activity against S. aureus and E. coli. Secondly, the amphipathic nature played a crucial role in determining the antimicrobial activity. The antibacterial activity of compounds $\mathbf{2 5 c - 2 5 f}$ remain intact against $S$. aureus even after increasing the net positive charge. Among all the synthesized biphenyl derivatives, $\mathbf{2 5} \mathbf{b}$ and $\mathbf{2 5 g}$ displayed the most potent antibacterial activity against $S$. aureus $(15.6 \mu \mathrm{M})$. Finally, $25 \mathrm{~g}$ revealed that an increase in cationic charge by utilizing guanidine groups along with increase in hydrophobicity produced excellent activity against Gram-negative E. coli $(7.6 \mu \mathrm{M})$ compared to the corresponding amine compound.

The active peptidomimetic compound $\mathbf{2 5} \mathrm{g}$ which contains less number of amino-acids is comparable with the MIC of MSI-78. MSI-78 (also known as pexiganan) is a chimera of magainin and melittin peptides [49]. This peptide was chosen as a reference compound as it is currently in Phase-III clinical trials and one of the most well-studied amphipathic antimicrobial peptides. Resistant strains of bacteria cannot be generated against MSI-78 even after repeated exposure to sub-inhibitory concentrations [15], and many studies have shown that the antimicrobial action of the peptide involves disruption of bacterial membranes [50, 51]. 
Table 1. Antibacterial activities of biphenyl peptidomimetic derivatives.

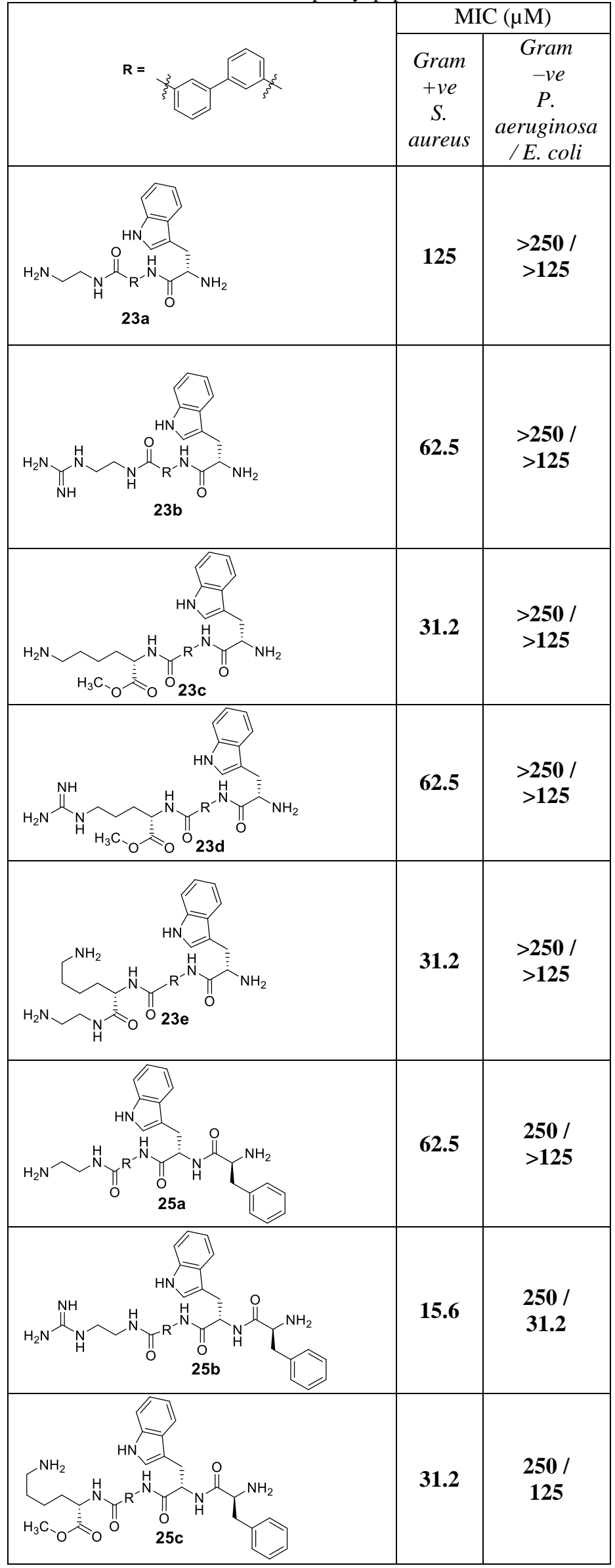




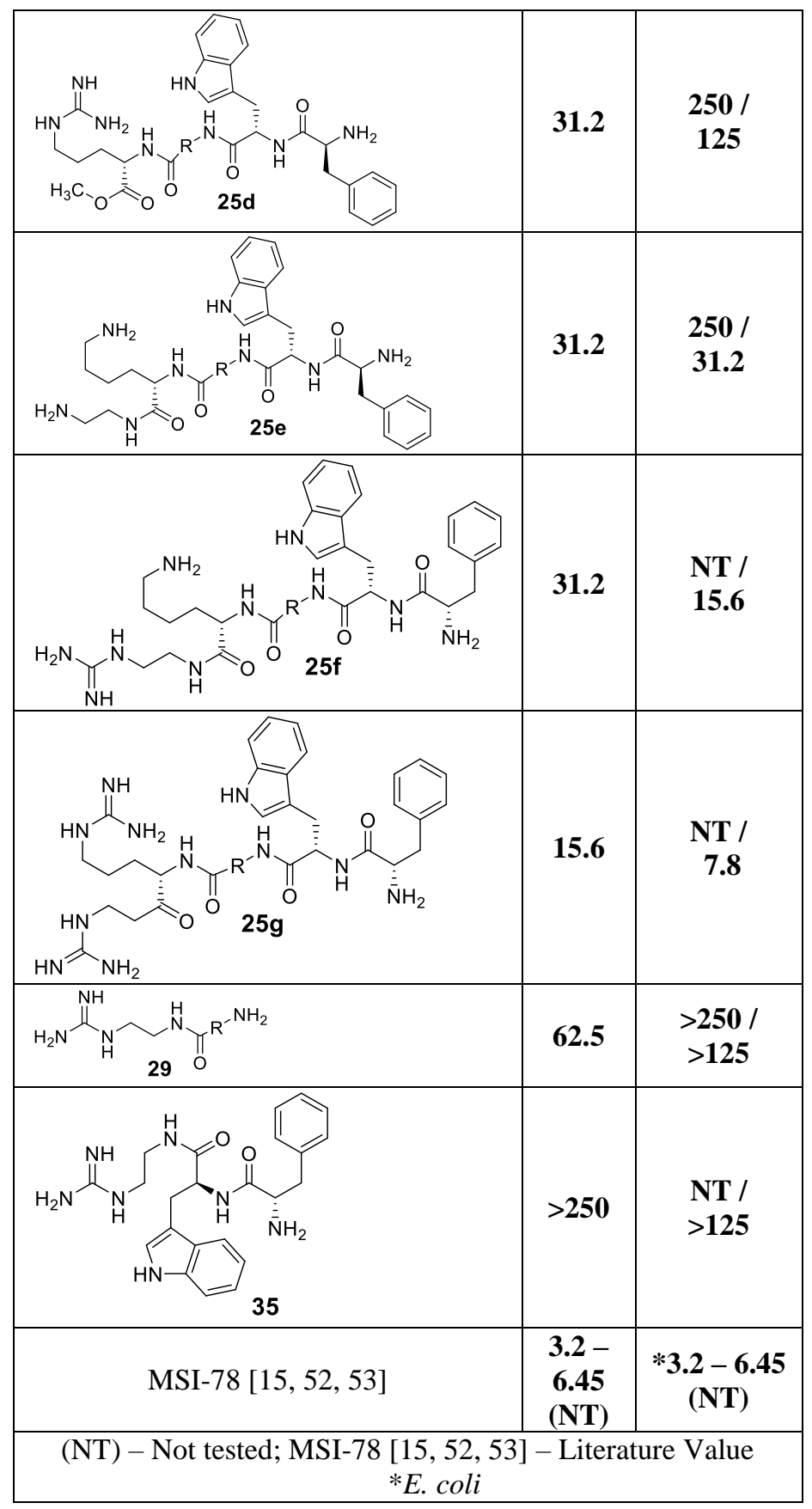

\subsection{Toxicity against human cells}

To further evaluate the utility of these biphenyl derivatives as antimicrobial agents, their specificity for bacterial cells over human cells was determined. Therefore, the in vitro toxicity of the most active compounds $(\mathbf{2 3 b}, \mathbf{2 3 d}, \mathbf{2 5 b} \mathbf{b} \mathbf{2 5}$ ) was assessed against MRC-5 normal human lung fibroblasts using the Alamar Blue (Resazurin) assay [54]. A dose-response curve was generated for each compound (shown in supplementary material Fig. S2) at concentrations ranging from 1-350 $\mu \mathrm{M}$ and their $\mathrm{IC}_{50}$ values were determined (shown in supplementary material Fig. S3). All of the tested compounds displayed very low toxicity $\left(\mathrm{IC}_{50}>300 \mu \mathrm{M}\right)$ towards human cells. Although amphipathic antibacterial agents are often cytotoxic, our compounds did not show noticeable cytotoxicity upto the concentration of $350 \mu \mathrm{M}$.

\subsection{Lipid bilayer membrane interactions}

The compounds ability to interact with lipid bilayers was assessed using tethered bilayer lipid membranes (tBLMs) in association with AC electrical impedance spectroscopy.[55, 56]. Compounds which are shown membrane conduction at concentration of 10 $\mu \mathrm{M}$ are only discussed. Membrane conduction responses of a zwitterionic phospholipid membrane to compounds 25b-25e increased with increasing concentration of compounds (Fig. 3A). Significant conduction changes are evident at concentrations equal to or higher than $10 \mu \mathrm{M}$. Interestingly, these responses are more muted in negatively-charged phospholipid membranes which mimic the negatively charged bacterial cell membranes (Fig. 3B).

The changes in membrane conduction are modest when compared to that produced by $\alpha$-hemolysin or gramicidin-A [56, 57] which produce ion channels in the membranes. This would indicate that it is unlikely that these compounds form membrane 
spanning ion channel-like pores. Alternatively, the changes in membrane conduction could be the result of the formation of toroidal pore-like structures in the membrane. Either the compounds form a part of the lipidic toroidal pore themselves, or they independently induce phospholipidic toroidal pore formation by altering the critical packing parameter of the membrane[58].

The membrane capacitance changes increased with compound concentration in both zwitterionic (Fig. 3C) and negatively-charged (Fig. 3D) tBLMs, with the exception of compound 25d which exhibited a slight decrease in capacitance at high concentrations in negatively-charged membranes. An increase in capacitance is indicative of a thinning of the lipid membrane and/or an increase in membrane dielectric caused by the presence of water molecules. This indicates these compounds may follow mechanism of pore formation like AMPs by membrane thinning effect [59].
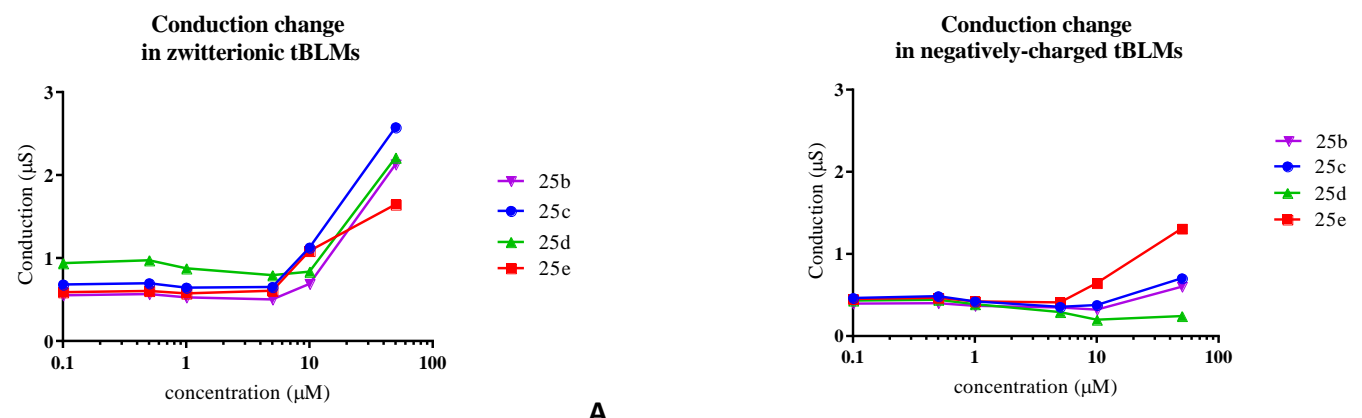

Capacitance change in zwitterionic tBLMs
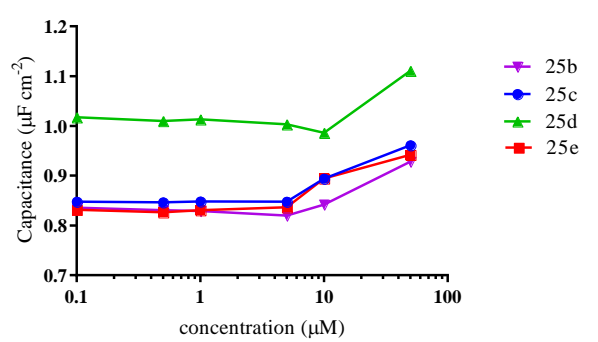

c

A

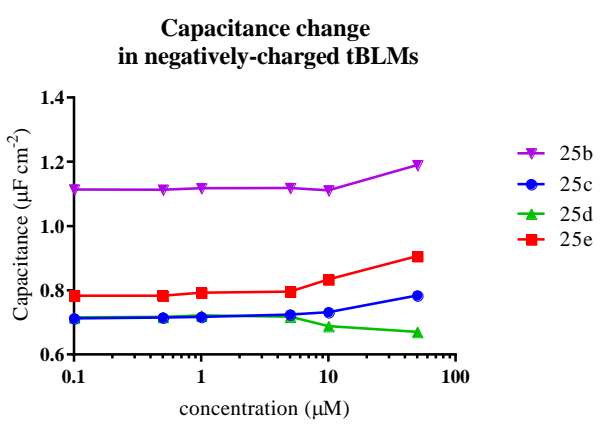

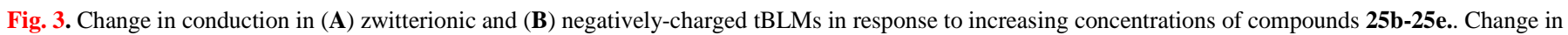
membrane capacitance in (C) zwitterionic and (D) negatively-charged tBLMs in response to increasing concentrations of compounds $\mathbf{2 5} \mathbf{b}-\mathbf{2 5 \mathbf { e }}$.

Notably, the change in membrane conduction at $10 \mu \mathrm{M}$ was correlated with antimicrobial activity, with compounds having lower MIC values (compounds 25c-25e) showing greater positive changes in membrane conduction in zwitterionic lipids than compounds with higher MIC values 25b (Fig. 4A). In negatively-charged lipids, however, the results were mixed and there was no clear relationship between MIC and conductance change (Fig. 4B). This would suggest that the effectiveness of these compounds is not so much related to their overall net cationic charge, rather their ability to insert into the bilayer proper. To test the hypothesis that the tryptophan moiety plays a significant role in membrane disruption, the change of conductance induced by compound 29, which lacks any Trp residue, was tested. As expected, compound 29 exhibited no change in membrane conduction in either zwitterionic or negatively-charged lipids, demonstrating the importance of the Trp residue.

\section{Change in conduction to $10 \mu \mathrm{M}$ of active compounds in zwitterionic tBLMs}

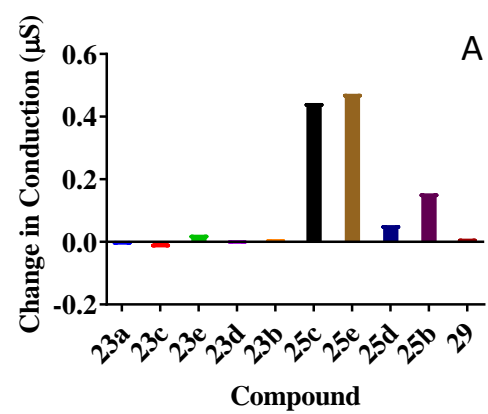

\section{Change in conduction to $10 \mu \mathrm{M}$ of active compounds in negatively charged tBLMs}

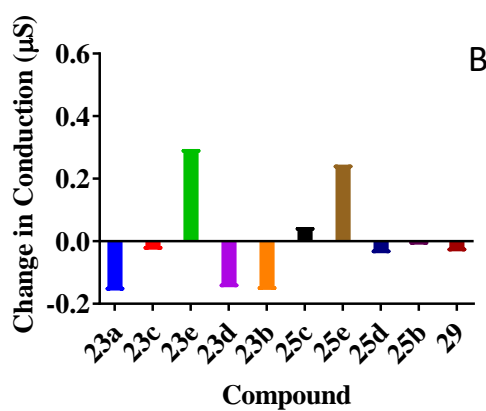

Fig. 4. The change in tBLM conduction of the various antimicrobial compounds at $10 \mu \mathrm{M}$ in (A) zwitterionic and (B) negatively-charged membranes.

\subsection{Cytoplasmic membrane depolarization}

We evaluated the disruption effect of the biphenyl derivatives on the bacterial cytoplasmic membrane using the membrane potential-sensitive dye diSC3-5 (3,3'-dipropylthiadicarbocyanine iodide). The distribution of diSC3-5 between the cell membrane and periphery medium is dependent on the cytoplasmic membrane potential gradient. The dye readily partitions into the bacterial cell membrane and aggregates within the membrane, causing self-quenching. If the antimicrobial compounds perturb the cell membrane, it can lead to the loss of the membrane potential gradient, causing the dye to be released into the medium. As a result, 
the fluorescence intensity of the dye increases. As shown in Fig. 5, compounds $23 \mathbf{b}, \mathbf{2 3 d}, \mathbf{2 5 b}, \mathbf{2 5 e}, \mathbf{2 5 f}$, and $25 \mathrm{~g}$ (added at $0.5 \times$, $1 \times, 2 \times$ or $4 \times$ MIC) induced disruption of the cytoplasmic membrane of $S$. aureus in a time and concentration-dependent manner. Interestingly, the most active compound 25g showed an increase in fluorescence intensity even at sub-MIC levels within $3 \mathrm{~min}$. Similarly, increases in fluorescence intensity of $\mathbf{2 5 e}$ and $\mathbf{2 5 f}$ also occurred at $1 \times$ MIC within 3 minutes.

We also conducted the cytoplasmic permeability assay on Gram-negative bacterium E. coli (K12) with the most active compound 25g. 25g also perturbs the cell membrane led to similar disruption of diSC3-5 fluorescence intensity (Fig. 5G), indicating that the cell membrane of both Gram-positive and Gram-negative bacteria can be disrupted. Taken together, these observations indicate that the biphenyl amphiphilic compounds can readily permeabilize the bacterial membrane, thus resulting in bacterial death.
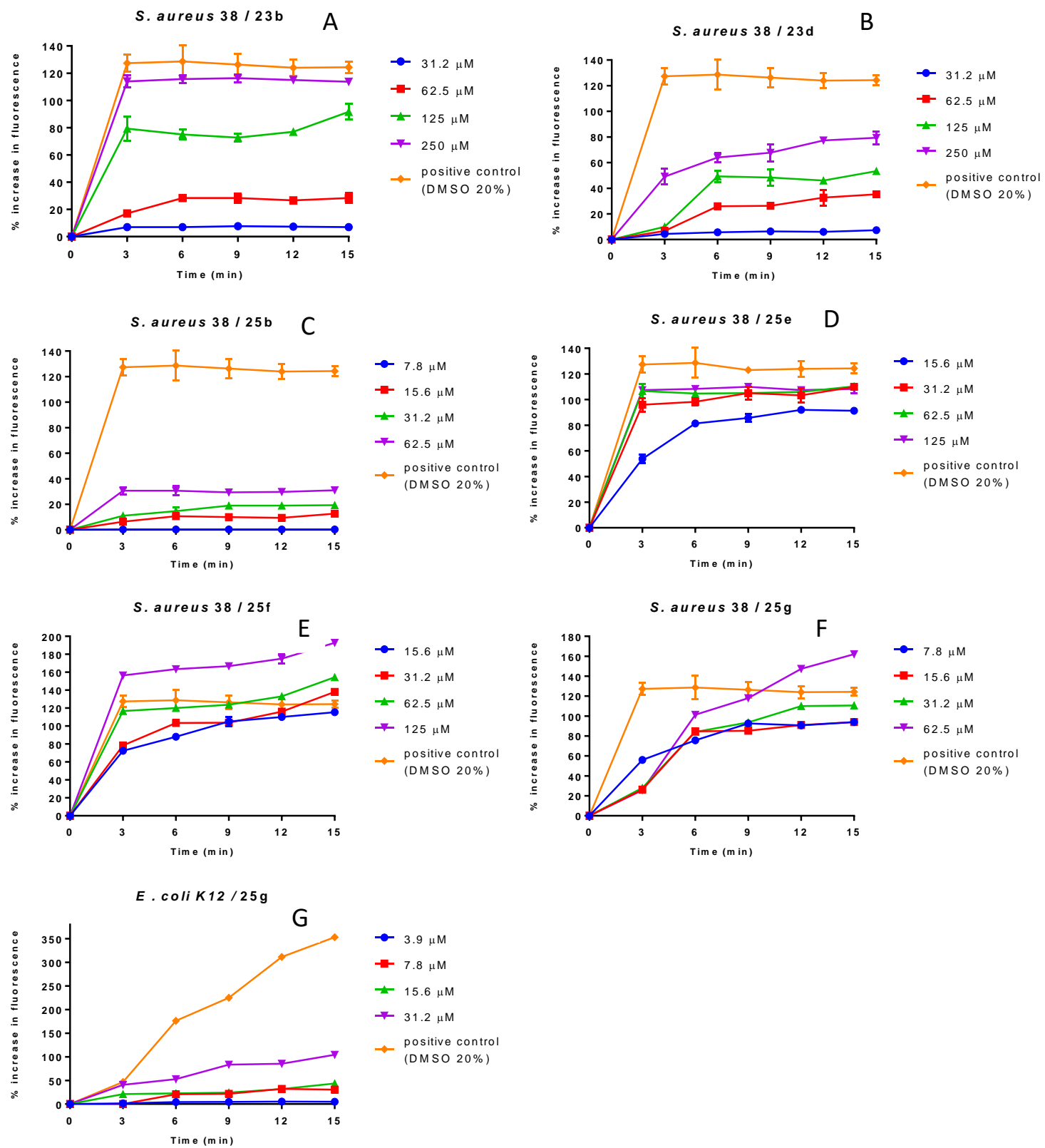

Fig. 5. (A-F) S. aureus cytoplasmic membrane disruption promoted by $\mathbf{2 3 b}, \mathbf{2 3 d}, \mathbf{2 5 b}, \mathbf{2 5 e}, \mathbf{2 5 f}, \mathbf{2 5 g}$. (G) E. coli cytoplasmic membrane disruption promoted by 25g. Error bars represent the standard error of triplicates $(n=3)$.

\subsection{Antibiofilm activity}

The ability of the amphiphilic biphenyl derivatives to inhibit established $S$. aureus or E. coli biofilms was measured at $250 \mu \mathrm{M}$ (Fig. 6). In general, the compounds showed low level of inhibition of biofilm formation. Compound 23b showed the highest level of disruption against $S$. aureus and E. coli of $41 \%$ and $39 \%$ respectively at $250 \mu \mathrm{M}$. Meanwhile, compound 25e displayed $30 \%$ inhibition against $S$. aureus biofilms but only $8 \%$ activity against biofilms of $E$. coli. The pre-established biofilms are harder to eradicate and have limited data available on novel AMPs with anti-biofilm properties [60]. Compound 23b containing less hydrophobic and cationic groups moderately disrupted both the $S$. aureus or E. coli biofilms compared to active antibacterial compounds. These results revealed that the increase in cationic charge and hydrophobicity elevates the activity against planktonic cells, but they are unable to disrupt the large aggregates of bacteria surrounded by an extracellular matrix. Previous studies have used a similar method for measuring the antibiofilm properties of cationic peptides, that is allowing the biofilm to form in the presence of the peptide [61]. Cirioni et al.[61] found that at a concentration of half the MIC, MSI-78 (pexiganan) was able to prevent biofilm formation by $P$. aeruginosa by $27.5 \%$. This is higher than the activity of the compounds in the current study 
which showed 39\% inhibition of biofilm production by another Gram-negative bacterium E. coli but at a concentration of 31 times the MIC. In an alternative biofilm study, where biofilms were formed prior to the addition of MSI-78 (pexiganan) was unable to minimize the amount of biofilm produced by with P. aeruginosa, E. coli or $S$. aureus even at a concentration of 128 times its MIC. However, in a similar preformed biofilm assay, another naturally occurring peptide, LL-37 which is also a membrane disrupting peptide [62], reduced the biofilm mass by approximately $40 \%$ at 4 times its MIC [63]. Thus, the current compounds show similar antibiofilm capabilities to cationic antimicrobial peptides, but future studies should examine whether the current compounds are able to disrupt preformed biofilms.

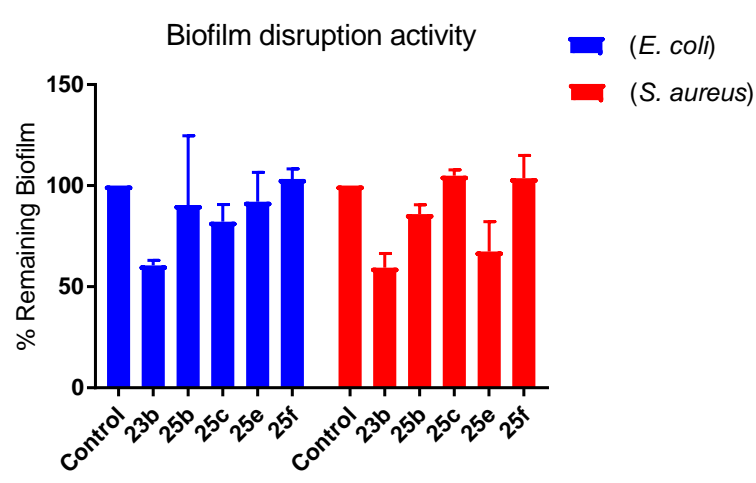

Fig. 6. Percentage of remaining biofilm of $S$. aureus and $E$. coli after 24 h treatment with the synthesized compounds at $250 \mu M$. The control represents the preestablished biofilms without any compounds. Error bars represent the standard error of triplicates $(\mathrm{n}=3)$.

\section{Conclusion}

In conclusion, we have developed novel peptidomimetics based on the 3,3'-biphenyl structural scaffold. The systematic tuning of hydrophobicity and cationic charge of the peptidomimetics resulted in moderate to excellent antibacterial activities. $\mathbf{2 5 g}$, the amphipathic peptidomimetic compound in which the hydrophobic Trp-Phe and cationic Arg-aminoethylguanindine segregated by biphenyl backbone showed excellent antibacterial activity against $S$. aureus $(\mathbf{1 5 . 6} \boldsymbol{\mu M})$ and $E$. coli $(\mathbf{7 . 8} \boldsymbol{\mu M})$ without cytotoxicity against mammalian cells. Based on the results of cytoplasmic permeability assay and tBLMs-AC impedance spectroscopy, we propose that the biphenyl peptidomimetics exhibit bacterial cell membrane disruption mechanism similar to most AMPs. The importance of tryptophan in mechanism of action was also revealed by compound 29. In addition, 23b biphenyl attached with hydrophobic Trp and cationic aminoethyl guanidine could disrupt biofilms of S. aureus and E. coli at $250 \mu \mathrm{M}$. Collectively, our results suggest biphenyl is a versatile core about which hydrophobic and cationic amino acids can be arranged in order to generate short cationic amphipathic peptidomimetics that mimic natural AMPs.

\section{Experimental section}

\subsection{General notes}

All chemical reagents were purchased from commercial sources (Combi-Blocks, Chem-Impex and Sigma Aldrich) and used without further purification. Solvents were commercial and used as obtained. Reactions were performed using oven-dried glassware under an atmosphere of nitrogen and in anhydrous conditions (as required). Room temperature refers to the ambient temperature. Yields refer to chromatographically and spectroscopically pure compounds unless otherwise stated. Reactions were monitored by thin layer chromatography (TLC) plates pre-coated with Merck silica gel 60 F254. Visualization was accomplished with UV light, a ninhydrin staining solution in $\mathrm{n}$-butanol. Flash chromatography and silica pipette plugs were performed under positive air pressure using Silica Gel 60 of 230-400 mesh (40-63 $\mu \mathrm{m}$ ) and also using Grace Davison LC60A 6- $\mu \mathrm{m}$ for reverse phase chromatography. Infrared spectra were recorded using a Cary 630 ATR spectrophotometer. Melting points were obtained using a OptiMelt melting point apparatus and are uncorrected. High-resolution mass spectrometry was performed by the Bioanalytical Mass Spectrometry facility, UNSW. Proton and Carbon NMR spectra were recorded in the solvents specified using a Bruker DPX 300 or a Bruker Avance 400 or $600 \mathrm{MHz}$ spectrometer as designated. Chemical shifts $(\delta)$ are quoted in parts per million (ppm), to the nearest $0.01 \mathrm{ppm}$ and internally referenced relative to the solvent nuclei. ${ }^{1} \mathrm{HNMR}$ spectral data are reported as follows [chemical shift in ppm; multiplicity in br, broad; s, singlet; d, doublet; t, triplet; q, quartet; quint, quintet; sext, sextet; sept, septet; m, multiplet; or as a combination of these (e.g. dd, dt etc.)]; coupling constant $(J)$ in hertz, integration, proton count and assignment.

\subsection{General methods}

\subsubsection{Procedure 1: peptide formation method a}

To a stirred solution of an acid (1 equiv), amine (1.0 equiv), HOBt (1.0 equiv), DIEA (2.5 equiv) in DMF ( $3-5 \mathrm{~mL})$ EDCI (1.2 equiv) was added portion-wise. The reaction was stirred overnight before the solvent was removed under reduced pressure and the resultant residue subjected to flash chromatography $\left(2-5 \% \mathrm{MeOH} / \mathrm{CH}_{2} \mathrm{Cl}_{2}\right.$ as the eluent) to afford the desired compound. 
To a stirred solution of an acid (1 equiv), amine (1.0 equiv), $\mathrm{HOBt}$ (1.0 equiv), PyBOP (1.1 equiv) in $\mathrm{CH}_{2} \mathrm{Cl}_{2}(3-5 \mathrm{~mL}) \mathrm{DIEA}$ (2.0 equiv) was added dropwise. The reaction was stirred overnight before the solvent was removed under reduced pressure and the resultant residue subjected to flash chromatography (2-5\% $\mathrm{MeOH} / \mathrm{CH}_{2} \mathrm{Cl}_{2}$ as the eluent) to afford the desired compound.

\subsubsection{Procedure 3: N-fmoc deprotection}

To a stirred solution of the Fmoc-protected peptide in DMF (3.0 - 5.0 mL)was added piperidine (2.0 equiv). The resultant solution was then stirred at $\mathrm{rt}$ for overnight. The solvent was then removed under reduced pressure and purified using flash chromatography ( $5 \%$ of 100:10:1; $\mathrm{CHCl}_{3}: \mathrm{MeOH}$ : aqueous $\mathrm{NH}_{3}$ and $95 \%$ of $\mathrm{CH}_{2} \mathrm{Cl}_{2}$ ) as eluent The resultant compounds isolated as TFA salt.

\subsubsection{Procedure 4: N-boc and Pbf deprotection}

To a stirred solution of the boc/Pbf protected peptide in $\mathrm{CH}_{2} \mathrm{Cl}_{2}(3.0 \mathrm{~mL})$ was added TFA $(3.0 \mathrm{~mL})$. The reaction mixture was stirred at room temperature overnight before the solvent was removed under reduced pressure. After triturating with diethyl ether, the residue was concentrated to dryness. For $\mathrm{Pbf}$ and deboc of guanidine the residue was dissolved in $\mathrm{CH}_{2} \mathrm{Cl}_{2}$ and $\mathrm{CH}_{3} \mathrm{CN}_{\text {and }}$ precipitated by addition of diethyl ether and filtered and dried. Some of the compounds were purified using reverse phase chromatography with $40 \% \mathrm{CH}_{3} \mathrm{CN} / \mathrm{H}_{2} \mathrm{O}$ as eluent utilizing GRACE instrument.

\subsection{Preparation of derivatives}

\subsection{1. ${ }^{1} \mathrm{H} N M R$ and ${ }^{13} \mathrm{C} N M R$ spectra of Methyl 3'-nitro-[1,1'-biphenyl]-3-carboxylate (9)}

1-Bromo-3-nitrobenzene 7 (5.0 g, $24.7 \mathrm{mmol})$, (3-(Methoxycarbonyl)phenyl)boronic acid 8 (5.34 g, $29.7 \mathrm{mmol})$, tetrakistriphenylphosphinepalladium(0) (1.40 g, $1.23 \mathrm{mmol})$, sodium carbonate $(2 \mathrm{M})(37 \mathrm{~mL}, 74.1 \mathrm{mmol})$, and 1,4-dioxane (120 $\mathrm{mL}$ ) were combined and the reaction mixture was heated at reflux under a nitrogen atmosphere for $16 \mathrm{~h}$. The reaction mixture was allowed to cool at room temperature and partitioned between ethyl acetate and water. The organic phase was separated, dried over magnesium sulfate, filtered, and the filtrate was concentrated to give a liquid. The crude product was purified by flash chromatography over silica with a hexanes:ethyl acetate gradient (100:0 to 90:10) to give (4.12 $\mathrm{g}, 65 \%)$ the title compound $\mathbf{9}$ as a yellow solid; m.p.: 96.5-96.6 ${ }^{\circ} \mathrm{C}$; ${ }^{1} \mathrm{H}$ NMR (400 MHz, DMSO- $\left.d_{6}\right): \delta 8.45(\mathrm{t}, J=4.00 \mathrm{~Hz}, 1 \mathrm{H}), 8.27-8.24(\mathrm{~m}, 2 \mathrm{H}), 8.19(\mathrm{dd}, J=$ $4.00,8.00 \mathrm{~Hz}, 1 \mathrm{H}), 8.08-8.01(\mathrm{~m}, 2 \mathrm{H}), 7.79(\mathrm{t}, J=8.00 \mathrm{~Hz}, 1 \mathrm{H}), 7.68(\mathrm{t}, J=8.00 \mathrm{~Hz}, 1 \mathrm{H}), 3.90(\mathrm{~s}, 3 \mathrm{H}) ;{ }^{13} \mathrm{C} \mathrm{NMR}(100 \mathrm{MHz}$, DMSO- $\left.d_{6}\right): \delta 166.4,148.9,141.0,138.8,133.9,132.3,131.1,131.0,130.2,129.6,127.9,123.1,121.8,52.8 ;$ IR (ATR): vmax 3312, 2953, 2342, 1722, 1520, 1429, 1348, 1301, 1236, 1191, 1104, 963, 883, 839, 801, 690; HRMS (ESI): m/z calcd for $\mathrm{C}_{14} \mathrm{H}_{11} \mathrm{NO}_{4} \mathrm{Na}[\mathrm{M}+\mathrm{Na}]^{+}:$280.0586; found: 280.0579 .

\subsection{2 ${ }^{1} \mathrm{H} N M R$ and ${ }^{13} \mathrm{C}$ NMR spectra of Methyl 3'-amino-[1,1'-biphenyl]-3-carboxylate (10)}

To a stirred solution of 3'-nitro-[1,1'-biphenyl]-3-carboxylic acid methyl ester 9 (4.0 g, $15.5 \mathrm{mmol})$ in anhydrous THF (100 mL) under nitrogen atmosphere $10 \%$ palladium on activated charcoal $(1.0 \mathrm{~g})$ was added. The reaction was evacuated and placed under a hydrogen atmosphere and stirred overnight. The reaction mixture was filtered through Celite, and the solvent was removed under reduced pressure to yield gray oil. The residue was chromatographed on silica, eluting with 3:1 hexane/EtOAc.

Concentration of the appropriate fractions provided the product as an off-white solid $(3.17 \mathrm{~g}, 90 \%$ yield $)$; m.p.: $84.9-85.1{ }^{\circ} \mathrm{C} ;{ }^{1} \mathrm{H}$ NMR $\left(400 \mathrm{MHz}, \mathrm{CDCl}_{3}\right): \delta 8.28(\mathrm{t}, J=4.00 \mathrm{~Hz}, 1 \mathrm{H}), 8.03(\mathrm{dt}, J=2.00,5.00 \mathrm{~Hz}, 1 \mathrm{H}), 7.79-7.76(\mathrm{~m}, 1 \mathrm{H}), 7.51(\mathrm{t}, J=12.00 \mathrm{~Hz}$, $1 \mathrm{H}), 7.27(\mathrm{q}, J=4.00 \mathrm{~Hz}, 1 \mathrm{H}), 7.06-7.03(\mathrm{~m}, 1 \mathrm{H}), 6.97(\mathrm{t}, J=4.00 \mathrm{~Hz}, 1 \mathrm{H}), 6.75-6.73(\mathrm{~m}, 1 \mathrm{H}), 3.96(\mathrm{~s}, 5 \mathrm{H}) ;{ }^{13} \mathrm{C} \mathrm{NMR}(100$ $\left.\mathrm{MHz}, \mathrm{CDCl}_{3}\right): \delta 167.1$ 146.6, 141.6, 141.3, 131.5, 130.6, 129.9, 128.7, 128.3, 128.2, 117.7, 114.6, 113.9, 52.2; HRMS (ESI): m/z calcd for $\mathrm{C}_{14} \mathrm{H}_{13} \mathrm{NO}_{2} \mathrm{Na}[\mathrm{M}+\mathrm{Na}]^{+} 250.0844$; found: 250.0838 .

\subsection{3. ${ }^{1} \mathrm{H}$ NMR and ${ }^{13} \mathrm{C}$ NMR spectra of Methyl (S)-3'-(2-((tert-butoxycarbonyl)amino)-3-(1H-indol-3-yl)propanamido)-[1,1'- biphenyl]-3-carboxylate (12)}

The title compound was prepared via protocol 1, using 10 (1.0 g, $4.4 \mathrm{mmol})$ and (tert-butoxycarbonyl)- $L$-tryptophan (1.33 g, 4.4 mmol) to afford the coupled product 12 as an off-white solid $(1.42 \mathrm{~g}, 63 \%)$; m.p.: $107.3-108.0{ }^{\circ} \mathrm{C}$; ${ }^{1} \mathrm{H} \mathrm{NMR}(400 \mathrm{MHz}, \mathrm{DMSO}-$ $\left.d_{6}\right): \delta 10.82(\mathrm{~s}, 1 \mathrm{H}), 10.17(\mathrm{~s}, 1 \mathrm{H}), 8.17(\mathrm{~s}, 1 \mathrm{H}), 7.98-7.91(\mathrm{~m}, 3 \mathrm{H}), 7.69-7.62(\mathrm{~m}, 3 \mathrm{H}), 7.45-7.38(\mathrm{~m}, 2 \mathrm{H}), 7.32(\mathrm{~d}, J=8.00 \mathrm{~Hz}$, $1 \mathrm{H}), 7.19(\mathrm{~s}, 1 \mathrm{H}), 7.05(\mathrm{t}, J=8.00 \mathrm{~Hz}, 1 \mathrm{H}), 6.99-6.97(\mathrm{~m}, 2 \mathrm{H}), 4.41-4.39(\mathrm{~m}, 1 \mathrm{H}), 3.90(\mathrm{~s}, 3 \mathrm{H}), 3.18-2.99(\mathrm{~m}, 2 \mathrm{H}), 1.34(\mathrm{~s}, 9 \mathrm{H})$; ${ }^{13} \mathrm{C}$ NMR (100 MHz, DMSO- $\left.d_{6}\right): \delta 171.8,166.5,155.8,140.9,140.2,139.9,136.5,131.9,130.8,130.8,128.7,127.7,127.4$, 124.2, 122.1, 121.3, 119.4, 118.6, 118.1, 111.8, 118.1, 111.8, 110.4, 78.6, 56.4, 52.8, 28.6, 28.3; IR (ATR).vmax 3304, 2330, $2099,1665,1605,1528,1491,1423,1303,1250,1160,1111,1082,1010,856,733,690 ; \mathrm{HRMS}(\mathrm{ESI}): \mathrm{m} / \mathrm{z}$ calcd for $\mathrm{C}_{30} \mathrm{H}_{31} \mathrm{~N}_{3} \mathrm{O}_{5}$ $\mathrm{Na}[\mathrm{M}+\mathrm{Na}]^{+}$536.2161; found: 536.2153.

4.3.4. ${ }^{1} \mathrm{H}$ NMR and ${ }^{13} \mathrm{C}$ NMR spectra of (S)-3'-(2-((tert-butoxycarbonyl)amino)-3-(1H-indol-3-yl)propanamido)-[1,1'-biphenyl]-3carboxylic acid (13)

To a solution of $12(1.2 \mathrm{~g}, 1.81 \mathrm{mmol})$ in THF $(10.0 \mathrm{~mL})$ and $\mathrm{MeOH}(10.0 \mathrm{~mL})$, was added a $1 \mathrm{~N} \mathrm{NaOH}_{(\mathrm{aq})}(3.63 \mathrm{~mL}, 3.63 \mathrm{mmol})$ and stirred at room temperature for $16 \mathrm{~h}$. Ethyl acetate was added and the layers were separated. The aqueous layer was then 
acidified with $1 \mathrm{~N} \mathrm{HCl}$ and then extracted with $\mathrm{CH}_{2} \mathrm{Cl}_{2}(2 \mathrm{X} 100 \mathrm{~mL})$ and then the solvent was removed under reduced pressure to yield $13(1.00 \mathrm{~g}, 85 \%)$ as an off-whit solid; m.p.: $140-140.3{ }^{\circ} \mathrm{C} ;{ }^{1} \mathrm{H}$ NMR $\left(400 \mathrm{MHz}, \mathrm{DMSO}-d_{6}\right): \delta 13.10(\mathrm{~s}, 1 \mathrm{H}), 10.82(\mathrm{~s}, 1 \mathrm{H})$, $10.17(\mathrm{~s}, 1 \mathrm{H}), 8.18(\mathrm{t}, J=4.00 \mathrm{~Hz}, 1 \mathrm{H}), 7.97-7.95(\mathrm{~m}, 2 \mathrm{H}), 7.90-7.87(\mathrm{~m}, 1 \mathrm{H}), 7.69-7.66(\mathrm{~m}, 2 \mathrm{H}), 7.61(\mathrm{t}, J=8.00 \mathrm{~Hz}, 1 \mathrm{H}), 7.45-$ $7.38(\mathrm{~m}, 2 \mathrm{H}), 7.32(\mathrm{~d}, J=8.00 \mathrm{~Hz}, 1 \mathrm{H}), 7.19(\mathrm{~s}, 1 \mathrm{H}), 7.06(\mathrm{t}, J=4.00 \mathrm{~Hz}, 1 \mathrm{H}), 6.98(\mathrm{t}, J=8.00 \mathrm{~Hz}, 2 \mathrm{H}), 4.41(\mathrm{q}, J=8.00 \mathrm{~Hz}$, $1 \mathrm{H}), 3.19-3.14(\mathrm{~m}, 1 \mathrm{H}), 3.05-3.00(\mathrm{~m}, 1 \mathrm{H}), 1.34(\mathrm{~s}, 9 \mathrm{H}) ;{ }^{13} \mathrm{C}$ NMR $\left(100 \mathrm{MHz}, \mathrm{DMSO}-d_{6}\right): \delta 171.7,167.6,155.8,140.7,140.2$, $140.1,136.5,132.0,129.9,128.8,127.8,127.6,124.3,122.1,121.4,119.3,119.1,118.7,118.1,111.8,110.4,79.6,78.6,56.3$, 28.6, 28.3; IR (ATR).vmax 3278, 3051, 2946, 2342, 2117, 1917, 1712, 1661, 1589, 1524, 1432, 1310, 1252, 1109, 973, 876, 790, 690; HRMS (ESI): m/z calcd for $\mathrm{C}_{29} \mathrm{H}_{29} \mathrm{~N}_{3} \mathrm{O}_{5} \mathrm{Na}[\mathrm{M}+\mathrm{Na}]^{+}$522.2005; found: 522.1996.

\subsection{5. ${ }^{1} \mathrm{H}$ NMR and ${ }^{13} \mathrm{C}$ NMR spectra of Methyl (S)-3'-(2-amino-3-(1H-indol-3-yl)propanamido)-[1,1'-biphenyl]-3-carboxylate} (14)

The title compound 14 was prepared via protocol 4 using 12 (1.4 g, 2.72 mmol) to yield an off-white solid (1.00 g, 89\%); m.p.: 86.4-86.7 ${ }^{\circ} \mathrm{C} ;{ }^{1} \mathrm{H}$ NMR (400 MHz, DMSO-d $)$ : $\delta 11.06(\mathrm{~s}, 1 \mathrm{H}), 10.73(\mathrm{~s}, 1 \mathrm{H}), 8.33(\mathrm{br} \mathrm{s}, 2 \mathrm{H}), 8.16-8.15(\mathrm{~m}, 1 \mathrm{H}), 8.00-7.97(\mathrm{~m}$, 1H), 7.92-7.89 (m, 1H), 7.86-7.85 (m, 1H), 7.68-7.60 (m, 3H), 7.48-7.46 (m, 2H), 7.36 (d, J=8.00 Hz, $1 \mathrm{H}), 7.26(\mathrm{~d}, J=4.00 \mathrm{~Hz}$, 1H), 7.09-7.05 (m, 1H), 6.98-6.94 (m, 1H), 4.21 (br s, $1 \mathrm{H}), 3.89(\mathrm{~s}, 3 \mathrm{H}), 3.40-3.25(\mathrm{~m}, 2 \mathrm{H}) ;{ }^{13} \mathrm{C} \mathrm{NMR}\left(100 \mathrm{MHz}, \mathrm{DMSO}-d_{6}\right): \delta$ 167.9, 166.6, 140.7, 140.1, 139.2, 136.7, 131.9, 130.9, 130.3, 130.1, 128.8, 127.5, 127.4, 125.4, 123.0, 121.7, 119.7, 119.0, 118.9, 118.4, 111.9, 107.1, 54.1, 52.8, 27.8; IR (ATR): vmax 3282, 3054, 2947, 2341, 2106, 1911, 1713, 1663, 1589, 1525, 1433, 1310, 1253, 1110, 974, 877, 791, 691; HRMS (ESI): m/z calcd for $\mathrm{C}_{25} \mathrm{H}_{23} \mathrm{~N}_{3} \mathrm{O}_{3}[\mathrm{M}+\mathrm{H}]^{+}:$413.1739; found 414.1810.

4.3.6. ${ }^{1} \mathrm{H}$ NMR and ${ }^{13} \mathrm{C}$ NMR spectra of Methyl 3'-((S)-2-((S)-2-((tert-butoxycarbonyl)amino)-3-phenylpropanamido)-3-(1H-indol3-yl)propanamido)-[1,1'-biphenyl]-3-carboxylate (16)

The title compound was prepared via protocol 1 using 14 and 15 (1.0 g, 3.76 mmol) to afford the coupled product 16 as an offwhite solid; m.p.: $116.3-117.2{ }^{\circ} \mathrm{C} ;{ }^{1} \mathrm{H}$ NMR (400 MHz, DMSO-d $)$ : $\delta 10.85(\mathrm{~s}, 1 \mathrm{H}), 10.20(\mathrm{~s}, 1 \mathrm{H}), 8.16-8.14(\mathrm{~m}, 2 \mathrm{H}), 7.98-7.95$ $(\mathrm{m}, 1 \mathrm{H}), 7.90-7.88(\mathrm{~m}, 2 \mathrm{H}), 7.66-7.62(\mathrm{~m}, 3 \mathrm{H}), 7.44-7.38(\mathrm{~m}, 2 \mathrm{H}), 7.32(\mathrm{~d}, J=8.00 \mathrm{~Hz}, 1 \mathrm{H}), 7.21-7.11(\mathrm{~m}, 6 \mathrm{H}), 7.07-7.03(\mathrm{~m}$, $1 \mathrm{H}), 6.95(\mathrm{dd}, J=8.00,14.00 \mathrm{~Hz}, 2 \mathrm{H}), 4.75(\mathrm{q}, J=8.00 \mathrm{~Hz}, 1 \mathrm{H}), 4.22-4.16(\mathrm{~m}, 1 \mathrm{H}), 3.89(\mathrm{~s}, 3 \mathrm{H}), 3.24(\mathrm{dd}, J=8.00,16.00 \mathrm{~Hz}$, $1 \mathrm{H}), 3.12(\mathrm{dd}, J=8.00,14.00 \mathrm{~Hz}, 1 \mathrm{H}), 2.93(\mathrm{dd}, J=4.00,12.00 \mathrm{~Hz}, 1 \mathrm{H}), 2.75-2.69(\mathrm{~m}, 1 \mathrm{H}), 1.28(\mathrm{~s}, 9 \mathrm{H}) ;{ }^{13} \mathrm{C} \mathrm{NMR}(100 \mathrm{MHz}$, DMSO- $\left.d_{6}\right): \delta 171.9,170.9,166.6,155.7,140.9,139.9,138.4,136.5,131.8,130.8,130.1,130.0,129.7,128.7,128.4,127.8,127.4$, 126.6, 124.1, 122.3, 121.4, 119.4, 119.0, 118.7, 118.1, 111.7, 110.0, 78.7, 56.4, 54.7, 52.8, 37.9, 28.6, 28.4; IR (ATR).vmax 3293, 3055, 2320, 2096, 1649, 1492, 1433, 1310, 1250, 1259, 1110, 1012, 882; HRMS (ESI): m/z calcd for $\mathrm{C}_{39} \mathrm{H}_{40} \mathrm{~N}_{4} \mathrm{O}_{6}\left[\mathrm{M}+\mathrm{H}^{+}\right.$: 683.2846; found: 683.2841 .

4.3.7. ${ }^{1} \mathrm{H} N M R$ and ${ }^{13} \mathrm{C} N M R$ spectra of 3'-((S)-2-((S)-2-((tert-butoxycarbonyl)amino)-3-phenylpropanamido)-3-(1H-indol-3yl)propanamido)-[1,1'-biphenyl]-3-carboxylic acid (17)

To a solution of $16(1.2 \mathrm{~g}, 2.33 \mathrm{mmol})$ in THF $(10.0 \mathrm{~mL})$ and $\mathrm{MeOH}(10.0 \mathrm{~mL})$, was added a $1 \mathrm{~N} \mathrm{NaOH}(\mathrm{aq})(4.66 \mathrm{~mL}, 4.66 \mathrm{mmol})$ and stirred at room temperature for $16 \mathrm{~h}$. Ethyl acetate was added and the layers were separated. The aqueous layer was then acidified with $1 \mathrm{~N} \mathrm{HCl}$ and then extracted with $\mathrm{CH}_{2} \mathrm{Cl}_{2}(2 \mathrm{X} 100 \mathrm{~mL})$ and then the solvent was removed under reduced pressure to yield $17(1.05 \mathrm{~g}, 90 \%)$ as an off-white solid; m.p.: $172.6-173.6{ }^{\circ} \mathrm{C} ;{ }^{1} \mathrm{H}$ NMR $\left(400 \mathrm{MHz}, \mathrm{DMSO}-d_{6}\right): \delta 13.08(\mathrm{br} \mathrm{s}, 1 \mathrm{H}), 10.84(\mathrm{~s}$, $1 \mathrm{H}), 10.20(\mathrm{~s}, 1 \mathrm{H}), 8.16-8.14(\mathrm{~m}, 2 \mathrm{H}), 7.96-7.85(\mathrm{~m}, 3 \mathrm{H}), 7.69-7.58(\mathrm{~m}, 3 \mathrm{H}), 7.44-7.38(\mathrm{~m}, 2 \mathrm{H}), 7.32(\mathrm{~d}, J=4.00 \mathrm{~Hz}, 1 \mathrm{H}), 7.21-$ $7.10(\mathrm{~m}, 6 \mathrm{H}), 7.08-7.03(\mathrm{~m}, 1 \mathrm{H}), 6.96(\mathrm{dd}, J=8.00,12.00 \mathrm{~Hz}, 2 \mathrm{H}), 4.75(\mathrm{q}, J=8.00 \mathrm{~Hz}, 1 \mathrm{H}), 4.21-4.16(\mathrm{~m}, 1 \mathrm{H}), 3.26-3.21(\mathrm{~m}$, $1 \mathrm{H}), 3.14-3.10(\mathrm{~m}, 1 \mathrm{H}), 2.95-2.90(\mathrm{~m}, 1 \mathrm{H}), 2.75-2.69(\mathrm{~m}, 1 \mathrm{H}), 1.28(\mathrm{~s}, 9 \mathrm{H}) ;{ }^{13} \mathrm{C}$ NMR $\left(100 \mathrm{MHz}, \mathrm{DMSO}-d_{6}\right): \delta 171.9,170.8$, $167.7,155.7,140.7,140.1,140.0,138.4,136.5,132.0,131.4,130.0,138.4,136.5,132.0,131.3,130.0,129.8,129.6,128.8,128.4$, $127.8,127.6,126.6,126.6,124.1,122.2,121.4,119.3,119.0,118.7,118.1,111.7,110.0,78.7,56.4,54.7,37.9,28.6,28.4 ;$ IR (ATR).vmax 2048, 1653, 1492, 1434, 1391, 1228, 1158, 1058, 849; HRMS (ESI): m/z calcd for $\mathrm{C}_{38} \mathrm{H}_{38} \mathrm{~N}_{4} \mathrm{O}_{6} \mathrm{Na}_{[\mathrm{M}}+\mathrm{Na}^{+}$: 669.2689; found: 669.2689 .

\subsection{8. ${ }^{1} \mathrm{H} N M R$ and ${ }^{13} \mathrm{C} N M R$ spectra of 1-(2-aminoethyl)2,3-Bis(tert-butoxycarbonyl)guanidine (18b)}

The title compound $\mathbf{1 8 b}$ was prepared by adding the solution of N,N'-bis-(Boc)-1H-Pyrazole-1-carboxamidine (2 g, $6.45 \mathrm{mmol})$ in THF $(50 \mathrm{ml})$ dropwise to ethylene diamine $(4 \mathrm{ml}, 59.6 \mathrm{mmol})$ in THF $(100 \mathrm{ml})$. After $30 \mathrm{~min}$ of mixing at room temperature solvent was evaporated then toluene $(100 \mathrm{ml})$ was added and evaporated in order to remove remaining traces of the ethylene diamine.The crude reaction mixture taken for next step due to the instability of the compound. ${ }^{1} \mathrm{H} \mathrm{NMR}\left(400 \mathrm{MHz}, \mathrm{CDCl}_{3}\right): \delta$ 11.50 (br s, $1 \mathrm{H}), 8.63$ (br s, $1 \mathrm{H}), 3.47$ (q, $J=4.00 \mathrm{~Hz}, 2 \mathrm{H}), 2.87$ (t, $J=4.00 \mathrm{~Hz}, 2 \mathrm{H}), 1.49(\mathrm{~s}, 9 \mathrm{H}), 1.48(\mathrm{~s}, 9 \mathrm{H}) ;{ }^{13} \mathrm{C} \mathrm{NMR}(100$ $\mathrm{MHz}, \mathrm{CDCl}_{3}$ ): $\delta 163.6,156.5,153.2,83.1,79.3,43.4,41.0,28.3,28.1$; IR (ATR).vmax 3385, 3068, 2972, 2887, 2807, 1613, $1519,1463,1347,1311,1249,1090,1161,884,799$.

\subsection{9. ${ }^{1} \mathrm{H} N M R$ and ${ }^{13} \mathrm{C} N M R$ spectra of Methyl $N^{w}$-((4-methoxy-2,3,6-trimethylphenyl)sulfonyl)-L-argininate (18d)}

The title compound 18d was prepared via protocol 3 using 20a $(0.9 \mathrm{~g}, 1.44 \mathrm{mmol})$ to yield the desired product as an off-white solid (450 mg, 77\%); m.p.: 136.3-137.3 ${ }^{\circ} \mathrm{C} ;{ }^{1} \mathrm{H}$ NMR (400 MHz, $\left.\mathrm{CDCl}_{3}\right): \delta 6.50(\mathrm{~s}, 1 \mathrm{H}), 6.46(\mathrm{br} \mathrm{s}, 1 \mathrm{H}), 6.38(\mathrm{br} \mathrm{s}, 2 \mathrm{H}), 3.80(\mathrm{~s}$, $3 \mathrm{H}), 3.67(\mathrm{~s}, 3 \mathrm{H}), 3.47-3.45(\mathrm{~m}, 1 \mathrm{H}), 3.15(\mathrm{br} \mathrm{s}, 2 \mathrm{H}), 2.65(\mathrm{~s}, 3 \mathrm{H}), 2.97(\mathrm{~s}, 3 \mathrm{H}), 2.10(\mathrm{~s}, 3 \mathrm{H}), 1.74-1.55(\mathrm{~m}, 4 \mathrm{H}) ;{ }^{13} \mathrm{C} \mathrm{NMR}(100$ $\left.\mathrm{MHz}, \mathrm{CDCl}_{3}\right): \delta 175.7,158.4,156.4,138.4,136.4,133.5,124.8,111.7,55.5,53.7,52.2,40.7,31.2,25.5,24.1,18.3,11.9 ;$ IR 
(ATR).vmax 3428, 3329, 2934, 1733, 1541, 1459, 1398, 1246, 1303, 1098, 1016, 911, 802; HRMS (ESI): m/z calcd for $\mathrm{C}_{17} \mathrm{H}_{28} \mathrm{~N}_{4} \mathrm{O}_{5} \mathrm{~S}[\mathrm{M}+\mathrm{H}]^{+}:$401.1780; found: 401.1851 .

\subsubsection{0. ${ }^{1} \mathrm{H} N M R$ and ${ }^{13} \mathrm{C} N M R$ spectra of tert-butyl (S)-(5-amino-6-((2-((tert-butoxycarbonyl)amino)ethyl)amino)-6-} oxohexyl)carbamate (18e)

The title compound was prepared via protocol 3, using $\mathbf{2 0 a}(630 \mathrm{mg}, 1.03 \mathrm{mmol})$ to yield the desired product $\mathbf{1 8 e}$ as an off-white solid (0.32 g, 80\%); m.p.: 206.2-207.5 ${ }^{\circ} \mathrm{C} ;{ }^{1} \mathrm{H}$ NMR (600 MHz, $\left.\mathrm{CDCl}_{3}\right): \delta 7.63(\mathrm{~s}, 1 \mathrm{H}), 5.09(\mathrm{~s}, 1 \mathrm{H}), 4.67(\mathrm{~s}, 1 \mathrm{H}), 3.34-3.08(\mathrm{~m}$, $6 \mathrm{H}), 1.84-1.76(\mathrm{~m}, 1 \mathrm{H}), 1.50-1.46(\mathrm{~m}, 2 \mathrm{H}), 1.42(\mathrm{~s}, 18 \mathrm{H}), 1.37-1.36(\mathrm{~m}, 3 \mathrm{H}) ;{ }^{13} \mathrm{C}$ NMR $\left(100 \mathrm{MHz}, \mathrm{CDCl}_{3}\right): \delta 175.6,156.5,156.1$, 79.4,79.1, 55.0, 40.6, 40.1, 39.7, 34.4, 29.8, 28.4, 28.4, 22.8; IR (ATR).vmax 3313, 2930, 1683, 1518, 1452, 1246, 1162, 994, 859, 779; HRMS (ESI): m/z calcd for $\mathrm{C}_{18} \mathrm{H}_{36} \mathrm{~N}_{4} \mathrm{O}_{5}[\mathrm{M}+\mathrm{H}]^{+}: 389.2686$; found: 389.2759.

\subsubsection{1. ${ }^{1} \mathrm{H}$ NMR and ${ }^{13} \mathrm{C}$ NMR spectra of tert-butyl (S)-(5-amino-6-((2-(2,3-dibocguanidino)ethyl)amino)-6-oxohexyl)carbamate $(18 f)$}

The title compound was prepared via protocol 3, using $\mathbf{2 0 b}(850 \mathrm{mg}, 1.07 \mathrm{mmol})$ to yield the desired product $\mathbf{1 8 f}$ as an off-white solid (0.45 g, 79\%); m.p.: 184.4-185.6 ${ }^{\circ} \mathrm{C} ;{ }^{1} \mathrm{H}$ NMR $\left(400 \mathrm{MHz}, \mathrm{CDCl}_{3}\right): \delta 11.43(\mathrm{~s}, 1 \mathrm{H}), 8.56(\mathrm{t}, J=4.00 \mathrm{~Hz}, 1 \mathrm{H}), 7.91(\mathrm{t}, J=$ $8.00 \mathrm{~Hz}, 1 \mathrm{H}), 4.59$ (br s, $1 \mathrm{H}), 3.59-3.55(\mathrm{~m}, 2 \mathrm{H}), 3.45-3.41(\mathrm{~m}, 2 \mathrm{H}), 3.33-3.30(\mathrm{~m}, 1 \mathrm{H}), 3.13-3.08(\mathrm{~m}, 2 \mathrm{H}), 1.82-1.77(\mathrm{~m}, 1 \mathrm{H})$, $1.52-1.51(\mathrm{~m}, 1 \mathrm{H}), 1.49(\mathrm{~s}, 18 \mathrm{H}), 1.49-1.45(\mathrm{~m}, 4 \mathrm{H}), 1.43(\mathrm{~s}, 9 \mathrm{H}), 1.39-1.37(\mathrm{~m}, 2 \mathrm{H}) ;{ }^{13} \mathrm{C} \mathrm{NMR}\left(100 \mathrm{MHz} \mathrm{CDCl}_{3}\right): \delta 175.6$, 163.2, 157.1, 156.0, 153.1, 83.4, 79.5, 55.4, 40.2, 40.1, 40.0, 34.8, 30.0, 34.8, 30.0, 28.4, 28.3, 28.1, 23.0; IR (ATR).vmax 3326, 2931, 1714, 1612, 1521, 1409, 1362, 1324, 1246, 1128, 1047, 854; HRMS (ESI): m/z calcd for $\mathrm{C}_{24} \mathrm{H}_{46} \mathrm{~N}_{6} \mathrm{O}_{7}[\mathrm{M}+\mathrm{H}]^{+}: 531.3428$; found: 531.3500 .

\subsubsection{2. ${ }^{1} \mathrm{H} N M R$ and ${ }^{13} \mathrm{C} N M R$ spectra of (S)-2-amino-N-(2-(2,3-dibocguanidino)ethyl)-5-(3-((4-methoxy-2,3,6- trimethylphenyl)sulfonyl)guanidino)pentanamide $(18 g)$}

The title compound was prepared via protocol 3, using $\mathbf{2 1 b}$ (730 $\mathrm{mg}, 0.82 \mathrm{mmol})$ to yield the desired product $\mathbf{1 8 g}$ as an off-white solid (0.48 g, 87\%); m.p.: 102.2-103.6 ${ }^{\circ} \mathrm{C} ;{ }^{1} \mathrm{H}$ NMR (400 MHz, $\left.\mathrm{CDCl}_{3}\right): \delta 11.39$ (br s, $\left.1 \mathrm{H}\right), 8.56(\mathrm{br} \mathrm{s}, 1 \mathrm{H}), 8.04(\mathrm{t}, J=4.00 \mathrm{~Hz}$, $1 \mathrm{H}), 6.51(\mathrm{~s}, 1 \mathrm{H}), 6.26(\mathrm{br} \mathrm{s}, 3 \mathrm{H}), 3.81(\mathrm{~s}, 3 \mathrm{H}), 3.54-3.39(\mathrm{~m}, 5 \mathrm{H}), 3.24-3.20(\mathrm{~m}, 2 \mathrm{H}), 2.67(\mathrm{~s}, 3 \mathrm{H}), 2.60(\mathrm{~s}, 3 \mathrm{H}), 2.11(\mathrm{~s}, 3 \mathrm{H})$, $1.76-1.61(\mathrm{~m}, 4 \mathrm{H}), 1.46(\mathrm{~s}, 9 \mathrm{H}), 1.45(\mathrm{~s}, 9 \mathrm{H}) ;{ }^{13} \mathrm{C} \mathrm{NMR}\left(100 \mathrm{MHz}, \mathrm{CDCl}_{3}\right): \delta 175.1,163.0,158.4,157.1,156.4,153.0,138.5$, 136.6, 133.6, 124.7, 111.7, 83.6, 79.8, 55.4, 54.3, 40.1, 31.7, 28.3, 28.0, 25.2, 24.1, 18.3, 11.9; IR (ATR).vmax 3326, 1719, 1611, 1543, 1439, 1409, 1326, 1248, 1115, 1046, 839, 803; HRMS (ESI): m/z calcd for $\mathrm{C}_{29} \mathrm{H}_{50} \mathrm{~N}_{8} \mathrm{O}_{8} \mathrm{~S}[\mathrm{M}+\mathrm{H}]^{+}: 671.3540 ;$ found: 671.3540 .

\subsubsection{3. ${ }^{1} \mathrm{H} N M R$ and ${ }^{13} \mathrm{C} N M R$ spectra of Methyl $N^{2}-(((9 H-f l u o r e n-9-y l) m e t h o x y)$ carbonyl $)-N^{w}-((4-m e t h o x y-2,3,6-$ trimethylphenyl)sulfonyl)-L-argininate (20')}

The title compound 20' was prepared by adding thionyl chloride $(0.23 \mathrm{~mL}, 3.28 \mathrm{mmol})$ dropwise to $N_{\alpha}$-Fmoc- $N_{\omega}$-MTR- $L$-arginine $(1.0 \mathrm{~g}, 1.64 \mathrm{mmol})$ in methanol $(20.0 \mathrm{~mL})$ at $0^{\circ} \mathrm{C}$ and then stirred at room temperature for $16 \mathrm{~h}$. The solvents were removed and reduced pressure and the residue was diluted with ethylacetate $(100.0 \mathrm{~mL})$ and washed with saturated $\mathrm{NaHCO}_{3}(40 \mathrm{~mL})$, saturated brine $(40 \mathrm{~mL})$, then dried $\left(\mathrm{Na}_{2} \mathrm{SO}_{4}\right)$ and concentrated under reduced pressure to afford a white solid $(0.95 \mathrm{~g}, 93 \%)$; m.p.: $94.0-$ $94.4{ }^{\circ} \mathrm{C} ;{ }^{1} \mathrm{H}$ NMR $\left(400 \mathrm{MHz}, \mathrm{CDCl}_{3}\right): \delta 7.76-7.35(\mathrm{~m}, 7 \mathrm{H}), 7.30-7.28(\mathrm{~m}, 2 \mathrm{H}), 6.50(\mathrm{~s}, 1 \mathrm{H}), 6.20(\mathrm{br} \mathrm{s}, 2 \mathrm{H}), 5.74-5.72(\mathrm{br} \mathrm{d}, J$ $=7.2 \mathrm{~Hz}), 4.38-4.29(\mathrm{~m}, 2 \mathrm{H}), 4.19-4.14(\mathrm{~m}, 2 \mathrm{H}), 3.79(\mathrm{~s}, 3 \mathrm{H}), 3.71(\mathrm{~s}, 3 \mathrm{H}), 3.22-3.21(\mathrm{~m}, 2 \mathrm{H}), 2.69(\mathrm{~s}, 3 \mathrm{H}), 2.62(\mathrm{~s}, 3 \mathrm{H}), 2.11(\mathrm{~s}$, $3 \mathrm{H}), 1.70-1.57(\mathrm{~m}, 4 \mathrm{H}) ;{ }^{13} \mathrm{C}$ NMR $\left(100 \mathrm{MHz}, \mathrm{CDCl}_{3}\right): \delta 172.7,158.5,156.3,143.7,143.6,141.2,138.5,136.5,133.5,127.8$, 127.1, 125.1, 124.8, 120.0, 111.7, 67.13, 55.4, 52.6, 47.1, 40.7, 30.1, 25.2, 24.1, 18.3, 17.9, 11.9; IR (ATR).vmax 2946, 1717, 1542, 1616, 1445, 1244, 1169, 1102; HRMS (ESI): m/z calcd for $\mathrm{C}_{32} \mathrm{H}_{38} \mathrm{~N}_{4} \mathrm{O}_{7} \mathrm{SNa}[\mathrm{M}+\mathrm{Na}]^{+}$: 645.2359; found: 645.2356 .

4.3.14. ${ }^{1} \mathrm{H}$ NMR and ${ }^{13} \mathrm{C}$ NMR spectra of (9H-fluoren-9-yl)methyl (S)-(1-((2-(2,3-diboc guanidino)ethyl)amino)-5-(3-((4-methoxy2,3,6-trimethylphenyl)sulfonyl)guanidino)-1-oxopentan-2-yl)carbamate (20b)

The title compound $\mathbf{2 0 b}$ was prepared from compound $\mathbf{1 8 b}(0.5 \mathrm{~g}, 1.64 \mathrm{mmol})$ and $N_{\alpha}$-Fmoc- $N_{\omega}$-MTR- $L$-arginine $(1.0 \mathrm{~g}, 1.64$ mmol) according to the protocol 2. Off-white solid (0.73 g, 50\%); m.p.: 148.0-148.6 ${ }^{\circ} \mathrm{C} ;{ }^{1} \mathrm{H} \mathrm{NMR}\left(400 \mathrm{MHz}, \mathrm{CDCl}_{3}\right): \delta 11.40(\mathrm{br}$ s, $1 \mathrm{H}), 8.61$ (br s, 1H), $7.98($ br s, $1 \mathrm{H}), 7.73(\mathrm{~d}, J=8.00 \mathrm{~Hz}, 2 \mathrm{H}), 7.57(\mathrm{~d}, J=8.00 \mathrm{~Hz}, 2 \mathrm{H}), 7.36(\mathrm{t}, J=8.00 \mathrm{~Hz}, 2 \mathrm{H}), 7.30-7.24$ $(\mathrm{m}, 2 \mathrm{H}), 6.50$ (br s, 1H), 6.23 (br s, 2H), 5.99 (d, J=8.00 Hz, 1H), 4.34-4.22 (m, 2H), 4.18-4.14 (m, 2H), 3.79 (s, 3H), 3.54-3.15 $(\mathrm{m}, 7 \mathrm{H}), 2.67(\mathrm{~s}, 3 \mathrm{H}), 2.60(\mathrm{~s}, 3 \mathrm{H}), 2.10(\mathrm{~s}, 3 \mathrm{H}), 1.84-1.57(\mathrm{~m}, 4 \mathrm{H}), 1.45(\mathrm{~s}, 18 \mathrm{H}) ;{ }^{13} \mathrm{C} \mathrm{NMR}\left(100 \mathrm{MHz}, \mathrm{CDCl}_{3}\right): \delta 163.3,162.8$, $159.7,158.5,157.2,156.4,156.3,153.0,143.8,143.8,141.3,138.6,136.6,133.4,127.7,127.1,125.2,124.8,120.0,83.6,80.4$, 80.1, 67.1, 55.4, 47.1, 42.1, 40.1, 28.2, 28.2, 28.0, 25.2, 24.1, 18.4, 12.0; IR (ATR).vmax 3324, 2976, 2064, 1717, 1615, 1543, 1446, 1304, 1248, 1117, 840; HRMS (ESI): m/z calcd for $\mathrm{C}_{44} \mathrm{H6}_{0} \mathrm{~N}_{8} \mathrm{O}_{10} \mathrm{~S}[\mathrm{M}+\mathrm{H}]^{+}$: 893.4153; found: 893.4224.

\subsubsection{5. ${ }^{1} \mathrm{H}$ NMR and ${ }^{13} \mathrm{C}$ NMR spectra of (9H-fluoren-9-yl)methyl tert-butyl (6-((2-((tert-butoxycarbonyl)amino)ethyl)amino)-6-} oxohexane-1,5-diyl)(S)-dicarbamate (2la)

The title compound $21 \mathrm{a}$ was prepared from compound $\mathbf{1 8 a}(0.34 \mathrm{~g}, 2.13 \mathrm{mmol})$ and $N_{\alpha}$-Fmoc- $N_{\varepsilon}$-Boc- $L$-lysine $(1.0 \mathrm{~g}, 2.13 \mathrm{mmol})$ according to the protocol 2. Off-white solid (0.65 g, 50\%); m.p.: 173.7-175.2 ${ }^{\circ} \mathrm{C} ;{ }^{1} \mathrm{H}$ NMR $\left(600 \mathrm{MHz}, \mathrm{DMSO}-d_{6}\right): \delta 7.90-7.87$ $(\mathrm{m}, 3 \mathrm{H}), 7.72(\mathrm{t}, J=6.00 \mathrm{~Hz}, 2 \mathrm{H}), 7.42-7.38(\mathrm{~m}, 3 \mathrm{H}), 7.32(\mathrm{t}, J=6.00 \mathrm{~Hz}, 2 \mathrm{H}), 6.73(\mathrm{~d}, J=6.00 \mathrm{~Hz}, 2 \mathrm{H}), 4.28-4.27(\mathrm{~m}, 1 \mathrm{H})$, 
4.24-4.20 (m, 2H), 3.88-3.87 (m, 1H), 3.12-3.00 (m, 2H), 2.99-2.96 (m, 2H), 2.90-2.86 (m, 2H), 1.74-1.46 (m, 3H), $1.36(\mathrm{~s}, 18 \mathrm{H})$, $1.28-1.19(\mathrm{~m}, 3 \mathrm{H}) ;{ }^{13} \mathrm{C}$ NMR $\left(150 \mathrm{MHz}, \mathrm{DMSO}-d_{6}\right): \delta 172.5,156.4,156.1,156.0,144.4,144.2,141.2,128.1,127.5,125.7,120.6$, 79.6, 79.4, 79.2, 79.2, 78.2, 77.8, 66.1, 55.2, 47.1, 46.3, 46.3, 32.1, 29.7, 28.7, 28.6, 26.4, 26.3, 23.3; IR (ATR).vmax 3356, 2943, 2265, 2106, 1526, 1447, 1389, 1526, 1240, 1167, 1025, 836, 735; HRMS (ESI): m/z calcd for $\mathrm{C}_{33} \mathrm{H}_{46} \mathrm{~N}_{4} \mathrm{O}_{7} \mathrm{Na}_{[\mathrm{M}}+\mathrm{Na}^{+}$: 633.3264; found: 633.3261 .

\subsubsection{6. ${ }^{1} \mathrm{H} N M R$ and ${ }^{13} \mathrm{C}$ NMR spectra of (9H-fluoren-9-yl)methyl tert-butyl (6-((2-(2,3-dibocguanidino)ethyl)amino)-6- oxohexane-1,5-diyl)(S)-dicarbamate $(21 b)$}

The title compound $\mathbf{2 1 b}$ was prepared from compound $\mathbf{1 8 b}(0.643 \mathrm{~g}, 2.13 \mathrm{mmol})$ and $N_{\alpha}$-Fmoc- $N_{\varepsilon}$-Boc- $L$-lysine $(1.0 \mathrm{~g}, 2.13$ mmol) according to the protocol 2. Off-white solid (0.89 g, 55\%); m.p.: 102.2-103.6 ${ }^{\circ} \mathrm{C} ;{ }^{1} \mathrm{H} \mathrm{NMR}\left(400 \mathrm{MHz}, \mathrm{CDCl}_{3}\right): \delta 11.43(\mathrm{~s}$, $1 \mathrm{H}), 8.65$ (br s, $1 \mathrm{H}), 8.07$ (br s, $1 \mathrm{H}), 7.75(\mathrm{~d}, J=8.00 \mathrm{~Hz}, 2 \mathrm{H}), 7.59(\mathrm{~d}, J=8.00 \mathrm{~Hz}, 2 \mathrm{H}), 7.39(\mathrm{t}, J=8.00 \mathrm{~Hz}, 2 \mathrm{H}), 7.33-7.26(\mathrm{~m}$, $2 \mathrm{H}), 5.65(\mathrm{~d}, J=4.00 \mathrm{~Hz}, 1 \mathrm{H}), 4.59$ (br s, 1H), 4.38-4.36 (m, 1H), 4.22-4.17 (m, 1H), 3.57-3.53 (m, 2H), 3.45-3.42 (m, 2H), 3.10$3.08(\mathrm{~m}, 2 \mathrm{H}), 1.87-1.80(\mathrm{~m}, 1 \mathrm{H}), 1.70-1.66(\mathrm{~m}, 1 \mathrm{H}), 1.50(\mathrm{~s}, 9 \mathrm{H}), 1.48(\mathrm{~s}, 9 \mathrm{H}), 1.42(\mathrm{~s}, 9 \mathrm{H}), 1.48-1.32(\mathrm{~m}, 6 \mathrm{H}) ;{ }^{13} \mathrm{C} \mathrm{NMR}(100$ $\left.\mathrm{MHz}, \mathrm{CDCl}_{3}\right): \delta 171.6,162.8,157.6,156.0,155.9,153.0,143.9,141.3,127.7,127.0,125.2,120.0,83.7,80.0,79.1,66.9,54.8$, 47.2, 41.5, 40.3, 32.9, 29.8, 28.4, 28.3, 28.0, 22.3; IR (ATR).vmax 3316, 2973, 1713, 1612, 1516, 1448, 1410, 1325, 1244, 1129, 1046, 857; HRMS (ESI): m/z calcd for $\mathrm{C}_{39} \mathrm{H}_{56} \mathrm{~N}_{6} \mathrm{O}_{9} \mathrm{Na}[\mathrm{M}+\mathrm{Na}]^{+}:$775.4006; found: 775.4006 .

\subsubsection{7. ${ }^{1} \mathrm{H} N M R$ and ${ }^{13} \mathrm{C} N M R$ spectra of tert-butyl (S)-(1-((3'-((2-((tert-butoxycarbonyl)amino)ethyl)carbamoyl)-[1,1'-biphenyl]-} 3-yl)amino)-3-(1H-indol-3-yl)-1-oxopropan-2-yl)carbamate (22a)

The title compound was prepared from compound $\mathbf{1 3}(100 \mathrm{mg}, 0.20 \mathrm{mmol})$ and $\mathbf{1 8 a}(32 \mathrm{mg}, 0.20 \mathrm{mmol})$ following the general protocol 1 to afford 22a as an off-white solid (83 mg, 65\%). ${ }^{1} \mathrm{H}$ NMR (400 MHz, DMSO-d6): $\delta 10.82(\mathrm{br} \mathrm{s}, 1 \mathrm{H}), 10.20(\mathrm{br} \mathrm{s}, 1 \mathrm{H})$, $8.60(\mathrm{t}, J=4.00 \mathrm{~Hz}, 1 \mathrm{H}), 8.10(\mathrm{~s}, 1 \mathrm{H}), 7.90(\mathrm{br} \mathrm{s}, 1 \mathrm{H}), 7.85(\mathrm{~d}, J=4.00 \mathrm{~Hz}, 1 \mathrm{H}), 7.75(\mathrm{~d}, J=8.00 \mathrm{~Hz}, 1 \mathrm{H}), 7.67(\mathrm{~d}, J=8.00 \mathrm{~Hz}$, $2 \mathrm{H}), 7.57(\mathrm{t}, J=8.00 \mathrm{~Hz}, 1 \mathrm{H}), 7.46-7.40(\mathrm{~m}, 2 \mathrm{H}), 7.33(\mathrm{~d}, J=4.00 \mathrm{~Hz}, 1 \mathrm{H}), 7.20(\mathrm{~s}, 1 \mathrm{H}), 7.08-6.92(\mathrm{~m}, 4 \mathrm{H}), 4.44-4.40(\mathrm{~m}, 1 \mathrm{H})$, 3.18-2.99 (m, 6H), $1.37(\mathrm{~s}, 18 \mathrm{H}) ;{ }^{13} \mathrm{C}$ NMR (100 MHz, DMSO-d $)$ : $\delta 166.7,156.2,140.6,140.6,136.5,135.7,129.8,129.4$, $127.8,126.9,125.9,124.3,122.3,121.3,119.2,119.1,118.7,118.3,111.8,110.4,79.6,78.6,78.2,28.7,28.6,28.3 ;$ IR (ATR).vmax 3298, 2974, 1669, 1492, 1453, 1247, 1158, 1010, 853; HRMS (ESI): m/z calcd for $\mathrm{C}_{36} \mathrm{H}_{43} \mathrm{~N}_{5} \mathrm{O}_{6} \mathrm{Na}\left[\mathrm{M}+\mathrm{Na}^{+}\right.$: 664.3111; found: 664.3102 .

4.3.18. ${ }^{1} \mathrm{H}$ NMR and ${ }^{13} \mathrm{C}$ NMR spectra of tert-butyl (S)-(1-((3'-((2-(2,3-dibocguanidino)ethyl)carbamoyl)-[1,1'-biphenyl]-3yl)amino)-3-(1H-indol-3-yl)-1-oxopropan-2-yl)carbamate $(22 b)$

The title compound was prepared from compound $\mathbf{1 3}(100 \mathrm{mg}, 0.20 \mathrm{mmol})$ and $\mathbf{1 8 b}(61 \mathrm{mg}, 0.2 \mathrm{mmol})$ following the general protocol 1 to afford 22b as an off-white solid (94 mg, 60\%); m.p.: 127.2-127.6 ${ }^{\circ} \mathrm{C} ;{ }^{1} \mathrm{H} \mathrm{NMR}\left(600 \mathrm{MHz}, \mathrm{DMSO}-d_{6}\right)$ : $\delta 11.49$ (br s, $1 \mathrm{H}), 10.81$ (br s, 1H), $10.15($ br s, $1 \mathrm{H}), 8.67(\mathrm{t}, J=6.00 \mathrm{~Hz}, 1 \mathrm{H}), 8.47$ (t, $J=6.00 \mathrm{~Hz}, 1 \mathrm{H}), 8.08(\mathrm{br} \mathrm{s}, 1 \mathrm{H}), 7.91(\mathrm{~s}, 1 \mathrm{H}), 7.82(\mathrm{~d}, J$ $=12.00 \mathrm{~Hz}, 1 \mathrm{H}), 7.75(\mathrm{~d}, J=12.00 \mathrm{~Hz}, 1 \mathrm{H}), 7.67-7.66(\mathrm{~m}, 2 \mathrm{H}), 7.56(\mathrm{t}, J=6.00 \mathrm{~Hz}, 1 \mathrm{H}), 7.32(\mathrm{~d}, J=6.00 \mathrm{~Hz}, 1 \mathrm{H}), 7.19(\mathrm{br} \mathrm{s}$, $1 \mathrm{H}), 7.05(\mathrm{t}, J=6.00 \mathrm{~Hz}, 1 \mathrm{H}), 6.99-6.95(\mathrm{~m}, 2 \mathrm{H}), 4.40(\mathrm{q}, J=6.00 \mathrm{~Hz}, 1 \mathrm{H}), 3.52(\mathrm{q}, J=6.00 \mathrm{~Hz}, 2 \mathrm{H}), 3.46(\mathrm{q}, J=6.00 \mathrm{~Hz}, 2 \mathrm{H})$, 3.17-3.13 (m, 1H), 3.04-3.00 (m, 1H), $1.43(\mathrm{~s}, 9 \mathrm{H}), 1.37(\mathrm{~s}, 9 \mathrm{H}), 1.33(\mathrm{~s}, 9 \mathrm{H}) ;{ }^{13} \mathrm{C}$ NMR (100 MHz, DMSO-d $): \delta 171.1,166.9$, $163.7,163.5,156.2,155.7,152.3,140.6,140.5,140.1,136.5,135.6,129.8,129.7,129.4,129.4,127.7,126.7,125.9,124.2,122.2$, $121.3,119.2,119.0,118.6,118.2,111.7,110.4,83.3,78.6,78.5,67.4,56.3,40.5,39.2,31.7,28.7,28.6,28.4,28.2,28 ;$ IR (ATR).vmax 2977, 1612, 1535, 1364, 1326, 1229, 1133, 875; HRMS (ESI): m/z calcd for $\mathrm{C}_{42} \mathrm{H}_{53} \mathrm{~N}_{7} \mathrm{O}_{8}[\mathrm{M}+\mathrm{H}]^{+}: 784.3956$; found: 784.4031.

4.3.19. ${ }^{1} \mathrm{H} N M R$ and ${ }^{13} C N M R$ spectra of methyl $N^{6}-($ tert-butoxycarbonyl)-N2-(3'-((S)-2-((tert-butoxycarbonyl)amino)-3-(1H-indol3-yl)propanamido)-[1,1'-biphenyl]-3-carbonyl)-L-lysinate (22c)

The title compound was prepared from compound $13(100 \mathrm{mg}, 0.20 \mathrm{mmol})$ and $18 \mathrm{c}(52 \mathrm{mg}, 0.2 \mathrm{mmol})$ following the general protocol 1 to afford 22c as an off-white solid (109 mg, 74\%); m.p.: 235.5-236.1 ${ }^{\circ} \mathrm{C} ;{ }^{1} \mathrm{H}$ NMR $\left(400 \mathrm{MHz}, \mathrm{DMSO}-d_{6}\right): \delta 10.82(\mathrm{~s}$, $1 \mathrm{H}), 10.17(\mathrm{~s}, 1 \mathrm{H}), 8.84(\mathrm{~d}, J=8.00 \mathrm{~Hz}, 1 \mathrm{H}), 8.14(\mathrm{~s}, 1 \mathrm{H}), 7.91-7.88(\mathrm{~m}, 2 \mathrm{H}), 7.79(\mathrm{~d}, J=8.00 \mathrm{~Hz}, 1 \mathrm{H}), 7.68(\mathrm{t}, J=4.00 \mathrm{~Hz}, 1 \mathrm{H})$, $7.59(\mathrm{t}, J=8.00 \mathrm{~Hz}, 1 \mathrm{H}), 7.47-7.41(\mathrm{~m}, 2 \mathrm{H}), 7.32(\mathrm{~d}, J=8.00 \mathrm{~Hz}, 1 \mathrm{H}), 7.20(\mathrm{~s}, 1 \mathrm{H}), 7.06(\mathrm{t}, J=8.00 \mathrm{~Hz}, 1 \mathrm{H}), 7.00-6.97(\mathrm{~m}, 2 \mathrm{H})$, $6.78(\mathrm{t}, J=8.00 \mathrm{~Hz}, 1 \mathrm{H}), 4.47-4.38(\mathrm{~m}, 2 \mathrm{H}), 3.66(\mathrm{~s}, 3 \mathrm{H}), 3.17-2.89(\mathrm{~m}, 4 \mathrm{H}), 1.81(\mathrm{t}, J=8.00 \mathrm{~Hz}, 1 \mathrm{H}), 1.41-1.37(\mathrm{~m}, 2 \mathrm{H}), 1.34(\mathrm{~s}$, $18 \mathrm{H}), 1.24-1.18(\mathrm{~m}, 2 \mathrm{H}) ;{ }^{13} \mathrm{C}$ NMR $\left(100 \mathrm{MHz}, \mathrm{DMSO}-d_{6}\right)$ : $\delta 173.2,166.9,156.0,155.7,140.7,140.5,140.1,136.5,134.8,130.0$, $129.8,129.4,127.7,127.1,126.1,124.2,122.3,121.3,119.0,118.6,118.2,111.7,110.4,79.6,78.5,77.8,53.2,52.3,30.7,29.5$, 28.7, 28.6, 28.2, 23.5; IR (ATR).vmax 2929, 2312, 1992, 1671, 1521, 1433, 1363, 1228, 1160, 1010, 860; HRMS (ESI): m/z calcd for $\mathrm{C}_{41} \mathrm{H}_{51} \mathrm{~N}_{5} \mathrm{O}_{8} \mathrm{Na}[\mathrm{M}+\mathrm{Na}]^{+}:$764.3635; found: 764.3630.

4.3.20. ${ }^{1} \mathrm{H} N \mathrm{NR}$ and ${ }^{13} \mathrm{C}$ NMR spectra of Methyl $N^{2}-\left(3^{\prime}-((S)-2-((\right.$ tert-butoxycarbonyl)amino)-3-(1H-indol-3-yl)propanamido)-[1,1'biphenyl]-3-carbonyl)- $N^{w}-((4-m e t h o x y-2,3,6$-trimethylphenyl)sulfonyl)-L-argininate (22d)

The title compound was prepared from compound $\mathbf{1 3}(100 \mathrm{mg}, 0.20 \mathrm{mmol})$ and $\mathbf{1 8 d}(80 \mathrm{mg}, 0.2 \mathrm{mmol})$ following the general protocol 1 to afford 22d as an off-white solid (104 mg, 59\%); m.p.: $172.2-173.1{ }^{\circ} \mathrm{C} ;{ }^{1} \mathrm{H}$ NMR $\left(600 \mathrm{MHz}, \mathrm{DMSO}-d_{6}\right)$ : $\delta 10.82(\mathrm{~s}$, $1 \mathrm{H}), 10.17(\mathrm{~s}, 1 \mathrm{H}), 8.88(\mathrm{~d}, J=12.00 \mathrm{~Hz}, 1 \mathrm{H}), 8.13(\mathrm{br} \mathrm{s}, 1 \mathrm{H}), 7.92-7.88(\mathrm{~m}, 2 \mathrm{H}), 7.79(\mathrm{~d}, J=12.00 \mathrm{~Hz}, 1 \mathrm{H}), 7.68-7.66(\mathrm{~m}, 2 \mathrm{H})$, $7.60(\mathrm{t}, J=6.00 \mathrm{~Hz}, 1 \mathrm{H}), 7.47-7.41(\mathrm{~m}, 2 \mathrm{H}), 7.33(\mathrm{~d}, J=12.00 \mathrm{~Hz}, 1 \mathrm{H}), 7.19(\mathrm{br} \mathrm{s}, 1 \mathrm{H}), 7.08-7.04(\mathrm{~m}, 1 \mathrm{H}), 7.00-6.96(\mathrm{~m}, 2 \mathrm{H})$, 6.74-6.66 (m, 2H), 6.48-6.26 (m, 2H), 4.48-4.40 (m, 2H), $3.77(\mathrm{~s}, 3 \mathrm{H}), 3.65(\mathrm{~s}, 3 \mathrm{H}), 3.15-2.99(\mathrm{~m}, 4 \mathrm{H}), 2.59(\mathrm{~s}, 3 \mathrm{H}), 2.51(\mathrm{~s}, 3 \mathrm{H})$, 
$2.02(\mathrm{~s}, 3 \mathrm{H}), 1.82-1.74(\mathrm{~m}, 2 \mathrm{H}), 1.52-1.49(\mathrm{~m}, 2 \mathrm{H}), 1.34(\mathrm{~s}, 9 \mathrm{H}) ;{ }^{13} \mathrm{C}$ NMR $\left(100 \mathrm{MHz}, \mathrm{DMSO}-d_{6}\right): \delta 173.0,171.8,166.9,157.9$, 156.6, 155.7, 140.7, 140.5, 140.1, 138.1, 136.5, 134.8, 130.1, 129.8, 129.5, 127.7, 127.1, 126.1, 124.3, 122.3, 121.3, 119.2, 119.1, 118.6, 118.3, 112.2, 111.8, 110.4, 79.6, 78.6, 56.3, 55.9, 53.0, 52.3, 28.6, 28.4, 24.1, 18.5, 12.2; IR (ATR).vmax 3305, 2932, $1669,1541,1456,1364,1303,1227,1159,1114,1013$; HRMS (ESI): m/z calcd for $\mathrm{C}_{46} \mathrm{H}_{55} \mathrm{~N}_{7} \mathrm{O}_{9} \mathrm{~S}[\mathrm{M}+\mathrm{H}]^{+}: 882.3782$; found: 882.3854.

4.3.21. ${ }^{1} \mathrm{H}$ NMR and ${ }^{13} \mathrm{C} N M R$ spectra of tert-butyl ((S)-5-(3'-((S)-2-((tert-butoxycarbonyl)amino)-3-(1H-indol-3yl)propanamido)-[1,1'-biphenyl]-3-carboxamido)-6-((2-((tert-butoxycarbonyl)amino)ethyl)amino)-6-oxohexyl)carbamate (22e)

The title compound was prepared from compound $\mathbf{1 3}(100 \mathrm{mg}, 0.20 \mathrm{mmol})$ and $\mathbf{1 8 e}(77 \mathrm{mg}, 0.20 \mathrm{mmol})$ following the general protocol 1 to afford 22e as an off-white solid $(139 \mathrm{mg}, 80 \%)$; m.p.: $131.5-131.7{ }^{\circ} \mathrm{C} ;{ }^{1} \mathrm{H}$ NMR $\left(600 \mathrm{MHz}, \mathrm{DMSO}-d_{6}\right): \delta 10.82(\mathrm{~s}$, $1 \mathrm{H}), 10.16(\mathrm{~s}, 1 \mathrm{H}), 8.55(\mathrm{~d}, J=6.00 \mathrm{~Hz}, 1 \mathrm{H}), 8.16(\mathrm{~s}, 1 \mathrm{H}), 8.01(\mathrm{t}, J=6.00 \mathrm{~Hz}, 1 \mathrm{H}), 7.92-7.91(\mathrm{~m}, 2 \mathrm{H}), 7.77-7.75(\mathrm{~m}, 1 \mathrm{H}), 7.68-$ $7.67(\mathrm{~m}, 1 \mathrm{H}), 7.57(\mathrm{t}, J=12.00 \mathrm{~Hz}, 1 \mathrm{H}), 7.45-7.43(\mathrm{~m}, 2 \mathrm{H}), 7.32(\mathrm{~d}, J=6.00 \mathrm{~Hz}, 1 \mathrm{H}), 7.20(\mathrm{~s}, 1 \mathrm{H}), 7.06(\mathrm{t}, J=6.00 \mathrm{~Hz}, 1 \mathrm{H})$, 6.99-6.96 (m, 2H), 6.77-6.74 (m, 2H), 4.43-4.37 (m, 2H), 3.18-2.86 (m, 8H), 1.77-1.68 (m, 2H), 1.37-1.36 (m, 2H), 1.36 (s, 9H), $1.34(\mathrm{~s}, 18 \mathrm{H}), 1.24-1.15(\mathrm{~m}, 2 \mathrm{H}) ;{ }^{13} \mathrm{C}$ NMR $\left(150 \mathrm{MHz}, \mathrm{DMSO}-d_{6}\right): \delta 172.4,171.8,166.7,156.1,156.0,155.8,140.6,140.6$, 136.5,135.3, 129.8, 129.3, 127.7, 127.2, 126.3, 124.3, 121.3, 119.2, 119.1, 118.7, 118.3, 111.7, 110.4, 78.6, 78.1, 77.7, 56.3, 54.1, 40.5, 39.3, 31.8, 31.4, 29.7, 23.7, 22.5; IR (ATR).vmax 2972, 2930, 1683, 1521, 1455, 1246, 1163, 1010, 861; HRMS (ESI): m/z calcd for $\mathrm{C}_{47} \mathrm{H}_{63} \mathrm{~N}_{7} \mathrm{O}_{9} \mathrm{Na}[\mathrm{M}+\mathrm{Na}]^{+}:$892.4585; found: 892.4575 .

\subsubsection{2. ${ }^{1} H$ NMR and ${ }^{13}$ C NMR spectra of (S)-3'-(2-amino-3-(1H-indol-3-yl)propanamido)-N-(2-aminoethyl)-[1,1'-biphenyl]-3-} carboxamide (23a)

The title compound was prepared from compound 22a (75 $\mathrm{mg}, 0.116 \mathrm{mmol})$ following the general protocol 4 to afford 23a as a white solid (45 mg, 89\%); m.p.: $164.5-164.7{ }^{\circ} \mathrm{C} ;{ }^{1} \mathrm{H}$ NMR $\left(600 \mathrm{MHz}, \mathrm{DMSO}-d_{6}\right): \delta 11.06(\mathrm{~d}, J=6.00 \mathrm{~Hz}, 1 \mathrm{H}), 10.70(\mathrm{~s}, 1 \mathrm{H})$, $8.78(\mathrm{t}, J=6.00 \mathrm{~Hz}, 1 \mathrm{H}), 8.30(\mathrm{br} \mathrm{s}, 3 \mathrm{H}), 8.13(\mathrm{t}, J=6.00 \mathrm{~Hz}, 1 \mathrm{H}), 7.90-7.87(\mathrm{~m}, 5 \mathrm{H}), 7.79-7.77(\mathrm{~m}, 1 \mathrm{H}), 7.68(\mathrm{~d}, J=12.00 \mathrm{~Hz}$, $1 \mathrm{H}), 7.62-7.60(\mathrm{~m}, 2 \mathrm{H}), 7.50-7.49(\mathrm{~m}, 2 \mathrm{H}), 7.37(\mathrm{~d}, J=12.00 \mathrm{~Hz}, 1 \mathrm{H}), 7.26(\mathrm{~d}, J=6.00 \mathrm{~Hz}, 1 \mathrm{H}), 7.10-7.07(\mathrm{~m}, 1 \mathrm{H}), 6.99-6.97$ $(\mathrm{m}, 1 \mathrm{H}), 4.21-4.20(\mathrm{~m}, 1 \mathrm{H}), 3.55(\mathrm{q}, J=6.00 \mathrm{~Hz}, 2 \mathrm{H}), 3.39-3.35(\mathrm{~m}, 2 \mathrm{H}), 3.28-3.25(\mathrm{~m}, 2 \mathrm{H}), 3.03(\mathrm{q}, J=6.00 \mathrm{~Hz}, 2 \mathrm{H}) ;{ }^{13} \mathrm{C} \mathrm{NMR}$ $\left(150 \mathrm{MHz}, \mathrm{DMSO}-d_{6}\right): \delta 167.9,167.2,140.6,140.4,139.1,136.7,135.3,130.1,129.9,129.6,127.5,127.1,126.1,125.4,123.1$, $121.7,119.6,119.0,118.9,118.5,111.9,107.1,54.1,40.5,39.1,37.6,27.8$; IR (ATR).vmax 3041, 2890, 1774, 1664, 1525, 1429, 1318, 1179, 835, 795, 744; HRMS (ESI): m/z calcd for $\mathrm{C}_{26} \mathrm{H}_{27} \mathrm{~N}_{5} \mathrm{O}_{2}[\mathrm{M}+\mathrm{H}]^{+}$: 442.2165; found: 442.2234 .

4.3.23. ${ }^{1} \mathrm{H} N M R$ and ${ }^{13} \mathrm{C} N M R$ spectra of (S)-3'-(2-amino-3-(1H-indol-3-yl)propanamido)-N-(2-guanidinoethyl)-[1,1'-biphenyl]-3carboxamide $(23 b)$

The title compound was prepared from compound $\mathbf{2 2 b}(90 \mathrm{mg}, 0.122 \mathrm{mmol})$ following the general protocol 4 to afford $\mathbf{2 3 b}$ as a white solid (29 mg, 50\%); m.p.: 236.7-238.0 ${ }^{\circ} \mathrm{C}$; ${ }^{1} \mathrm{H}$ NMR $\left(600 \mathrm{MHz}, \mathrm{DMSO}-d_{6}\right): \delta 11.05(\mathrm{br} \mathrm{s}, 1 \mathrm{H}), 10.69(\mathrm{~s}, 1 \mathrm{H}), 8.77(\mathrm{t}, J=$ $6.00 \mathrm{~Hz}, 1 \mathrm{H}), 8.28$ (br s, 3H), $8.12(\mathrm{t}, J=6.00 \mathrm{~Hz}, 1 \mathrm{H}), 7.89-7.87(\mathrm{~m}, 2 \mathrm{H}), 7.78-7.77(\mathrm{~m}, 1 \mathrm{H}), 7.70-7.67(\mathrm{~m}, 2 \mathrm{H}), 7.62-7.59(\mathrm{~m}$, 2H), 7.49-7.48 (m, 3H), 7.38-7.36 (m, 2H), 7.26 (d, J=6.00 Hz, 2H), 7.10-7.07 (m, 1H), 6.99-6.97 (m, $1 \mathrm{H}), 4.20(\mathrm{t}, J=6.00 \mathrm{~Hz}$, $1 \mathrm{H}), 3.45(\mathrm{q}, J=6.00 \mathrm{~Hz}, 2 \mathrm{H}), 3.39-3.36(\mathrm{~m}, 1 \mathrm{H}), 3.28-3.24(\mathrm{~m}, 1 \mathrm{H}) ;{ }^{13} \mathrm{C}$ NMR $\left(150 \mathrm{MHz}, \mathrm{DMSO}-d_{6}\right): \delta 167.9,167.1,157.5$, 140.6, 140.4, 139.1, 135.3, 130.1, 129.8, 129.6, 127.5, 126.9, 126.0, 125.4, 123.1, 121.7, 119.6, 119.0, 118.9, 118.5, 112.0, 107.1,54.1, 40.8, 39.1, 27.8; IR (ATR).vmax 3178, 3080, 2340, 2110, 1657, 1542, 1430, 1316, 1200, 1148, 835, 797, 743; HRMS (ESI): $\mathrm{m} / \mathrm{z}$ calcd for $\mathrm{C}_{27} \mathrm{H}_{29} \mathrm{~N}_{7} \mathrm{O}_{2}[\mathrm{M}+\mathrm{H}]^{+}:$484.2383; found: 484.2455.

\subsubsection{4. ${ }^{1} \mathrm{H} N M R$ and ${ }^{13} \mathrm{C} N M R$ spectra of Methyl (3'-((S)-2-amino-3-(1H-indol-3-yl)propanamido)-[1,1'-biphenyl]-3-carbonyl)-L-} lysinate (23c)

The title compound was prepared from compound 22c (50 mg, $0.067 \mathrm{mmol})$ following the general protocol 4 to afford $23 \mathbf{c}$ as a gummy solid (36 mg, 70\%); ${ }^{1} \mathrm{H}$ NMR $\left(600 \mathrm{MHz}, \mathrm{DMSO}-d_{6}\right): \delta 11.00(\mathrm{~s}, 1 \mathrm{H}), 10.70(\mathrm{~s}, 1 \mathrm{H}), 8.89(\mathrm{~d}, J=6.00 \mathrm{~Hz}, 1 \mathrm{H}), 8.29(\mathrm{br} \mathrm{s}$, $3 \mathrm{H}), 8.14-8.13(\mathrm{~m}, 1 \mathrm{H}), 7.93-7.91(\mathrm{~m}, 1 \mathrm{H}), 7.87-7.86(\mathrm{~m}, 1 \mathrm{H}), 7.80-7.75(\mathrm{~m}, 4 \mathrm{H}), 7.68(\mathrm{~d}, J=12.00 \mathrm{~Hz}, 1 \mathrm{H}), 7.62-7.60(\mathrm{~m}, 2 \mathrm{H})$, 7.50-7.48 (m, 2H), 7.37-7.36 (m, 1H), $7.26(\mathrm{~d}, J=6.00 \mathrm{~Hz}, 1 \mathrm{H}), 7.10-7.07(\mathrm{~m}, 1 \mathrm{H}), 6.99-6.97(\mathrm{~m}, 1 \mathrm{H}), 4.50-4.46(\mathrm{~m}, 1 \mathrm{H}), 4.20$ (br s, 1H), $3.67(\mathrm{~s}, 3 \mathrm{H}), 3.35-3.25(\mathrm{~m}, 2 \mathrm{H}), 2.80-2.79(\mathrm{~m}, 2 \mathrm{H}), 1.86-1.39(\mathrm{~m}, 6 \mathrm{H}) ;{ }^{13} \mathrm{C} \mathrm{NMR}\left(100 \mathrm{MHz}, \mathrm{DMSO}-d_{6}\right): \delta 173.1,167.9$, 166.9, 158.6, 158.4, 140.6, 140.4, 139.1, 136.7, 134.8, 130.2, 130.1, 129.6, 127.5, 127.2, 126.2, 125.4, 123.2, 121.6, 119.6, $118.95,118.9,118.6,111.9,107.1,54.1,53.0,52.4,40.5,40.4,39.0,30.4,27.8,27.0,23.1$; IR (ATR).vmax 3251, 3044, 2932, 2098, 1666, 1524, 1432, 1338, 1178, 1118, 835, 796, 743, 719; HRMS (ESI): m/z calcd for $\mathrm{C}_{31} \mathrm{H}_{35} \mathrm{~N}_{5} \mathrm{O}_{4}\left[\mathrm{M}+\mathrm{H}^{+}: 542.2689\right.$; found: 542.2157 .

4.3.25. ${ }^{1} \mathrm{H}$ NMR and ${ }^{13} \mathrm{C} N M R$ spectra of Methyl (3'-((S)-2-amino-3-(1H-indol-3-yl)propanamido)-[1,1'-biphenyl]-3-carbonyl)-Largininate $(23 d)$

The title compound was prepared from compound 22d (90 mg, $0.10 \mathrm{mmol})$ following the general protocol 4 to afford $23 \mathbf{d}$ as a gummy solid (50 mg, 54\%). ${ }^{1} \mathrm{H}$ NMR $\left(600 \mathrm{MHz}, \mathrm{DMSO}-d_{6}\right): \delta 11.04(\mathrm{~s}, 1 \mathrm{H}), 10.66(\mathrm{~s}, 1 \mathrm{H}), 8.93(\mathrm{~d}, J=6.00 \mathrm{~Hz}, 1 \mathrm{H}), 8.27(\mathrm{br} \mathrm{s}$, $3 \mathrm{H}), 8.13(\mathrm{br} \mathrm{s}, 1 \mathrm{H}), 7.92(\mathrm{~d}, J=6.00 \mathrm{~Hz}, 2 \mathrm{H}), 7.79(\mathrm{~d}, J=12.00 \mathrm{~Hz}, 1 \mathrm{H}), 7.73-7.45(\mathrm{~m}, 6 \mathrm{H}), 7.38-7.25(\mathrm{~m}, 2 \mathrm{H}), 7.10-6.97(\mathrm{~m}$, $3 \mathrm{H}), 4.52-4.49(\mathrm{~m}, 1 \mathrm{H}), 4.19-4.18(\mathrm{~m}, 1 \mathrm{H}), 3.68(\mathrm{~s}, 3 \mathrm{H}), 3.35-3.12(\mathrm{~m}, 4 \mathrm{H}), 1.92-1.54(\mathrm{~m}, 4 \mathrm{H}) ;{ }^{13} \mathrm{C}$ NMR $\left(150 \mathrm{MHz}, \mathrm{DMSO}-d_{6}\right)$ : $\delta 172.9,167.9,166.9,162.2,158.7,158.5,157.2,140.6,140.4,139.1,136.7,134.8,130.2,130.1,129.6,127.5,127.2,126.2$, $125.4,123.2,121.7,119.6,118.9,118.9,118.8,118.5,112.0,107.1,54.1,52.8,52.5,40.7,40.5,28.1,27.8,25.8 ;$ IR (ATR).vmax 
, 3192, 3065, 2118, 1660, 1539, 1434, 1315, 1227, 1159, 836, 797, 744; HRMS (ESI): $\mathrm{m} / \mathrm{z}$ calcd for $\mathrm{C}_{31} \mathrm{H}_{35} \mathrm{~N}_{7} \mathrm{O}_{4}[\mathrm{M}+\mathrm{H}]^{+}$: 570.3114; found: 570.2820 .

4.3.26. ${ }^{1} \mathrm{H} N M R$ and ${ }^{13} \mathrm{C} N M R$ spectra of $N$-((S)-6-amino-1-((2-aminoethyl)amino)-1-oxohexan-2-yl)-3'-((S)-2-amino-3-(1H-indol3-yl)propanamido)-[1,1'-biphenyl]-3-carboxamide (23e)

The title compound was prepared from compound $22 \mathrm{c}(100 \mathrm{mg}, 0.114 \mathrm{mmol})$ following the general protocol 4 to afford $23 \mathbf{e}$ as a white solid (45 mg, 70\%); m.p.: 237.6-238.0 ${ }^{\circ} \mathrm{C} ;{ }^{1} \mathrm{H}$ NMR (600 MHz, DMSO- $\left.d_{6}\right): \delta 11.05(\mathrm{~d}, J=4.00 \mathrm{~Hz}, 1 \mathrm{H}), 10.71(\mathrm{~s}, 1 \mathrm{H})$, $8.68(\mathrm{~d}, J=4.00 \mathrm{~Hz}, 1 \mathrm{H}), 8.29-8.23(\mathrm{~m}, 4 \mathrm{H}), 8.16(\mathrm{~s}, 1 \mathrm{H}), 7.94(\mathrm{~d}, J=4.00 \mathrm{~Hz}, 1 \mathrm{H}), 7.85(\mathrm{br} \mathrm{s}, 4 \mathrm{H}), 7.77-7.75(\mathrm{~m}, 4 \mathrm{H}), 7.67(\mathrm{~d}, J$ $=8.00 \mathrm{~Hz}, 1 \mathrm{H}), 7.60-7.58(\mathrm{~m}, 2 \mathrm{H}), 7.51-7.47(\mathrm{~m}, 2 \mathrm{H}), 7.36(\mathrm{~d}, J=8.00 \mathrm{~Hz}, 1 \mathrm{H}), 7.25(\mathrm{~d}, J=4.00 \mathrm{~Hz}, 1 \mathrm{H}), 7.08(\mathrm{t}, J=4.00 \mathrm{~Hz}$, $1 \mathrm{H}), 6.97(\mathrm{t}, J=4.00 \mathrm{~Hz}, 1 \mathrm{H}), 4.44-4.41(\mathrm{~m}, 1 \mathrm{H}), 4.21-4.20(\mathrm{~m}, 1 \mathrm{H}), 3.37-3.24(\mathrm{~m}, 4 \mathrm{H}), 2.88-2.77(\mathrm{~m}, 4 \mathrm{H}), 1.86-1.70(\mathrm{~m}, 2 \mathrm{H})$, $1.60-1.52(\mathrm{~m}, 2 \mathrm{H}), 1.44-1.31(\mathrm{~m}, 2 \mathrm{H}){ }^{13} \mathrm{C}$ NMR (150 MHz, DMSO- $\left.d_{6}\right): \delta 172.8,167.9,166.8,158.9,158.7,158.5,140.7,140.3$, 139.1, 136.7, 135.2, 130.0, 129.4, 127.5, 127.3, 126.3, 125.4, 123.2, 121.7, 119.6, 118.9, 118.6, 116.7, 111.9, 107.1, 54.1, 53.8, 40.5, 39.1, 38.9, 36.9, 31.2, 27.8, 27.2, 23.2; IR (ATR).vmax 3257, 3052, 2930, 2099, 1664, 1524, 1431, 1317, 1170, 797, 744, 720; HRMS (ESI): $\mathrm{m} / \mathrm{z}$ calcd for $\mathrm{C}_{32} \mathrm{H}_{39} \mathrm{~N}_{7} \mathrm{O}_{3}[\mathrm{M}+\mathrm{H}]^{+}:$570.3114; found: 570.2820.

4.3.27. ${ }^{1} \mathrm{H} N M R$ and ${ }^{13} \mathrm{C}$ NMR spectra of tert-butyl $\left((S)-1-\left(\left((S)-1-\left(\left(3^{\prime}-((2-((\right.\right.\right.\right.\right.$ tert-butoxycarbonyl)amino)ethyl)carbamoyl)-[1,1'biphenyl]-3-yl)amino)-3-(1H-indol-3-yl)-1-oxopropan-2-yl)amino)-1-oxo-3-phenylpropan-2-yl)carbamate (24a)

The title compound was prepared from compound $17(100 \mathrm{mg}, 0.15 \mathrm{mmol})$ and $18 \mathbf{a}(25 \mathrm{mg}, 0.15 \mathrm{mmol})$ following the general protocol 1 to afford 24a as an off-white solid $(94 \mathrm{mg}, 80 \%)$; m.p.: $126.7-128.0{ }^{\circ} \mathrm{C} ;{ }^{1} \mathrm{H}$ NMR $\left(400 \mathrm{MHz}, \mathrm{DMSO}-d_{6}\right): \delta 10.82(\mathrm{~s}$, $1 \mathrm{H}), 10.15(\mathrm{~s}, 1 \mathrm{H}), 8.57-8.56(\mathrm{~m}, 1 \mathrm{H}), 8.43(\mathrm{~d}, J=8.00 \mathrm{~Hz}, 1 \mathrm{H}), 8.10(\mathrm{~s}, 1 \mathrm{H}), 7.81-7.67(\mathrm{~m}, 7 \mathrm{H}), 7.52(\mathrm{t}, J=8.00 \mathrm{~Hz}, 1 \mathrm{H}), 7.30$ $(\mathrm{d}, J=8.00 \mathrm{~Hz}, 1 \mathrm{H}), 7.17-6.91(\mathrm{~m}, 9 \mathrm{H}), 6.76(\mathrm{~d}, J=8.00 \mathrm{~Hz}, 1 \mathrm{H}), 4.75(\mathrm{q}, J=8.00 \mathrm{~Hz}, 1 \mathrm{H}), 4.26-4.21(\mathrm{~m}, 1 \mathrm{H}), 3.29-3.03(\mathrm{~m}$, $6 \mathrm{H}), 2.73-2.72(\mathrm{~m}, 1 \mathrm{H}), 2.60-2.54(\mathrm{~m}, 1 \mathrm{H}), 1.36(\mathrm{~s}, 9 \mathrm{H}), 1.29(\mathrm{~s}, 9 \mathrm{H}) ;{ }^{13} \mathrm{C}$ NMR $\left(100 \mathrm{MHz}\right.$, DMSO- $\left.d_{6}\right): \delta 171.9,166.7,160.0$, 156.2, 155.7, 155.1, 140.0, 139.8, 138.9, 138.3, 137.1, 136.5, 135.6, 134.9, 129.7, 129.3, 129.3, 128.3, 127.7, 127.5, 126.5, 125.3, 124.2, 121.4, 120.2, 119.0, 118.7, 111.7, 110.1, 78.5, 78.1, 56.0, 54.5, 37.8, 28.7, 28.5, 28.2; IR (ATR).vmax 3299, 2976, 1663, 1518, 1455, 1246, 1160, 1118, 1021, 806; HRMS (ESI): m/z calcd for $\mathrm{C}_{45} \mathrm{H}_{52} \mathrm{~N}_{6} \mathrm{O}_{7} \mathrm{Na}$ [M + Na] $]^{+}: 811.3795$; found: 811.3789.

4.3.28. ${ }^{1} \mathrm{H} N M R$ and ${ }^{13} \mathrm{C}$ NMR spectra of tert-butyl ((S)-1-(((S)-1-((3'-((2-(2,3-dibocguanidino)ethyl)carbamoyl)-[1,1'-biphenyl]3-yl)amino)-3-(1H-indol-3-yl)-1-oxopropan-2-yl)amino)-1-oxo-3-phenylpropan-2-yl)carbamate (24b)

The title compound was prepared from compound $\mathbf{1 7}(100 \mathrm{mg}, 0.15 \mathrm{mmol})$ and $\mathbf{1 8 b}(46 \mathrm{mg}, 0.15 \mathrm{mmol})$ following the general protocol 1 to afford $\mathbf{2 4 b}$ as an off-white solid $(95 \mathrm{mg}, 68 \%)$; m.p.: $206.3-206.5{ }^{\circ} \mathrm{C} ;{ }^{1} \mathrm{H}$ NMR $\left(600 \mathrm{MHz}, \mathrm{DMSO}-d_{6}\right): \delta 11.50(\mathrm{~s}$, $1 \mathrm{H}), 10.80(\mathrm{~s}, 1 \mathrm{H}), 10.20(\mathrm{~s}, 1 \mathrm{H}), 8.41-8.45(\mathrm{~m}, 1 \mathrm{H}), 8.14(\mathrm{br} \mathrm{s}, 1 \mathrm{H}), 8.07(\mathrm{br} \mathrm{s}, 1 \mathrm{H}), 7.88(\mathrm{~s}, 1 \mathrm{H}), 7.82(\mathrm{~d}, J=4.00 \mathrm{~Hz}, 1 \mathrm{H}), 7.73$ $(\mathrm{d}, J=4.00 \mathrm{~Hz}, 1 \mathrm{H}), 7.62(\mathrm{t}, J=8.00 \mathrm{~Hz}, 2 \mathrm{H}), 7.55(\mathrm{t}, J=4.00 \mathrm{~Hz}, 1 \mathrm{H}), 7.42-7.40(\mathrm{~m}, 2 \mathrm{H}), 7.32-7.31(\mathrm{~m}, 1 \mathrm{H}), 7.20-7.13(\mathrm{~m}, 7 \mathrm{H})$, $7.05(\mathrm{t}, J=4.00 \mathrm{~Hz}, 1 \mathrm{H}), 6.97-6.92(\mathrm{~m}, 2 \mathrm{H}), 4.75-4.74(\mathrm{~m}, 1 \mathrm{H}), 4.18-4.17(\mathrm{~m}, 1 \mathrm{H}), 3.50(\mathrm{t}, J=4.00 \mathrm{~Hz}, 2 \mathrm{H}), 3.45(\mathrm{q}, J=4.00 \mathrm{~Hz}$, $2 \mathrm{H}), 3.25-3.21(\mathrm{~m}, 1 \mathrm{H}), 3.13-3.09(\mathrm{~m}, 1 \mathrm{H}), 2.93-2.90(\mathrm{~m}, 1 \mathrm{H}), 2.73-2.69(\mathrm{~m}, 1 \mathrm{H}), 1.42(\mathrm{~s}, 9 \mathrm{H}), 1.37(\mathrm{~s}, 9 \mathrm{H}), 1.28(\mathrm{~s}, 9 \mathrm{H}) ;{ }^{13} \mathrm{C}$ NMR (150 MHz, DMSO- $\left.d_{6}\right): \delta 171.9,170.8,166.9,163.6,156.2,155.7,152.3,140.6,140.5,139.9,138.4,136.5,135.7,129.8$, 129.6, 129.4, 128.4, 127.8, 126.7, 126.6, 125.9, 124.1, 122.4, 121.4, 119.2, 118.9, 118.7, 118.3, 111.7, 110.0, 83.3, 78.6, 56.4, 54.6, 40.5, 39.2, 37.9, 31.7, 28.7, 28.6, 28.0; IR (ATR).vmax 2974, 1641, 1539, 1364, 1326, 1250, 1133, 1049, 876; HRMS (ESI): $\mathrm{m} / \mathrm{z}$ calcd for $\mathrm{C}_{51} \mathrm{H}_{62} \mathrm{~N}_{8} \mathrm{O}_{9} \mathrm{Na}[\mathrm{M}+\mathrm{Na}]^{+}:$953.4537; found: 953.4533 .

4.3.29. ${ }^{1} \mathrm{H} N M R$ and ${ }^{13} \mathrm{C} N M R$ spectra of Methyl $N^{6}$-(tert-butoxycarbonyl)- $N^{2}-\left(3^{\prime}-((S)-2-((S)-2-((\right.$ tert-butoxycarbonyl)amino)-3phenylpropanamido)-3-(1H-indol-3-yl)propanamido)-[1,1'-biphenyl]-3-carbonyl)-L-lysinate (24c)

The title compound was prepared from compound $17(100 \mathrm{mg}, 0.15 \mathrm{mmol})$ and $18 \mathrm{c}(39 \mathrm{mg}, 0.15 \mathrm{mmol})$ following the general protocol 1 to afford $\mathbf{2 4 c}$ as an off-white solid $(106 \mathrm{mg}, 80 \%)$; m.p.: $132.5-133.9^{\circ} \mathrm{C} ;{ }^{1} \mathrm{H}$ NMR $\left(400 \mathrm{MHz}, \mathrm{DMSO}-d_{6}\right): \delta 10.85(\mathrm{~s}$, $1 \mathrm{H}), 10.20(\mathrm{~s}, 1 \mathrm{H}), 8.83(\mathrm{~d}, J=8.00 \mathrm{~Hz}, 1 \mathrm{H}), 8.16-8.12(\mathrm{~m}, 2 \mathrm{H}), 7.90-7.88(\mathrm{~m}, 2 \mathrm{H}), 7.76(\mathrm{~d}, J=8.00 \mathrm{~Hz}, 1 \mathrm{H}), 7.65-7.56(\mathrm{~m}, 3 \mathrm{H})$, 7.46-7.43 (m, 2H), $7.32(\mathrm{~d}, J=8.00 \mathrm{~Hz}, 1 \mathrm{H}), 7.21-7.14(\mathrm{~m}, 6 \mathrm{H}), 7.06(\mathrm{t}, J=4.00 \mathrm{~Hz}, 1 \mathrm{H}), 6.99-6.93(\mathrm{~m}, 2 \mathrm{H}), 6.78(\mathrm{t}, J=4.00 \mathrm{~Hz}$, $1 \mathrm{H}), 4.76(\mathrm{q}, J=8.00 \mathrm{~Hz}, 1 \mathrm{H}), 4.44(\mathrm{q}, J=8.00 \mathrm{~Hz}, 1 \mathrm{H}), 4.22-4.16(\mathrm{~m}, 1 \mathrm{H}), 3.66(\mathrm{~s}, 3 \mathrm{H}), 3.27-3.21(\mathrm{~m}, 1 \mathrm{H}), 3.15-3.09(\mathrm{~m}, 1 \mathrm{H})$, 2.95-2.94 (m, 3H), 2.75-2.69 (m, 1H), 1.83-1.80 (m, 2H), 1.40-1.37 (m, 2H), $1.34(\mathrm{~s}, 9 \mathrm{H}), 1.29(\mathrm{~s}, 9 \mathrm{H}), 1.18-1.14(\mathrm{~m}, 2 \mathrm{H}) ;{ }^{13} \mathrm{C}$ NMR (100 MHz, DMSO- $\left.d_{6}\right): \delta 173.2,171.9,170.8,166.9,156.0,155.7,140.6,140.5,139.8,138.4,136.5,134.8,130.0,129.8$, 129.6, 129.5, 128.4, 127.8, 127.2, 126.6, 126.1, 124.1, 122.4, 121.4, 119.2, 118.9, 118.7, 118.3, 118.7, 118.3, 111.7, 110.0, 78.7, 77.7, 56.4, 54.6, 53.2, 37.9, 31.4, 30.7, 29.6, 28.7, 28.6; IR (ATR).vmax 3305, 3047, 2925, 1652, 1509, 1453, 1363, 1245, 1161, 1012, 855; HRMS (ESI): $\mathrm{m} / \mathrm{z}$ calcd for $\mathrm{C}_{50} \mathrm{H}_{60} \mathrm{~N}_{6} \mathrm{O}_{9} \mathrm{Na}[\mathrm{M}+\mathrm{Na}]^{+}: 911.4319$; found: 911.4316.

4.3.30. ${ }^{1} \mathrm{H}$ NMR and ${ }^{13} \mathrm{C} N M R$ spectra of Methyl $N^{2}-\left(3^{\prime}-((S)-2-((S)-2-((\right.$ tert-butoxycarbonyl)amino)-3-phenylpropanamido)-3-(1Hindol-3-yl)propanamido)-[1,1'-biphenyl]-3-carbonyl)- $N^{w}-((4-$ methoxy-2,3,6-trimethylphenyl)sulfonyl)-L-argininate (24d)

The title compound was prepared from compound $\mathbf{1 7}(100 \mathrm{mg}, 0.15 \mathrm{mmol})$ and $\mathbf{1 8 d}(60 \mathrm{mg}, 0.15 \mathrm{mmol})$ following the general protocol 1 to afford 24d as an off-white solid $(115 \mathrm{mg}, 75 \%)$; m.p.: $179.5-179.7^{\circ} \mathrm{C} ;{ }^{1} \mathrm{H}$ NMR $\left(600 \mathrm{MHz}, \mathrm{DMSO}-d_{6}\right): \delta 10.85$ (s, $1 \mathrm{H}), 10.20(\mathrm{~s}, 1 \mathrm{H}), 8.87(\mathrm{~d}, J=4.00 \mathrm{~Hz}, 1 \mathrm{H}), 8.15-8.12(\mathrm{~m}, 2 \mathrm{H}), 7.89-7.88(\mathrm{~m}, 2 \mathrm{H}), 7.77(\mathrm{~d}, J=4.00 \mathrm{~Hz}, 1 \mathrm{H}), 7.64-7.57(\mathrm{~m}, 3 \mathrm{H})$, 7.45-7.41 (m, 2H), $7.33(\mathrm{~d}, J=4.00 \mathrm{~Hz}, 1 \mathrm{H}), 7.21-7.13(\mathrm{~m}, 6 \mathrm{H}), 7.07-7.04(\mathrm{~m}, 1 \mathrm{H}), 6.98-6.93(\mathrm{~m}, 2 \mathrm{H}), 6.66(\mathrm{br} \mathrm{s}, 2 \mathrm{H}), 4.75(\mathrm{q}, J$ $=4.00 \mathrm{~Hz}, 1 \mathrm{H}), 4.46-4.42(\mathrm{~m}, 1 \mathrm{H}), 4.21-4.17(\mathrm{~m}, 1 \mathrm{H}), 3.77(\mathrm{~s}, 3 \mathrm{H}), 3.65(\mathrm{~s}, 3 \mathrm{H}), 3.25-3.22(\mathrm{~m}, 1 \mathrm{H}), 3.14-3.06(\mathrm{~m}, 3 \mathrm{H}), 2.94-2.91$ $(\mathrm{m}, 1 \mathrm{H}), 2.74-2.70(\mathrm{~m}, 1 \mathrm{H}), 2.59(\mathrm{~s}, 3 \mathrm{H}), 2.02(\mathrm{~s}, 3 \mathrm{H}), 1.84-1.59(\mathrm{~m}, 2 \mathrm{H}), 1.52-1.47(\mathrm{~m}, 2 \mathrm{H}), 1.29(\mathrm{~s}, 9 \mathrm{H}) ;{ }^{13} \mathrm{C} \mathrm{NMR}(150 \mathrm{MHz}$ 
DMSO- $\left.d_{6}\right): \delta 172.9,171.9,166.9,157.9,155.7,140.7,140.5,139.8,138.4,138.1,136.5,136.0,134.8,130.1,129.8,129.6,129.5$, $128.4,127.8,127.2,126.6,126.1,124.1,122.5,121.4,119.3,118.9,118.7,118.3,112.1,111.7,110.0,79.6,78.7,56.4,55.9,52.9$, 52.4, 40.5, 37.9, 28.6, 28.4, 24.1, 18.5, 12.1; IR (ATR).vmax 2931, 1649, 1541, 1454, 1363, 1304, 1227, 1158, 1114, 1013; HRMS (ESI): $\mathrm{m} / \mathrm{z}$ calcd for $\mathrm{C}_{55} \mathrm{H}_{64} \mathrm{~N}_{8} \mathrm{O}_{10} \mathrm{~S}[\mathrm{M}+\mathrm{H}]^{+}:$1029.4466; found: 1029.4540 .

4.3.31. ${ }^{1} \mathrm{H} N M R$ and ${ }^{13} \mathrm{C} N M R$ spectra of tert-butyl $((S)-1-(((S)-3-(1 H$-indol-3-yl)-1-oxo-1-((3'-(( S)-2,2,18,18-tetramethyl-4,9,16trioxo-3,17-dioxa-5,8,15-triazanonadecan-10-yl)carbamoyl)-[1,1'-biphenyl]-3-yl)amino)propan-2-yl)amino)-1-oxo-3phenylpropan-2-yl)carbamate (24e)

The title compound was prepared from compound $17(100 \mathrm{mg}, 0.15 \mathrm{mmol})$ and $\mathbf{1 8 e}(58 \mathrm{mg}, 0.15 \mathrm{mmol})$ following the general protocol 1 to afford 24e as an off-white solid (106 mg, 70\%); m.p.: 131.9-132.4 ${ }^{\circ} \mathrm{C} ;{ }^{1} \mathrm{H}$ NMR $\left(600 \mathrm{MHz}, \mathrm{DMSO}-d_{6}\right): \delta 10.84(\mathrm{~s}$, $1 \mathrm{H}), 10.19(\mathrm{~s}, 1 \mathrm{H}), 8.53(\mathrm{~d}, J=6.00 \mathrm{~Hz}, 1 \mathrm{H}), 8.13(\mathrm{br} \mathrm{s}, 2 \mathrm{H}), 8.00(\mathrm{t}, J=6.00 \mathrm{~Hz}, 1 \mathrm{H}), 7.91-7.88(\mathrm{~m}, 2 \mathrm{H}), 7.73(\mathrm{~d}, J=12.00 \mathrm{~Hz}$, 1H), 7.63-7.62 (m, 2H), 7.56 (t, $J=6.00 \mathrm{~Hz}, 1 \mathrm{H}), 7.44-7.42(\mathrm{~m}, 2 \mathrm{H}), 7.31(\mathrm{~d}, J=12.00 \mathrm{~Hz}, 1 \mathrm{H}), 7.21-7.13(\mathrm{~m}, 6 \mathrm{H}), 7.06-7.03(\mathrm{~m}$, $1 \mathrm{H}), 6.97-6.92(\mathrm{~m}, 2 \mathrm{H}), 6.76-6.73(\mathrm{~m}, 2 \mathrm{H}), 4.75(\mathrm{q}, J=6.00 \mathrm{~Hz}, 1 \mathrm{H}), 4.39-4.37(\mathrm{~m}, 1 \mathrm{H}), 4.20-4.16(\mathrm{~m}, 1 \mathrm{H}), 3.25-3.05(\mathrm{~m}, 4 \mathrm{H})$, 3.00-2.86 (m, 5H), 2.73-2.69 (m, 1H), 1.75-1.67 (m, 2H), 1.34 (s, 9H), $1.33(\mathrm{~s}, 9 \mathrm{H}), 1.28(\mathrm{~s}, 9 \mathrm{H}), 1.16-1.13(\mathrm{~m}, 2 \mathrm{H}), 0.96-0.94(\mathrm{~m}$, $2 \mathrm{H}) ;{ }^{13} \mathrm{C}$ NMR $\left(150 \mathrm{MHz}, \mathrm{DMSO}-d_{6}\right): \delta 172.4,171.9,170.8,166.7,156.1,156.0,155.7,140.6,140.5,139.8,138.4,136.5,135.3$, $129.8,129.6,129.3,128.4,127.8,127.2,126.6,126.2,124.1,122.5,121.4,118.9,118.3,111.7,110.0,78.7,78.1,77.7,56.4,54.6$ 54.0, 56.4, 54.6, 54.0, 40.5, 39.3, 37.9, 31.8, 29.7, 28.7, 28.6, 28.5, 23.6; IR (ATR).vmax 3292, 2973, 1650, 1510, 1453, 1247, 1163, 1045, 856, 741; HRMS (ESI): $\mathrm{m} / \mathrm{z}$ calcd for $\mathrm{C}_{56} \mathrm{H}_{72} \mathrm{~N}_{8} \mathrm{O}_{10} \mathrm{Na}[\mathrm{M}+\mathrm{Na}]^{+}:$1039.5269; found: 1039.5261 .

4.3.32. ${ }^{1} \mathrm{H} N M R$ and ${ }^{13} \mathrm{C} N M R$ spectra of tert-butyl ((S)-1-(((S)-1-((3'-(((S)-6-amino-1-((2-(2,3-dibocguanidino)ethyl)amino)-1oxohexan-2-yl)carbamoyl)-[1,1'-biphenyl]-3-yl)amino)-3-(1H-indol-3-yl)-1-oxopropan-2-yl)amino)-1-oxo-3-phenylpropan-2yl)carbamate $(24 f)$

The title compound was prepared from compound $\mathbf{1 7}(100 \mathrm{mg}, 0.15 \mathrm{mmol})$ and $\mathbf{1 8 f}(80 \mathrm{mg}, 0.15 \mathrm{mmol})$ following the general protocol 1 to afford $24 f$ as an off-white solid $\left(128 \mathrm{mg}\right.$, 74\%); m.p.: $192.5-194.0{ }^{\circ} \mathrm{C} ;{ }^{1} \mathrm{H} \mathrm{NMR}\left(600 \mathrm{MHz}, \mathrm{DMSO}-d_{6}\right)$ : $\delta 11.50(\mathrm{~s}$, $1 \mathrm{H}), 10.80(\mathrm{~s}, 1 \mathrm{H}), 10.19(\mathrm{~s}, 1 \mathrm{H}), 8.52(\mathrm{~d}, J=12.00 \mathrm{~Hz}, 1 \mathrm{H}), 8.35(\mathrm{t}, J=6.00 \mathrm{~Hz}, 1 \mathrm{H}), 8.13(\mathrm{br} \mathrm{s}, 3 \mathrm{H}), 7.90-7.74(\mathrm{~m}, 2 \mathrm{H}), 7.73(\mathrm{~d}$, $J=12.00 \mathrm{~Hz}, 1 \mathrm{H}), 7.64-7.62(\mathrm{~m}, 2 \mathrm{H}), 7.55(\mathrm{t}, J=12.00 \mathrm{~Hz}, 1 \mathrm{H}), 7.44-7.41(\mathrm{~m}, 2 \mathrm{H}), 7.31(\mathrm{~d}, J=12.00 \mathrm{~Hz}, 1 \mathrm{H}), 7.20-7.12(\mathrm{~m}$, $6 \mathrm{H}), 7.07-7.03(\mathrm{~m}, 1 \mathrm{H}), 6.98-6.92(\mathrm{~m}, 2 \mathrm{H}), 6.73(\mathrm{t}, J=6.00 \mathrm{~Hz}, 1 \mathrm{H}), 4.75(\mathrm{q}, J=6.00 \mathrm{~Hz}, 1 \mathrm{H}), 4.40(\mathrm{q}, J=12.00 \mathrm{~Hz}, 1 \mathrm{H}), 4.20-$ $4.15(\mathrm{~m}, 1 \mathrm{H}), 3.34-3.36(\mathrm{~m}, 2 \mathrm{H}), 3.30-3.10(\mathrm{~m}, 4 \mathrm{H}), 2.94-2.86(\mathrm{~m}, 3 \mathrm{H}), 2.74-2.71(\mathrm{~m}, 1 \mathrm{H}), 1.75-1.68(\mathrm{~m}, 2 \mathrm{H}), 1.43(\mathrm{~s}, 9 \mathrm{H}), 1.38$ $(\mathrm{s}, 9 \mathrm{H}), 1.37-1.34(\mathrm{~m}, 2 \mathrm{H}), 1.28(\mathrm{~s}, 9 \mathrm{H}), 1.32(\mathrm{~s}, 9 \mathrm{H}) ;{ }^{13} \mathrm{C}$ NMR $\left(150 \mathrm{MHz}, \mathrm{DMSO}-d_{6}\right): \delta 172.6,172.0,170.8,166.5,163.5,156.1$, $155.7,152.3,151.8,140.6,140.5,139.8,136.5,135.3,129.8,129.6,129.3,128.4,127.8,127.2,126.6,126.2,124.1,121.3,119.3$, 118.9, 118.7,118.4, 111.7, 110.0, 83.3, 79.6, 78.6, 77.7, 56.4, 54.6, 54.1, 38.3, 31.9, 29.7, 28.7, 28.5, 28.4, 28.0, 23.6; IR (ATR).vmax 3284, 3066, 2973, 1635, 1540, 1363, 1322, 1247, 1131, 1022, 856, 741; HRMS (ESI): m/z calcd for $\mathrm{C}_{62} \mathrm{H}_{82} \mathrm{~N}_{10} \mathrm{O}_{12} \mathrm{Na}[\mathrm{M}+\mathrm{Na}]^{+}:$1181.6011; found: 1181.6010 .

4.3.33. ${ }^{1} \mathrm{H}$ NMR and ${ }^{13} \mathrm{C}$ NMR spectra of tert-butyl $\left((S)-1-\left(\left((S)-1-\left(\left(3^{\prime}-(((S)-1-((2-(2,3-\right.\right.\right.\right.\right.$ dibocguanidino $)$ ethyl)amino $)-5-(3-((4-)$ methoxy-2,3,6-trimethylphenyl)sulfonyl)guanidino)-1-oxopentan-2-yl)carbamoyl)-[1,1'-biphenyl]-3-yl)amino)-3-(1H-indol-3-yl)1-oxopropan-2-yl)amino)-1-oxo-3-phenylpropan-2-yl)carbamate (24g)

The title compound was prepared from compound $17(50 \mathrm{mg}, 0.075 \mathrm{mmol})$ and $\mathbf{1 8 g}(50 \mathrm{mg}, 0.15 \mathrm{mmol})$ following the general protocol 1 to afford $\mathbf{2 4 g}$ as a gummy solid $(50 \mathrm{mg}, 49 \%) .{ }^{1} \mathrm{H}$ NMR $\left(600 \mathrm{MHz}, \mathrm{DMSO}-d_{6}\right): \delta 11.40(\mathrm{~s}, 1 \mathrm{H}), 10.84(\mathrm{~s}, 1 \mathrm{H}), 10.19(\mathrm{~s}$, $1 \mathrm{H}), 8.56(\mathrm{~d}, J=12.00 \mathrm{~Hz}, 1 \mathrm{H}), 8.33(\mathrm{t}, J=6.00 \mathrm{~Hz}, 1 \mathrm{H}), 8.18-8.14(\mathrm{~m}, 3 \mathrm{H}), 7.91-7.89(\mathrm{~m}, 2 \mathrm{H}), 7.75-7.89(\mathrm{~m}, 2 \mathrm{H}), 7.74(\mathrm{~d}, J=$ $12.00 \mathrm{~Hz}, 1 \mathrm{H}), 7.69-7.62(\mathrm{~m}, 2 \mathrm{H}), 7.56(\mathrm{t}, J=12.00 \mathrm{~Hz}, 1 \mathrm{H}), 7.43-7.40(\mathrm{~m}, 2 \mathrm{H}), 7.32(\mathrm{~d}, J=12.00 \mathrm{~Hz}, 1 \mathrm{H}), 7.21-7.09(\mathrm{~m}, 6 \mathrm{H})$, $7.06(\mathrm{t}, J=6.00 \mathrm{~Hz}, 1 \mathrm{H}), 6.95(\mathrm{dd}, J=12.00,24.00 \mathrm{~Hz}, 2 \mathrm{H}), 6.78-6.66(\mathrm{~m}, 2 \mathrm{H}), 6.56-6.36(\mathrm{~m}, 2 \mathrm{H}), 4.75(\mathrm{q}, J=6.00 \mathrm{~Hz}, 1 \mathrm{H})$, $4.43(\mathrm{q}, J=12.00 \mathrm{~Hz}, 1 \mathrm{H}), 4.21-4.15(\mathrm{~m}, 1 \mathrm{H}), 3.75(\mathrm{~s}, 3 \mathrm{H}), 3.27-3.05(\mathrm{~m}, 8 \mathrm{H}), 2.94-2.90(\mathrm{~m}, 1 \mathrm{H}), 2.74-2.68(\mathrm{~m}, 1 \mathrm{H}), 2.57(\mathrm{~s}$, $3 \mathrm{H}), 2.49(\mathrm{~s}, 3 \mathrm{H}), 2.00(\mathrm{~s}, 3 \mathrm{H}), 1.80-1.53(\mathrm{~m}, 4 \mathrm{H}), 1.41(\mathrm{~s}, 9 \mathrm{H}), 1.38(\mathrm{~s}, 9 \mathrm{H}), 1.28(\mathrm{~s}, 9 \mathrm{H}) ;{ }^{13} \mathrm{C}$ NMR $\left(150 \mathrm{MHz}, \mathrm{DMSO}-d_{6}\right): \delta$ $172.4,170.8,166.6,163.5,157.9,156.6,156.0,152.3,140.5,140.53,139.8,138.4,138.1,136.5,136.0,135.1,129.8,129.6$, 129.3, 128.4, 127.7, 126.6, 126.2, 124.1, 121.4, 118.9, 112.1, 111.7, 110.0, 83.3, 79.6, 78.7, 56.4, 55.9, 54.6, 53.6, 40.5, 38.3, 29.5, 28.5, 28.4, 28.0, 24.0, 18.4, 12; IR (ATR).vmax 3310, 2305, 2095, 1868, 1609, 1543, 1363, 1304, 1246, 1112, 740, 683; HRMS (ESI): $\mathrm{m} / \mathrm{z}$ calcd for $\mathrm{C}_{67} \mathrm{H}_{86} \mathrm{~N}_{12} \mathrm{O}_{13} \mathrm{~S}[\mathrm{M}+\mathrm{H}]^{+}$: 1299.6158 ; found: 1299.6229 .

4.3.34. ${ }^{1} \mathrm{H} N M R$ and ${ }^{13} \mathrm{C} N M R$ spectra of 3'-((S)-2-((S)-2-amino-3-phenylpropanamido)-3-(1H-indol-3-yl)propanamido)-N-(2aminoethyl)-[1,1'-biphenyl]-3-carboxamide (25a)

The title compound was prepared from compound $\mathbf{2 4 a}(80 \mathrm{mg}, 0.101 \mathrm{mmol})$ following the general protocol 4 to afford $\mathbf{2 5 a}$ as a white solid (38 mg, 65\%); m.p.: 206.9-207.5 ${ }^{\circ} \mathrm{C} ;{ }^{1} \mathrm{H}$ NMR (400 MHz, DMSO- $\left.d_{6}\right): \delta 10.86(\mathrm{~d}, J=4.00 \mathrm{~Hz}, 1 \mathrm{H}), 10.40(\mathrm{~s}, 1 \mathrm{H})$, $8.94(\mathrm{t}, J=4.00 \mathrm{~Hz}, 1 \mathrm{H}), 8.60(\mathrm{~d}, J=8.00 \mathrm{~Hz}, 1 \mathrm{H}), 8.27(\mathrm{br} \mathrm{s}, 3 \mathrm{H}), 8.16(\mathrm{br} \mathrm{s}, 1 \mathrm{H}), 7.84-7.83(\mathrm{~m}, 2 \mathrm{H}), 7.76-7.67(\mathrm{~m}, 5 \mathrm{H}), 7.55(\mathrm{t}$, $J=16.00 \mathrm{~Hz}, 1 \mathrm{H}), 7.32(\mathrm{~d}, J=8.00 \mathrm{~Hz}, 1 \mathrm{H}), 7.20-7.05(\mathrm{~m}, 6 \mathrm{H}), 7.02-6.98(\mathrm{~m}, 3 \mathrm{H}), 4.77-4.76(\mathrm{~m}, 2 \mathrm{H}), 3.70(\mathrm{q}, J=4.00 \mathrm{~Hz}, 1 \mathrm{H})$, $3.54(\mathrm{q}, J=8.00 \mathrm{~Hz}, 1 \mathrm{H}), 3.20-3.17(\mathrm{~m}, 1 \mathrm{H}), 3.07-2.99(\mathrm{~m}, 3 \mathrm{H}), 2.89-2.83(\mathrm{~m}, 1 \mathrm{H}), 2.63-2.57(\mathrm{~m}, 1 \mathrm{H}) ;{ }^{13} \mathrm{C} \mathrm{NMR}(100 \mathrm{MHz}$, DMSO- $\left.d_{6}\right): \delta 172.3,170.9,167.2,164.7,140.1,139.1,137.6,136.6,135.2,134.8,129.8,129.5,129.4,128.5,127.7,127.5,126.8$, $125.5,124.4,121.4,120.3,119.1,118.7,111.8,109.9,55.3,54.6,39.1,37.9,28.6$; IR (ATR).vmax 2919, 2848, 2250, 1654, 1537, 1397, 1299, 1173, 1067, 743; HRMS (ESI): m/z calcd for $\mathrm{C}_{35} \mathrm{H}_{36} \mathrm{~N}_{6} \mathrm{O}_{3}[\mathrm{M}+\mathrm{H}]^{+}:$: 589.2849; found: 589.2911 .

4.3.35 ${ }^{1} \mathrm{H} N M R$ and ${ }^{13} \mathrm{C} N M R$ spectra of 3'-((S)-2-((S)-2-amino-3-phenylpropanamido)-3-(1H-indol-3-yl)propanamido)-N-(2guanidinoethyl)-[1,1'-biphenyl]-3-carboxamide $(25 b)$ 
The title compound was prepared from compound $\mathbf{2 4 b}(80 \mathrm{mg}, 0.08 \mathrm{mmol})$ following the general protocol 4 to afford $\mathbf{2 5 b}$ as a white gummy solid (27 mg, 49\%). ${ }^{1} \mathrm{H}$ NMR (600 MHz, DMSO- $\left.d_{6}\right): \delta 10.89$ (br s, $\left.1 \mathrm{H}\right), 10.35(\mathrm{br} \mathrm{s}, 1 \mathrm{H}), 8.94(\mathrm{~d}, J=4.00 \mathrm{~Hz}, 1 \mathrm{H})$ $8.75(\mathrm{t}, J=4.00 \mathrm{~Hz}, 1 \mathrm{H}), 8.11-7.93(\mathrm{~m}, 4 \mathrm{H}), 7.87-7.85(\mathrm{~m}, 1 \mathrm{H}), 7.77-7.75(\mathrm{~m}, 1 \mathrm{H}), 7.68(\mathrm{~d}, J=8.00 \mathrm{~Hz}, 1 \mathrm{H}), 7.63-7.58(\mathrm{~m}, 4 \mathrm{H})$, 7.46-7.42 (m, 4H), 7.26-7.15 (m, 6H), 7.08-6.97 (m, 4H), $4.82(\mathrm{q}, J=4.00 \mathrm{~Hz}, 1 \mathrm{H}), 4.07(\mathrm{t}, J=4.00 \mathrm{~Hz}, 1 \mathrm{H}), 3.43(\mathrm{q}, J=4.00$ $\mathrm{Hz}, 2 \mathrm{H}), 3.28-3.24(\mathrm{~m}, 1 \mathrm{H}), 3.14-3.08(\mathrm{~m}, 2 \mathrm{H}), 2.97-2.93(\mathrm{~m}, 1 \mathrm{H}) ;{ }^{13} \mathrm{C}$ NMR $\left(150 \mathrm{MHz}, \mathrm{DMSO}-d_{6}\right): \delta 169.8,166.6,158.1,157.9$, $156.9,140.2,140.0,139.3,136.0,134.8,129.5,129.4,129.41,129.1,128.4,127.2,127.0,126.3,125.5,123.7,122.1,121.0,118.9$, 118.4, 118.3, 117.8, 111.4, 109.2, 87.8, 54.5, 53.3, 40.3, 38.6, 37.1, 28.0; IR (ATR).vmax 3276, 3189, 3064, 1651, 1538, 1433, 1318, 1201, 1150, 836, 798, 742 HRMS (ESI): m/z calcd for $\mathrm{C}_{36} \mathrm{H}_{38} \mathrm{~N}_{8} \mathrm{O}_{3}[\mathrm{M}+\mathrm{H}]^{+}:$: 631.3067; found: 631.3141 .

\subsubsection{6. ${ }^{1} \mathrm{H} N M R$ and ${ }^{13} \mathrm{C} N M R$ spectra of Methyl (3'-((S)-2-((S)-2-amino-3-phenylpropanamido)-3-(1H-indol-3-yl)propanamido)-} [1,1'-biphenyl]-3-carbonyl)-L-lysinate (25c)

The title compound was prepared from compound $\mathbf{2 4 c}(90 \mathrm{mg}, 0.112 \mathrm{mmol})$ following the general protocol 4 to afford $\mathbf{2 5 c}$ as a white gummy solid (46 mg, 60\%). ${ }^{1} \mathrm{H}$ NMR $\left(600 \mathrm{MHz}, \mathrm{DMSO}-d_{6}\right): \delta 10.89$ (br s, $\left.1 \mathrm{H}\right), 10.35(\mathrm{~s}, 1 \mathrm{H}), 8.94(\mathrm{~d}, J=4.00 \mathrm{~Hz}, 1 \mathrm{H})$, $8.87(\mathrm{~d}, J=8.00 \mathrm{~Hz}, 1 \mathrm{H}), 8.13-7.90(\mathrm{~m}, 5 \mathrm{H}), 7.79-7.68(\mathrm{~m}, 5 \mathrm{H}), 7.63-7.59(\mathrm{~m}, 2 \mathrm{H}), 7.46-7.44(\mathrm{~m}, 2 \mathrm{H}), 7.33(\mathrm{~d}, J=4.00 \mathrm{~Hz}, 1 \mathrm{H})$, 7.26-7.15 (m, 6H), 7.07-7.05 (m, 1H), 6.99-6.97 (m, 1H), $4.81(\mathrm{q}, J=4.00 \mathrm{~Hz}, 1 \mathrm{H}), 4.49-4.45(\mathrm{~m}, 1 \mathrm{H}), 4.07(\mathrm{t}, J=4.00 \mathrm{~Hz}, 1 \mathrm{H})$, $3.66(\mathrm{~s}, 3 \mathrm{H}), 3.28-3.24(\mathrm{~m}, 1 \mathrm{H}), 3.14-3.09(\mathrm{~m}, 2 \mathrm{H}), 2.99-2.94(\mathrm{~m}, 1 \mathrm{H}), 2.79-2.77(\mathrm{~m}, 2 \mathrm{H}), 1.85-1.80(\mathrm{~m}, 2 \mathrm{H}), 1.60-1.53(\mathrm{~m}, 2 \mathrm{H})$, $1.47-1.38(\mathrm{~m}, 2 \mathrm{H}) ;{ }^{13} \mathrm{C}$ NMR $\left(150 \mathrm{MHz}, \mathrm{DMSO}-d_{6}\right): \delta 173.1,170.3,168.6,167.0,158.5,158.3,140.6,140.5,139.9,136.6,135.2$, $134.8,130.0,130.0,129.5,128.9,127.7,127.5,127.1,126.2,124.2,122.6,121.5,119.4,118.9,118.8,118.3,111.8,109.7,55.0$, 53.7, 52.9, 52.4, 39.1, 37.6, 30.4, 28.5, 27.0, 23.1; IR (ATR).vmax 3276, 3195, 3081, 2109, 1540, 1433, 1318, 1198, 798, 743; HRMS (ESI): $\mathrm{m} / \mathrm{z}$ calcd for $\mathrm{C}_{40} \mathrm{H}_{44} \mathrm{~N}_{6} \mathrm{O}_{5}[\mathrm{M}+\mathrm{H}]^{+}: 689.3373$; found: 689.3448 .

4.3.37. ${ }^{1} \mathrm{H}$ NMR and ${ }^{13} \mathrm{C} N M R$ spectra of Methyl (3'-((S)-2-((S)-2-amino-3-phenylpropanamido)-3-(1H-indol-3-yl)propanamido)[1,1'-biphenyl]-3-carbonyl)-L-argininate (25d)

The title compound was prepared from compound $\mathbf{2 4 d}(90 \mathrm{mg}, 0.087 \mathrm{mmol})$ following the general protocol 4 to afford $\mathbf{2 5 d}$ as a brown gummy solid $(25 \mathrm{mg}, 40 \%) .{ }^{1} \mathrm{H}$ NMR $\left(600 \mathrm{MHz}, \mathrm{DMSO}-d_{6}\right): \delta 10.89(\mathrm{~s}, 1 \mathrm{H}), 10.35(\mathrm{~s}, 1 \mathrm{H}), 8.94(\mathrm{dd}, J=4.00,12.00 \mathrm{~Hz}$ $2 \mathrm{H}), 8.13-8.12(\mathrm{~m}, 4 \mathrm{H}), 7.93-7.90(\mathrm{~m}, 2 \mathrm{H}), 7.79-7.78(\mathrm{~m}, 1 \mathrm{H}), 7.69(\mathrm{~d}, J=8.00 \mathrm{~Hz}, 1 \mathrm{H}), 7.64-7.60(\mathrm{~m}, 3 \mathrm{H}), 7.48-7.33(\mathrm{~m}, 4 \mathrm{H})$, 7.27-7.16 (m, 7H), 7.08-7.06 (m, 1H), 7.00-6.98 (m, 1H), $4.82(\mathrm{q}, J=-4.00 \mathrm{~Hz}, 1 \mathrm{H}), 4.52-4.49(\mathrm{~m}, 1 \mathrm{H}), 4.10(\mathrm{br} \mathrm{s}, 1 \mathrm{H}), 3.67(\mathrm{~s}$, $3 \mathrm{H}), 3.29-3.25(\mathrm{~m}, 1 \mathrm{H}), 3.15-3.09(\mathrm{~m}, 4 \mathrm{H}), 2.99-2.95(\mathrm{~m}, 1 \mathrm{H}), 1.91-1.54(\mathrm{~m}, 4 \mathrm{H}) ;{ }^{13} \mathrm{C}$ NMR $\left(150 \mathrm{MHz}, \mathrm{DMSO}-d_{6}\right): \delta 172.9$, 170.3, 168.4, 166.9, 158.2, 157.2, 140.6, 140.4, 139.8, 136.6, 135.1, 134.8, 130.1, 130.0, 129.9, 129.5, 128.9, 129.6, 128.9, 127.7, $126.1,124.2,122.6,121.5,119.4,118.9,118.9,118.3,111.8,109.7,55.0,53.7,52.8,52.4,40.7,40.5,37.5,28.5,28.1,25.8 ; \mathrm{IR}$

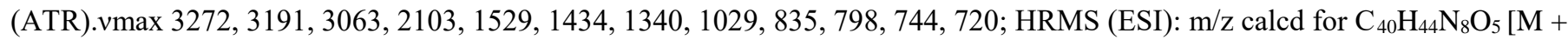
$\mathrm{H}]^{+}:$717.3435; found: 717.3501 .

4.3.38. ${ }^{1} \mathrm{H} N M R$ and ${ }^{13} \mathrm{C} N M R$ spectra of $N$-((S)-6-amino-1-((2-aminoethyl)amino $)-1$-oxohexan-2-yl)-3'-((S)-2-((S)-2-amino-3phenylpropanamido)-3-(1H-indol-3-yl)propanamido)-[1,1'-biphenyl]-3-carboxamide (25e)

The title compound was prepared from compound $\mathbf{2 4 e}(90 \mathrm{mg}, 0.088 \mathrm{mmol})$ following the general protocol 4 to afford $\mathbf{2 5 e}$ as a gummy solid (45 mg, 49\%). ${ }^{1} \mathrm{H}$ NMR $\left(600 \mathrm{MHz}, \mathrm{DMSO}-d_{6}\right): \delta 10.91(\mathrm{~s}, 1 \mathrm{H}), 10.36(\mathrm{~s}, 1 \mathrm{H}), 8.97(\mathrm{~d}, J=6.00 \mathrm{~Hz}, 1 \mathrm{H}), 8.68(\mathrm{~d}, J=$ $6.00 \mathrm{~Hz}, 1 \mathrm{H}), 8.24(\mathrm{t}, J=6.00 \mathrm{~Hz}, 1 \mathrm{H}), 8.16-7.67(\mathrm{~m}, 12 \mathrm{H}), 7.68(\mathrm{~d}, J=6.00 \mathrm{~Hz}, 1 \mathrm{H}), 7.62-7.58(\mathrm{~m}, 2 \mathrm{H}), 7.46-7.45(\mathrm{~m}, 2 \mathrm{H}), 7.33$ $(\mathrm{d}, J=12.00 \mathrm{~Hz}, 1 \mathrm{H}), 7.26-7.15(\mathrm{~m}, 6 \mathrm{H}), 7.06(\mathrm{t}, J=6.00 \mathrm{~Hz}, 1 \mathrm{H}), 6.98(\mathrm{t}, J=6.00 \mathrm{~Hz}, 1 \mathrm{H}), 4.81(\mathrm{q}, J=6.00 \mathrm{~Hz}, 1 \mathrm{H}), 4.44-4.41$ $(\mathrm{m}, 1 \mathrm{H}), 4.09(\mathrm{t}, J=6.00 \mathrm{~Hz}, 1 \mathrm{H}), 3.31-3.30(\mathrm{~m}, 2 \mathrm{H}), 3.27(\mathrm{dd}, J=6.00,12.00 \mathrm{~Hz}, 1 \mathrm{H}), 3.15-3.09(\mathrm{~m}, 2 \mathrm{H}), 2.97(\mathrm{dd}, J=12.00$, $15.00 \mathrm{~Hz}, 1 \mathrm{H}), 2.87(\mathrm{t}, J=6.00 \mathrm{~Hz}, 2 \mathrm{H}), 2.77(\mathrm{br} \mathrm{s}, 2 \mathrm{H}), 1.84-1.81(\mathrm{~m}, 1 \mathrm{H}), 1.76-1.72(\mathrm{~m}, 1 \mathrm{H}), 1.59-1.52(\mathrm{~m}, 2 \mathrm{H}), 1.42-1.32(\mathrm{~m}$, $2 \mathrm{H}) ;{ }^{13} \mathrm{C}$ NMR (150 MHz, DMSO- $\left.d_{6}\right): \delta 172.8,170.3,168.5,166.9,158.5,158.3,140.5,139.8,136.6,135.1,135.12,130.0$, $129.9,129.4,128.8,127.7,127.5,127.2,126.2,124.2,122.6,121.5,119.3,118.9,118.7,118.3,118.8,109.7,55.03,53.8,53.7$, 40.5, 39.5, 39.2, 39.9, 37.4, 36.9, 31.3, 28.4, 27.1, 23.2; IR (ATR).vmax 3274, 3056, 2926, 2119, 1661, 1526, 1431, 1200, 1121, 836, 797, 743, 721; HRMS (ESI): $\mathrm{m} / \mathrm{z}$ calcd for $\mathrm{C}_{41} \mathrm{H}_{48} \mathrm{~N}_{8} \mathrm{O}_{4}[\mathrm{M}+\mathrm{H}]^{+}:$717.3435; found: 717.3501 .

4.3.39. ${ }^{1} \mathrm{H} N M R$ and ${ }^{13} \mathrm{C} N M R$ spectra of $N$-((S)-6-amino-1-((2-guanidinoethyl)amino)-1-oxohexan-2-yl)-3'-((S)-2-((S)-2-amino-3phenylpropanamido)-3-(1H-indol-3-yl)propanamido)-[1,1'-biphenyl]-3-carboxamide (25f)

The title compound was prepared from compound $\mathbf{2 4 f}(100 \mathrm{mg}, 0.086 \mathrm{mmol})$ following the general protocol 4 to afford $\mathbf{2 5 f}$ as a gummy solid (41 mg, 40\%). ${ }^{1} \mathrm{H}$ NMR (600 MHz, DMSO-d $)$ : $\delta 10.90(\mathrm{~d}, J=6.00 \mathrm{~Hz}, 1 \mathrm{H}), 10.35(\mathrm{~s}, 1 \mathrm{H}), 8.93(\mathrm{br} \mathrm{s}, 1 \mathrm{H}), 8.65(\mathrm{~d}$, $J=6.00 \mathrm{~Hz}, 1 \mathrm{H}), 8.20-8.13(\mathrm{~m}, 4 \mathrm{H}), 7.96-7.91(\mathrm{~m}, 2 \mathrm{H}), 7.84-7.53(\mathrm{~m}, 7 \mathrm{H}), 7.51-7.43(\mathrm{~m}, 2 \mathrm{H}), 7.37-7.10(\mathrm{~m}, 8 \mathrm{H}), 7.10-7.04(\mathrm{~m}$, $1 \mathrm{H}), 7.00-6.97(\mathrm{~m}, 1 \mathrm{H}), 6.54(\mathrm{br} \mathrm{s}, 1 \mathrm{H}), 4.82(\mathrm{q}, J=6.00 \mathrm{~Hz}, 1 \mathrm{H}), 4.47-4.44(\mathrm{~m}, 1 \mathrm{H}), 4.06(\mathrm{br} \mathrm{s}, 1 \mathrm{H}), 3.46-3.39(\mathrm{~m}, 2 \mathrm{H}), 3.27-$ $2.77(\mathrm{~m}, 8 \mathrm{H}), 1.91-1.24(\mathrm{~m}, 6 \mathrm{H}) ;{ }^{13} \mathrm{C}$ NMR $\left(150 \mathrm{MHz}, \mathrm{DMSO}-d_{6}\right): \delta 172.9,170.3,166.7,158.5,158.3,157.4,140.5,139.7,136.5$, 135.1, 130.0, 129.9, 129.4, 128.9, 127.7, 127.5, 126.3, 124.2, 123.4, 122.63, 122.6, 121.5, 119.4, 118.9, 118.7, 118.4, 118.3, 116.7, 111.8, 109.7, 54.9, 54.0, 53.7, 40.8, 40.5, 39.2, 38.4, 31.4, 28.5, 27.2, 23.2; IR (ATR).vmax 3265, 3065, 1655, 1537, 1428, 1170, 1128, 1001,787; HRMS (ESI): m/z calcd for $\mathrm{C}_{42} \mathrm{H}_{50} \mathrm{~N}_{10} \mathrm{O}_{4}[\mathrm{M}+\mathrm{H}]^{+}:$759.4017; found: 759.4084 .

4.3.40. ${ }^{1} \mathrm{H}$ NMR and ${ }^{13} \mathrm{C} N \mathrm{NMR}$ spectra of 3'-((S)-2-((S)-2-amino-3-phenylpropanamido)-3-(1H-indol-3-yl)propanamido)- $N$ - $((S)-5$ guanidino-1-((2-guanidinoethyl)amino)-1-oxopentan-2-yl)-[1,1'-biphenyl]-3-carboxamide (25g) 
The title compound was prepared from compound $\mathbf{2 4 g}(48 \mathrm{mg}, 0.036 \mathrm{mmol})$ following the general protocol 4 to afford $\mathbf{2 5 g}$ as a gummy solid $(20 \mathrm{mg}, 40 \%) .{ }^{1} \mathrm{H}$ NMR $\left(600 \mathrm{MHz}, \mathrm{DMSO}-d_{6}\right): \delta 10.84(\mathrm{~s}, 1 \mathrm{H}), 10.27(\mathrm{~s}, 1 \mathrm{H}), 8.84(\mathrm{~s}, 1 \mathrm{H}), 8.62(\mathrm{~d}, J=6.00 \mathrm{~Hz}$, $1 \mathrm{H}), 8.16-8.11(\mathrm{~m}, 2 \mathrm{H}), 7.94(\mathrm{~d}, J=6.00 \mathrm{~Hz}, 1 \mathrm{H}), 7.76(\mathrm{~d}, J=12.00 \mathrm{~Hz}, 1 \mathrm{H}), 7.67(\mathrm{~d}, J=12.00 \mathrm{~Hz}, 1 \mathrm{H}), 7.62-7.56(\mathrm{~m}, 3 \mathrm{H}), 7.46$ $(\mathrm{d}, J=6.00 \mathrm{~Hz}, 2 \mathrm{H}), 7.34(\mathrm{~d}, J=12.00 \mathrm{~Hz}, 1 \mathrm{H}), 7.28-7.14(\mathrm{~m}, 8 \mathrm{H}), 7.08-7.06(\mathrm{~m}, 2 \mathrm{H}), 7.01-6.97(\mathrm{~m}, 1 \mathrm{H}), 4.82(\mathrm{q}, J=6.00 \mathrm{~Hz}$, $1 \mathrm{H}), 4.51-4.46(\mathrm{~m}, 1 \mathrm{H}), 4.07$ (br s, 1H), 3.25-3.19 (m, 6H), 3.15-3.12 (m, 3H), 2.96-2.94 (m, 1H), 1.89-1.84 (m, 1H), 1.76-1.72 $(\mathrm{m}, 1 \mathrm{H}), 1.60-1.50(\mathrm{~m}, 2 \mathrm{H}) ;{ }^{13} \mathrm{C}$ NMR $\left(150 \mathrm{MHz}, \mathrm{DMSO}-d_{6}\right): \delta 172.6,170.3,166.8,158.6,158.4,158.2,157.5,157.2,140.6$, $140.5,139.8,136.6,135.1,130.0,130.0,129.8,129.4,128.8,128.8,127.7,127.4,127.2,126.2,124.1,122.6,121.4,119.4,118.9$, 118.7, 118.4, 116.8, 111.8, 109.8, 55.0, 53.5, 40.98, 40.9, 40.6, 38.4, 29.1, 28.4, 25.8; IR (ATR).vmax 3279, 3186, 3086, 1646, 1529, 1431, 1175, 1125, 798, 743; HRMS (ESI): m/z calcd for $\mathrm{C}_{42} \mathrm{H}_{50} \mathrm{~N}_{12} \mathrm{O}_{4}[\mathrm{M}+\mathrm{H}]^{+}$: 787.4078 ; found: 787.4152 .

\subsubsection{1. ${ }^{1} \mathrm{H} N M R$ and ${ }^{13} \mathrm{C} N M R$ spectra of 3'-nitro-[1,1'-biphenyl]-3-carboxylic acid (26)}

To the solution of $9(1.2 \mathrm{~g}, 3.88 \mathrm{mmol})$ in THF $(10.0 \mathrm{~mL})$ and $\mathrm{MeOH}(10.0 \mathrm{~mL})$, was added a $1 \mathrm{~N} \mathrm{NaOH}(\mathrm{aq})(7.77 \mathrm{~mL}, 7.77 \mathrm{mmol})$ and stirred at room temperature for $16 \mathrm{~h}$. Ethyl acetate was added and the layers were separated. The aqueous layer was then acidified with $1 \mathrm{~N} \mathrm{HCl}$ and then extracted with $\mathrm{CH}_{2} \mathrm{Cl}_{2}(2 \mathrm{X} 100 \mathrm{~mL})$ and then the solvent was removed under reduced pressure to yield $26(0.84 \mathrm{~g}, 90 \%)$ as a pale-yellow solid; m.p.: $209.4-210.6{ }^{\circ} \mathrm{C} ;{ }^{1} \mathrm{H}$ NMR $\left(400 \mathrm{MHz}, \mathrm{DMSO}-d_{6}\right): \delta 13.19(\mathrm{br}, 1 \mathrm{H}), 8.44(\mathrm{~s}$, $1 \mathrm{H}), 8.25(\mathrm{br} \mathrm{s}, 2 \mathrm{H}), 8.18(\mathrm{~d}, J=7.60 \mathrm{~Hz}, 1 \mathrm{H}), 8.02(\mathrm{t}, J=8.00 \mathrm{~Hz}, 1 \mathrm{H}), 7.78(\mathrm{t}, J=8.00 \mathrm{~Hz}, 1 \mathrm{H})$; ${ }^{13} \mathrm{C} \mathrm{NMR}(100 \mathrm{MHz}, \mathrm{DMSO}-$ $\left.d_{6}\right): \delta 167.5,148.9,141.3,138.6,133.9,132.2,131.9,131.1,130.1,129.8,128.1,123.1,121.8 ;$ IR (ATR).vmax 2965, 2840, 2541, 2099, 1681, 1590, 1514, 1421, 1189, 1095, 928, 853; HRMS (ESI): m/z calcd for $\mathrm{C}_{13} \mathrm{H}_{9} \mathrm{NO}_{4} \mathrm{Na}[\mathrm{M}+\mathrm{Na}]^{+}: 266.0429$; found: 266.0424.

\subsubsection{2. ${ }^{1} \mathrm{H} N M R$ and ${ }^{13} \mathrm{C} N M R$ spectra of $N$-(2-(2,3-dibocguanidino)ethyl)-3'-nitro-[1,1'-biphenyl]-3-carboxamide (27)}

The title compound 27 was prepared from compound $\mathbf{1 8 b}(0.621 \mathrm{~g}, 2.00 \mathrm{mmol})$ and $\mathbf{3 3}(0.5 \mathrm{~g}, 2.00 \mathrm{mmol})$ according to the protocol 2. Off-white solid (0.47 g, 45\%); m.p.: 117.6-118.9 ${ }^{\circ} \mathrm{C} ;{ }^{1} \mathrm{H}$ NMR $\left(400 \mathrm{MHz}, \mathrm{CDCl}_{3}\right): \delta 11.51(\mathrm{br} \mathrm{s}, 1 \mathrm{H}), 8.83-8.82(\mathrm{~m}$, $1 \mathrm{H}), 8.26-8.16(\mathrm{~m}, 3 \mathrm{H}), 8.00-7.97(\mathrm{~m}, 1 \mathrm{H}), 7.84-7.82(\mathrm{~m}, 1 \mathrm{H}), 7.66-7.63(\mathrm{~m}, 1 \mathrm{H}), 7.56(\mathrm{t}, J=8.00 \mathrm{~Hz}, 1 \mathrm{H}), 3.80-3.77(\mathrm{~m}, 2 \mathrm{H})$, 3.71-3.67 (m, 2H), $1.51(\mathrm{~s}, 9 \mathrm{H}), 1.49(\mathrm{~s}, 9 \mathrm{H}) ;{ }^{13} \mathrm{C} \mathrm{NMR}\left(100 \mathrm{MHz}, \mathrm{CDCl}_{3}\right): \delta 167.1,162.7,157.9,153.0,148.8,142.0,139.1$, 135.4, 133.2, 129.9, 129.8, 129.1, 126.9, 126.3, 122.4, 122.0, 83.8, 79.9, 79.7, 42.5, 39.7, 28.3, 28.2, 28.0; IR (ATR).vmax 3196, 2985, 2930, 1784, 1719, 1532, 1473, 1268, 1139, 869; HRMS (ESI): m/z calcd for $\mathrm{C}_{41} \mathrm{H}_{51} \mathrm{~N}_{5} \mathrm{O}_{8}[\mathrm{M}+\mathrm{Na}]^{+}: 550.2278$; found: 550.2273 .

\subsubsection{3. ${ }^{1} \mathrm{H}$ NMR and ${ }^{13} \mathrm{C}$ NMR spectra of 3'-amino-N-(2-guanidinoethyl)-[1,1'-biphenyl]-3-carboxamide (28)}

The title compound 28 was prepared from $27(0.25 \mathrm{~g}, 0.47 \mathrm{mmol})$ according to the protocol 4 . Pale brown solid (139 $\mathrm{mg}, 90 \%$ yield); m.p.: $183.8-184.5^{\circ} \mathrm{C} ;{ }^{1} \mathrm{H}$ NMR $\left(400 \mathrm{MHz}, \mathrm{DMSO}-d_{6}\right): \delta 8.93(\mathrm{t}, J=5.20 \mathrm{~Hz}, 1 \mathrm{H}), 8.54(\mathrm{t}, J=2.00 \mathrm{~Hz}, 1 \mathrm{H}), 8.28-8.25(\mathrm{~m}$, $3 \mathrm{H}), 7.98(\mathrm{t}, J=7.60 \mathrm{~Hz}, 2 \mathrm{H}), 7.83-7.75(\mathrm{~m}, 2 \mathrm{H}), 7.65(\mathrm{t}, J=8.00 \mathrm{~Hz}, 1 \mathrm{H}), 7.26(\mathrm{br} \mathrm{s}, 3 \mathrm{H}), 3.48-3.43(\mathrm{~m}, 2 \mathrm{H}), 3.39-3.35(\mathrm{~m}, 2 \mathrm{H})$; ${ }^{13} \mathrm{C}$ NMR (100 MHz, DMSO- $\left.d_{6}\right): \delta 166.8,157.5,148.9,141.5,138.3,135.5,133.9,131.1,130.3,129.8,128.0,126.1,123.0$, 121.7, 40.7, 39.1; IR (ATR).vmax 3280, 3155, 2341, 2112, 1638, 1522, 1457, 1344, 1299, 1192, 1114, 996, 864, 798, 675, 730; HRMS (ESI): $\mathrm{m} / \mathrm{z}$ calcd for $\mathrm{C}_{16} \mathrm{H}_{17} \mathrm{~N}_{5} \mathrm{O}_{3}[\mathrm{M}+\mathrm{H}]^{+}: 327.1331$; found: 328.1401 .

\subsubsection{4. ${ }^{1} \mathrm{H} N M R$ and ${ }^{13} \mathrm{C} N M R$ spectra of 3'-amino-N-(2-guanidinoethyl)-[1,1'-biphenyl]-3-carboxamide (29)}

To a stirred solution of $\mathbf{2 8}(0.1 \mathrm{~g}, 0.305 \mathrm{mmol})$ in anhydrous THF $(100 \mathrm{~mL})$ under nitrogen atmosphere $10 \%$ palladium on activated charcoal $(0.15 \mathrm{~g})$ was added. The reaction was evacuated and placed under a hydrogen atmosphere and stirred overnight. The reaction mixture was filtered through celite, and the solvent was removed under reduced pressure to yield the desired product 29 as a brown solid (39 mg, 40\% yield); m.p.: 233.0-233. $6^{\circ} \mathrm{C} ;{ }^{1} \mathrm{H}$ NMR (400 MHz, DMSO- $\left.d_{6}\right): \delta 8.76(\mathrm{t}, J=5.20 \mathrm{~Hz}, 1 \mathrm{H}), 8.07$ (br s, 1H), $7.83(\mathrm{~d}, J=7.60 \mathrm{~Hz}, 1 \mathrm{H}), 7.72(\mathrm{~d}, J=8.00 \mathrm{~Hz}, 1 \mathrm{H}), 7.66(\mathrm{t}, J=5.60 \mathrm{~Hz}, 1 \mathrm{H}), 7.54(\mathrm{t}, J=8.00 \mathrm{~Hz}, 1 \mathrm{H}), 7.14(\mathrm{t}, J=$ $7.60 \mathrm{~Hz}, 1 \mathrm{H}), 6.90-6.84(\mathrm{~m}, 2 \mathrm{H}), 6.62-6.59(\mathrm{~m}, 1 \mathrm{H}), 5.28(\mathrm{br} \mathrm{s}, 2 \mathrm{H}), 3.44-3.37(\mathrm{~m}, 4 \mathrm{H}) ;{ }^{13} \mathrm{C} \mathrm{NMR}\left(100 \mathrm{MHz}, \mathrm{DMSO}-d_{6}\right): \delta 167.2$, $157.5,149.5,141.6,140.6,135.0,129.9,129.7,129.3,126.4,125.7,115.0,114.0,112.7,40.8,39.0$; IR (ATR).vmax 3262, 3144 , 2849, 2587, 2342, 1621, 1541, 1471, 1309, 1182, 1129, 807; HRMS (ESI): m/z calcd for $\mathrm{C}_{16} \mathrm{H}_{19} \mathrm{~N}_{5} \mathrm{O}[\mathrm{M}+\mathrm{H}]^{+}: 298.1590$; found: 298.1660 .

\subsubsection{5. ${ }^{1} \mathrm{H}$ NMR and ${ }^{13} \mathrm{C}$ NMR spectra of Methyl L-tryptophanate (31)}

The title compound 31 was prepared by adding thionyl chloride $(0.79 \mathrm{~mL}, 9.80 \mathrm{mmol})$ dropwise to $L$-Tryptophan $(1.0 \mathrm{~g}, 4.90$ $\mathrm{mmol})$ in methanol $(20.0 \mathrm{~mL})$ at $0^{\circ} \mathrm{C}$ and then stirred at room temperature for $16 \mathrm{~h}$. The solvents were removed and reduced pressure and the residue was diluted with ethylacetate $(100.0 \mathrm{~mL})$ and washed with saturated $\mathrm{NaHCO}_{3}(40 \mathrm{~mL})$, saturated brine $(40$ $\mathrm{mL})$, then dried $\left(\mathrm{Na}_{2} \mathrm{SO}_{4}\right)$ and concentrated under reduced pressure to afford a white solid $(1.00 \mathrm{~g}, 94 \%)$; m.p.: 89.4-89.9 ${ }^{\circ} \mathrm{C}$; ${ }^{1} \mathrm{H}$ NMR (400 MHz, DMSO- $\left.d_{6}\right): \delta 10.87(\mathrm{~s}, 1 \mathrm{H}), 7.48(\mathrm{~d}, J=8.00 \mathrm{~Hz}, 1 \mathrm{H}), 7.33(\mathrm{~d}, J=8.00 \mathrm{~Hz}, 1 \mathrm{H}), 7.12(\mathrm{br} \mathrm{s}, 1 \mathrm{H}), 7.05(\mathrm{t}, J=$ $8.00 \mathrm{~Hz}, 1 \mathrm{H}), 6.97(\mathrm{t}, J=8.00 \mathrm{~Hz}, 1 \mathrm{H}), 3.63(\mathrm{t}, J=8.00 \mathrm{~Hz}, 1 \mathrm{H}), 3.55(\mathrm{~s}, 1 \mathrm{H}), 3.05-2.91(\mathrm{~m}, 2 \mathrm{H})$; ${ }^{13} \mathrm{C} \mathrm{NMR}(100 \mathrm{MHz}, \mathrm{DMSO}-$ $\left.d_{6}\right): \delta 176.1,136.5,127.8,124.1,121.3,118.8,118.7,111.8,110.3,55.6,51.8,40.6,31.1$; IR (ATR).vmax 3356, 3292, 3096, $3051,2916,2871,2338,2095,1727,1567,1448,1351,1290,1222,1104,1012,945,890,805,737$; HRMS (ESI): m/z calcd for $\mathrm{C}_{12} \mathrm{H}_{14} \mathrm{~N}_{2} \mathrm{O}_{2}[\mathrm{M}+\mathrm{H}]^{+}: 219.1055$; found: 219.1125 . 
The title compound was prepared via protocol 1, using $N$-(tert-Butoxycarbonyl)- $L$-phenylalanine (1.21 g, $4.6 \mathrm{mmol})$ and $\mathbf{3 1}$ (1.00 $\mathrm{g}, 4.6 \mathrm{mmol})$ to afford the coupled product 32 as an off-white solid $(1.40 \mathrm{~g}, 65 \%)$; m.p.: $135.3-135.7{ }^{\circ} \mathrm{C} ;{ }^{1} \mathrm{H} \mathrm{NMR}(400 \mathrm{MHz}$, DMSO-d $)): \delta 10.89(\mathrm{~s}, 1 \mathrm{H}), 8.29(\mathrm{~d}, J=8.00 \mathrm{~Hz}, 1 \mathrm{H}), 7.49(\mathrm{~d}, J=8.00 \mathrm{~Hz}, 1 \mathrm{H}), 7.34(\mathrm{~d}, J=8.00 \mathrm{~Hz}, 1 \mathrm{H}), 7.23-7.18(\mathrm{~m}, 6 \mathrm{H})$, $7.07(\mathrm{t}, J=8.00 \mathrm{~Hz}, 1 \mathrm{H}), 6.99(\mathrm{t}, J=8.00 \mathrm{~Hz}, 1 \mathrm{H}), 6.87(\mathrm{~d}, J=12.00 \mathrm{~Hz}, 1 \mathrm{H}), 4.55(\mathrm{q}, J=8.00 \mathrm{~Hz}, 1 \mathrm{H}), 4.23-4.18(\mathrm{~m}, 1 \mathrm{H}), 3.55$ $(\mathrm{s}, 3 \mathrm{H}), 3.20-3.07(\mathrm{~m}, 2 \mathrm{H}), 2.95-2.90(\mathrm{~m}, 1 \mathrm{H}), 2.72-2.66(\mathrm{~m}, 1 \mathrm{H}), 1.28(\mathrm{~s}, 9 \mathrm{H}) ;{ }^{13} \mathrm{C}$ NMR $\left(100 \mathrm{MHz}, \mathrm{DMSO}-d_{6}\right): \delta 172.6,172.2$, 155.6, 138.5, 136.5, 129.6, 128.4, 127.5, 126.6, 124.2, 121.4, 118.9, 118.4, 111.8, 109.6, 78.5, 56.0, 53.5, 52.2, 37.8, 28.5, 28.2, 27.5; IR (ATR).vmax 3295, 3001, 2952, 1694, 1648, 1525, 1433, 1288, 1164, 1112, 922, 846; HRMS (ESI): $\mathrm{m} / \mathrm{z}$ calcd for $\mathrm{C}_{26} \mathrm{H}_{31} \mathrm{~N}_{3} \mathrm{O}_{5}[\mathrm{M}+\mathrm{H}]^{+}:$465.23; found: 337.14340

\subsubsection{7. ${ }^{1} H$ NMR and ${ }^{13}$ C NMR spectra of (tert-butoxycarbonyl)-L-phenylalanyl-L-tryptophan (33)}

To a solution of $31(1.4 \mathrm{~g}, 3.00 \mathrm{mmol})$ in THF $(10.0 \mathrm{~mL})$ and $\mathrm{MeOH}(10.0 \mathrm{~mL})$, was added a $1 \mathrm{~N} \mathrm{NaOH}(\mathrm{aq})(6.0 \mathrm{~mL}, 6.00 \mathrm{mmol})$ and stirred at room temperature for $16 \mathrm{~h}$. Ethyl acetate was added and the layers were separated. The aqueous layer was then acidified with $1 \mathrm{~N} \mathrm{HCl}$ and then extracted with $\mathrm{CH}_{2} \mathrm{Cl}_{2}(2 \mathrm{X} 100 \mathrm{~mL})$ and then the solvent was removed under reduced pressure to yield $33(1.23 \mathrm{~g}, 91 \%)$ as an off-white solid; m.p.: $133.2-134.0{ }^{\circ} \mathrm{C} ;{ }^{1} \mathrm{H}$ NMR $\left(400 \mathrm{MHz}, \mathrm{DMSO}-d_{6}\right): \delta 10.89(\mathrm{~s}, 1 \mathrm{H}), 8.08(\mathrm{~d}, J=$ $8.00 \mathrm{~Hz}, 1 \mathrm{H}), 7.54(\mathrm{~d}, J=8.00 \mathrm{~Hz}, 1 \mathrm{H}), 7.33(\mathrm{~d}, J=8.00 \mathrm{~Hz}, 1 \mathrm{H}), 7.24-7.17(\mathrm{~m}, 6 \mathrm{H}), 7.08-7.04(\mathrm{~m}, 1 \mathrm{H}), 7.00-6.96(\mathrm{~m}, 1 \mathrm{H}), 6.87$ $(\mathrm{d}, J=-8.00 \mathrm{~Hz}, 1 \mathrm{H}), 4.51(\mathrm{q}, J=8.00 \mathrm{~Hz}, 1 \mathrm{H}), 4.21-4.15(\mathrm{~m}, 1 \mathrm{H}), 3.25-3.17(\mathrm{~m}, 1 \mathrm{H}), 3.11-3.06(\mathrm{~m}, 1 \mathrm{H}), 2.96-2.92(\mathrm{~m}, 1 \mathrm{H})$, 2.71-2.65 (m, 1H), $1.28(\mathrm{~s}, 9 \mathrm{H}) ;{ }^{13} \mathrm{C}$ NMR (100 MHz, DMSO- $\left.d_{6}\right): \delta 173.6,172.1,155.6,138.5,136.5,129.6,128.4,127.7,126.5$, 124.1, 121.3, 118.8, 118.6, 111.8, 110.3, 110.0, 78.5, 56.1, 53.3, 37.9, 31.4, 28.5, 27.5, 22.5, 14.4; IR (ATR).vmax 3310, 3046, 2926, 1650, 1509, 1436, 1364, 1247, 1158, 1011, 848; HRMS (ESI): m/z calcd for $\mathrm{C}_{25} \mathrm{H}_{29} \mathrm{~N}_{3} \mathrm{O}_{5} \mathrm{Na}[\mathrm{M}+\mathrm{H}]^{+}: 474.2005$; found: 474.1998.

\subsubsection{8. ${ }^{1} \mathrm{H}$ NMR and ${ }^{13} \mathrm{C} N \mathrm{NR}$ spectra of tert-butyl ((S)-1-(((S)-1-((2-(2,3-dibocguanidino)ethyl)amino)-3-(1H-indol-3-yl)-1- oxopropan-2-yl)amino)-1-oxo-3-phenylpropan-2-yl)carbamate (34)}

The title compound $\mathbf{3 4}$ was prepared from compound $\mathbf{1 8 b}(0.333 \mathrm{~g}, 1.1 \mathrm{mmol})$ and $\mathbf{3 3}(0.5 \mathrm{~g}, 1.1 \mathrm{mmol})$ according to the protocol 2. Off-white solid (0.36 g, 45\%); m.p.: $180.6-181.2{ }^{\circ} \mathrm{C} ;{ }^{1} \mathrm{H}$ NMR (400 MHz, DMSO- $\left.d_{6}\right): \delta 11.47$ (br s, $\left.1 \mathrm{H}\right), 10.80(\mathrm{~d}, J=4.00 \mathrm{~Hz}$, $1 \mathrm{H}), 8.37(\mathrm{t}, J=4.00 \mathrm{~Hz}, 1 \mathrm{H}), 8.13(\mathrm{t}, J=4.00 \mathrm{~Hz}, 1 \mathrm{H}), 7.91(\mathrm{~d}, J=8.00 \mathrm{~Hz}, 1 \mathrm{H}), 7.57(\mathrm{~d}, J=8.00 \mathrm{~Hz}, 1 \mathrm{H}), 7.30(\mathrm{~d}, J=8.00 \mathrm{~Hz}$, 1H), 7.20-7.06 (m, 6H), 7.07-7.02 (m, 1H), 6.98-6.94 (m, 1H), $6.88(\mathrm{~d}, J=8.00 \mathrm{~Hz}, 1 \mathrm{H}), 4.48(\mathrm{q}, J=4.00 \mathrm{~Hz}, 1 \mathrm{H}), 4.15-4.09(\mathrm{~m}$, $1 \mathrm{H}), 3.27-2.95(\mathrm{~m}, 6 \mathrm{H}), 2.90-2.85(\mathrm{~m}, 1 \mathrm{H}), 2.69-2.63(\mathrm{~m}, 1 \mathrm{H}), 1.44(\mathrm{~s}, 9 \mathrm{H}), 1.38(\mathrm{~s}, 9 \mathrm{H}), 1.28(\mathrm{~s}, 9 \mathrm{H}) ;{ }^{13} \mathrm{C} \mathrm{NMR}(100 \mathrm{MHz}$, DMSO-d $\left.d_{6}\right): \delta 172.0,171.6,163.5,156.0,155.6,152.3,138.5,136.5,129.6,128.4,127.8,126.6,124.0,121.3,118.9,118.6,111.7$, $110.3,83.3,78.7,78.6,56.4,53.8,38.5,37.9,37.8,28.6,28.5,28.4,28.1$; IR (ATR).vmax 2974, 1637, 1523, 1363, 1248, 1132, 1021; HRMS (ESI): $\mathrm{m} / \mathrm{z}$ calcd for $\mathrm{C}_{38} \mathrm{H}_{53} \mathrm{~N}_{7} \mathrm{O}_{8}[\mathrm{M}+\mathrm{H}]^{+}:$736.3956; found: 736.4023.

4.3.49. ${ }^{1} \mathrm{H} N M R$ and ${ }^{13} \mathrm{C} N M R$ spectra of (S)-2-amino-N-((S)-1-((2-guanidinoethyl)amino)-3-(1H-indol-3-yl)-1-oxopropan-2-yl)-3phenylpropanamide (35 TFA Salt)

The title compound was prepared via protocol 4, using $34(0.150 \mathrm{~g}, 0.203 \mathrm{mmol})$ to yield the desired product 35 as a brown gummy solid (40 mg, 47\%). ${ }^{1} \mathrm{H}$ NMR (400 MHz, DMSO- $\left.d_{6}\right): \delta 10.87(\mathrm{br} \mathrm{s}, 1 \mathrm{H}), 8.81(\mathrm{~d}, J=8.00 \mathrm{~Hz}, 1 \mathrm{H}), 8.30(\mathrm{t}, J=4.00 \mathrm{~Hz}$, $1 \mathrm{H}), 8.06$ (br s, 3H), 7.64-7.62 (m, 2H), 7.34-7.24 (m, 9H), 7.16 (d, J=4.00 Hz, 1H), 7.08-7.04 (m, 1H), 7.00-6.96 (m, 1H), 4.58$4.52(\mathrm{~m}, 1 \mathrm{H}), 4.03$ (br s, $1 \mathrm{H}), 3.26-2.88(\mathrm{~m}, 8 \mathrm{H}) ;{ }^{13} \mathrm{C}$ NMR (100 MHz, DMSO- $\left.d_{6}\right): \delta 172.0,168.3,157.5,136.6,135.2,130.0$, 129.0, 127.64, 127.6, 124.3, 121.4, 118.9, 118.7, 111.8, 110.0, 54.2, 53.6, 38.5, 37.5, 28.6; IR (ATR).vmax 3060, 2919, 1670, 1542, 1421, 1199, 1128, 1002, 825; HRMS (ESI): m/z calcd for $\mathrm{C}_{23} \mathrm{H}_{2}{ }_{9} \mathrm{~N}_{7} \mathrm{O}_{2}[\mathrm{M}+\mathrm{H}]^{+}$: 436.2383; found: 436.2451.

\subsection{Antibacterial activity}

The antimicrobial activity of compounds was evaluated through the broth micro dilution assay using the procedure described by CLSI.[64] Briefly, Staphylococcus aureus [SA38] were grown to mid-log phase in Muller-Hinton broth (MHB) with shaking at $120 \mathrm{rpm}$ and incubated at $37{ }^{\circ} \mathrm{C}$ for $18-24 \mathrm{~h}$. Following incubation, bacteria were washed three times using PBS pH $7.4 \mathrm{with}$ centrifugation at $3500 \mathrm{~g}$ for $10 \mathrm{~min}$ after each wash. After washing, bacteria were diluted with fresh MHB. The turbidity of the bacterial suspensions were adjusted so that $\mathrm{OD}_{600 \mathrm{~nm}}$ was 0.1 , which gave $1 \times 10^{8} \mathrm{cfu} / \mathrm{ml}$, and then further diluted to achieve $1-2 \times 10^{5}$ $\mathrm{cfu} / \mathrm{ml}$ as a final bacterial concentration. Each compound was added at concentrations ranging from $250-3.9 \mu \mathrm{M}$ through serial two-fold dilution. Wells in microtitre plates were loaded with $100 \mu \mathrm{l}$ of inoculum containing $1-2 \times 10^{5} \mathrm{cfu} / \mathrm{ml} \mathrm{bacteria}$. Wells containing only bacteria and without any compound were used as a negative controls (i.e. no inhibition of growth). Wells without bacteria but containing compound acted as another control. The microtitre plate was wrapped with paraffin to prevent evaporation and incubated with shaking at $120 \mathrm{rpm}$ and $37{ }^{\circ} \mathrm{C}$ for $18-24 \mathrm{~h}$. After incubation, spectrophotometric reading of the wells was taken at $600 \mathrm{~nm}$. The minimal inhibitory concentration (MIC) was defined as the lowest concentration of the biphenyl compounds that causes $100 \%$ inhibition of microbial growth. The same procedure was followed for the two Gram-negative bacteria, Pseudomonas aeruginosa [PA01], and Escherichia coli [K12]. Each experiment was performed in triplicate and was repeated in three independent experiments. The MICs of the compounds were compared to published MIC [15, 52, 53] of MSI-78. The method for determining the MIC of MSI-78 [52, 53] , that recommended by the CLSI (formerly named the National Committee for Clinical Laboratory Standards (NCCLS)) was exactly the same as described herein for the current compounds. 
Normal human lung fibroblasts MRC-5 were cultured in minimal essential medium (MEM, Invitrogen) supplemented with $10 \%$ foetal calf serum (FCS), 1\% L-glutamine-penicillin-streptomycin, $2 \%$ sodium bicarbonate, $1 \%$ non-essential amino acids (NEAA) and $1 \%$ sodium pyruvate. The cell line was maintained at $37{ }^{\circ} \mathrm{C}$ in $5 \% \mathrm{CO}_{2}$ as an adherent monolayer and was passaged upon reaching confluence by standard cell culture techniques. MRC- 5 cells were seeded at $2 \times 10^{4}$ cells per well in 96 -well plates to ensure full confluence (quiescence). Cells were treated $24 \mathrm{~h}$ after seeding with 0.1 to $1000 \mu \mathrm{M}$ of compounds. After $72 \mathrm{~h}$ drug incubation, the treated media was replaced with fresh media containing 10\% Alamar blue and the cells were incubated for another $6 \mathrm{~h}$. The metabolic activity was detected by spectrophotometric analysis by assessing the absorbance of Alamar blue as previously described by Pasquier et al. [65] Cell proliferation was determined and expressed as a percentage of untreated control cells. The determination of $\mathrm{IC}_{50}$ values was performed using GraphPad Prism 6 (San Diego, CA, USA).]. Each experiment was performed in triplicate and was repeated in three independent experiments.

\subsection{Tethered bilayer lipid membranes}

The ability of the biphenyl derivatives to interact with lipid bilayers was tested using tethered bilayer lipid membranes (tBLMs) in association with AC electrical impedance spectroscopy techniques [55, 56]. Lipid bilayers were anchored to a gold substrate which were created using the solvent exchange technique described previously [56, 57]. In short, tethered benzyl-disulfide (tetraethyleneglycol) $n=2$ C20-phytanyl tethers: benzyl-disulfide-tetra-ethyleneglycol-OH spacers were pre-prepared in the ratio of 1:10 and were coated onto a gold patterned polycarbonate slide containing a large gold return electrode (SDx Tethered Membranes Pty Ltd, Australia). Attached to this slide was a specialised cartridge chamber which allows for easy addition of reagent between tethering and reference electrodes. A $3 \mathrm{mM}$ solution of a standard mobile lipid phase [70\% zwitterionic C20 Diphytanyl-GlyceroPhosphatidylcholine lipid: 30\% C20 Diphytanyl-diglyceride-OH ether] was added to the tethering chemistries. All lipids were dissolved in 100\% ethanol. Lipids were left for 2 minutes to associate with the tethering chemistries before being washed with $3 \mathrm{x}$ $200 \mathrm{ml}$ phosphate buffered saline (PBS). The membranes formed from these lipids are designated as the "zwitterionic membranes". Alternatively, negatively charged membranes, that resemble those present in many bacterial species, were produced using the same mobile lipid phase which was instead supplemented with 30\% palmitoyl-oleoyl-phosphatidylglycerol (POPG) (Avanti Lipids, USA). The presence of a lipid bilayer was verified using AC electrical impedance spectrometry. These measures were done using a TethaPod ${ }^{\mathrm{TM}}$ operated with TethaQuick ${ }^{\mathrm{TM}}$ software (SDx Tethered Membranes Pty Ltd, Australia). The signal employed was $50 \mathrm{mV}$ peak-to-peak AC excitation at $0.1-2000 \mathrm{~Hz}$ with four steps per decade. Impedance data were fitted to a constant phase element (CPE) in series with a resistor/capacitor. The CPE represents the capacitance of the gold electrode interface, whist the resistor and capacitor represent the resistance and capacitance of the tethered membrane respectively. Fitting was done using a proprietary adaptation of a Lev Mar fitting routine as described previously [56]. All tethered membrane assays were performed in triplicate. Individual results shown are of typical responses to the antimicrobial compounds.

\subsection{Cytoplasmic membrane permeability assay}

The method was adopted from Wu et al. [66] with slight modification. Bacterial cytoplasmic membrane permeability was determined using membrane potential sensitive dye diSC3-5 (3,3'-dipropylthiadicarbocyanine iodide) which penetrates inside bacterial cells depending on the membrane potential gradient of the cytoplasmic membrane. Staphylococcus aureus [SA38] and Escherichia coli [K12] were grown in MHB to mid-log phase by incubating with shaking at $37^{\circ} \mathrm{C}$ for $18-24 \mathrm{~h}$. Following incubation bacteria were washed with $5 \mathrm{mM}$ HEPES containing $20 \mathrm{mM}$ glucose $\mathrm{pH}(7.2)$ and resuspended in the same buffer to an $\mathrm{OD}_{600}$ 0.05-0.06 which gave $1 \times 10^{7} \mathrm{CFU} / \mathrm{ml}$. diSC3-5 was added at $4 \mu \mathrm{M}$ to the bacterial suspension. The suspensions were incubated at room temperature for $1 \mathrm{~h}$ in the dark for maximum dye take-up by bacterial cell. Then, $100 \mathrm{mM} \mathrm{KCl}$ was added to balance the $\mathrm{K}+$ outside and inside the bacterial cell to prevent further uptake or outflow of the dye. For Gram-negative bacteria, $0.5 \mathrm{mM}$ EDTA was used to remove the stabilizing divalent cations from the lipopolysaccharide (LPS) layer which help in dye penetration without affecting bacterial growth. $100 \mu \mathrm{l}$ of bacterial suspension was added in a 96-well microtiter plate with equal volume of antimicrobial compounds. Dimethyl sulfoxide (DMSO) was used as a positive control to achieve maximum fluorescence while bacterial suspension containing only dye and HEPES buffer set as blank to subtract the background. Fluorescence was measured with a luminescence spectrophotometer at 3 min intervals at an excitation wavelength of $622 \mathrm{~nm}$ and an emission wavelength of $670 \mathrm{~nm}$. The experiment was performed in triplicate.

\subsection{Biofilm inhibition assay}

Bacterial cultures (S. aureus and E. coli) were grown in $\mathrm{LB}_{10}$ media overnight at $37{ }^{\circ} \mathrm{C}$ with shaking at $150 \mathrm{rpm}$. Cultures were diluted (1:20) in LB medium and $200 \mu$ aliquots were dispensed to flat bottom 96-well plate wells (Sarstedt Australia). Cultures were supplemented with varying concentrations of synthetic compounds dissolved in DMSO. The cultures were grown in 96-well plate wells overnight along with synthetic compounds. Control cultures were supplemented with an equal amount of DMSO. Plates were sealed with self-adhesive microplate sealers (TopSeal-A, PerkinElmer) to allow air diffusion and to prevent condensation. Cultures were incubated overnight at $37^{\circ} \mathrm{C}$ with shaking at $150 \mathrm{rpm}$. Biofilms adhered on polystyrene substratum were quantified by crystal violet staining as described previously[67]. All cultures were prepared in triplicate.

\section{Acknowledgments}

We thank the NMR and BMSF facilities at UNSW Australia for supporting the characterization of the synthesized compounds. This work was supported by a Discovery Project from Australian Research Council grant (DP 140102195 and DP160101664). 
Rajesh Kuppusamy is thankful to the University of New South Wales for a Tuition Fee Scholarship (TFS) and to Naresh Kumar for a Living Allowance Scholarship. We declare that Bruce Cornell is a shareholder of SDx Tethered Membranes Pty Ltd

\section{References}

[1] W.H. Organization, WHO Antimicrobial Resistance: Global Report on Surveillance, April 2014, in.

[2] C.K. Naber, Staphylococcus aureus bacteremia: epidemiology, pathophysiology, and management strategies, Clinical infectious diseases, 48 (2009) S231-S237.

[3] K.L. Brown, R.E. Hancock, Cationic host defense (antimicrobial) peptides, Current opinion in immunology, 18 (2006) 24-30.

[4] R.E. Hancock, H.-G. Sahl, Antimicrobial and host-defense peptides as new anti-infective therapeutic strategies, Nature biotechnology, 24 (2006) 1551-1557.

[5] S. Wagner, R. Sommer, S. Hinsberger, C. Lu, R.W. Hartmann, M. Empting, A. Titz, Novel strategies for the treatment of Pseudomonas aeruginosa infections, Journal of medicinal chemistry, 59 (2016) 5929-5969.

[6] M.S. Butler, M.A. Blaskovich, M.A. Cooper, Antibiotics in the clinical pipeline at the end of 2015, The Journal of Antibiotics, (2016).

[7] S. Choi, A. Isaacs, D. Clements, D. Liu, H. Kim, R.W. Scott, J.D. Winkler, W.F. DeGrado, De novo design and in vivo activity of conformationally restrained antimicrobial arylamide foldamers, Proceedings of the National Academy of Sciences, 106 (2009) 6968-6973.

[8] A.C. Nilsson, H. Janson, H. Wold, A. Fugelli, K. Andersson, C. Håkangård, P. Olsson, W.M. Olsen, LTX-109 is a novel agent for nasal decolonization of methicillin-resistant and-sensitive Staphylococcus aureus, Antimicrobial agents and chemotherapy, 59 (2015) 145-151.

[9] F. García-Olmedo, A. Molina, J.M. Alamillo, P. Rodríguez-Palenzuéla, Plant defense peptides, Peptide Science, 47 (1998) 479-491.

[10] S. Kurata, Recognition and elimination of diversified pathogens in insect defense systems, Molecular diversity, 10 (2006) 599-605.

[11] A.C. Rinaldi, Antimicrobial peptides from amphibian skin: an expanding scenario: Commentary, Current opinion in chemical biology, 6 (2002) 799-804.

[12] H. Sugiarto, P.-L. Yu, Avian antimicrobial peptides: the defense role of $\beta$-defensins, Biochemical and biophysical research communications, 323 (2004) 721-727.

[13] K. Kuroda, G.A. Caputo, Antimicrobial polymers as synthetic mimics of host-defense peptides, Wiley Interdisciplinary Reviews: Nanomedicine and Nanobiotechnology, 5 (2013) 49-66.

[14] B. Mensa, G.L. Howell, R. Scott, W.F. DeGrado, Comparative mechanistic studies of brilacidin, daptomycin, and the antimicrobial peptide LL16, Antimicrobial agents and chemotherapy, 58 (2014) 5136-5145.

[15] Y. Ge, D.L. MacDonald, K.J. Holroyd, C. Thornsberry, H. Wexler, M. Zasloff, In vitro antibacterial properties of pexiganan, an analog of magainin, Antimicrobial agents and chemotherapy, 43 (1999) 782-788.

[16] B.M. Peters, M.E. Shirtliff, M.A. Jabra-Rizk, Antimicrobial peptides: primeval molecules or future drugs?, PLoS Pathog, 6 (2010) e1001067.

[17] A.A. Bahar, D. Ren, Antimicrobial peptides, Pharmaceuticals, 6 (2013) 1543-1575.

[18] P. Méndez-Samperio, Peptidomimetics as a new generation of antimicrobial agents: current progress, Infection and drug resistance, 7 (2014) 229.

[19] Y. Chen, C.T. Mant, S.W. Farmer, R.E. Hancock, M.L. Vasil, R.S. Hodges, Rational design of $\alpha$-helical antimicrobial peptides with enhanced activities and specificity/therapeutic index, Journal of Biological Chemistry, 280 (2005) 1231612329.

[20] A.J. Karlsson, R.M. Flessner, S.H. Gellman, D.M. Lynn, S.P. Palecek, Polyelectrolyte multilayers fabricated from antifungal $\beta$-peptides: design of surfaces that exhibit antifungal activity against Candida albicans, Biomacromolecules, 11 (2010) 2321-2328.

[21] N.P. Chongsiriwatana, J.A. Patch, A.M. Czyzewski, M.T. Dohm, A. Ivankin, D. Gidalevitz, R.N. Zuckermann, A.E. Barron, Peptoids that mimic the structure, function, and mechanism of helical antimicrobial peptides, Proceedings of the National Academy of Sciences, 105 (2008) 2794-2799.

[22] R. Kapoor, M.W. Wadman, M.T. Dohm, A.M. Czyzewski, A.M. Spormann, A.E. Barron, Antimicrobial peptoids are effective against Pseudomonas aeruginosa biofilms, Antimicrobial agents and chemotherapy, 55 (2011) 3054-3057.

[23] M.L. Huang, S.B.Y. Shin, M.A. Benson, V.J. Torres, K. Kirshenbaum, A comparison of linear and cyclic peptoid oligomers as potent antimicrobial agents, ChemMedChem, 7 (2012) 114-122.

[24] N. Srinivas, P. Jetter, B.J. Ueberbacher, M. Werneburg, K. Zerbe, J. Steinmann, B. Van der Meijden, F. Bernardini, A. Lederer, R.L. Dias, Peptidomimetic antibiotics target outer-membrane biogenesis in Pseudomonas aeruginosa, Science, 327 (2010) 1010-1013. 
[25] S. Mosca, J. Keller, N. Azzouz, S. Wagner, A. Titz, P.H. Seeberger, G. Brezesinski, L. Hartmann, Amphiphilic Cationic B3R3-Peptides: Membrane Active Peptidomimetics and Their Potential as Antimicrobial Agents, Biomacromolecules, 15 (2014) 1687-1695.

[26] A. Makovitzki, D. Avrahami, Y. Shai, Ultrashort antibacterial and antifungal lipopeptides, Proceedings of the National Academy of Sciences, 103 (2006) 15997-16002.

[27] C. Ghosh, J. Haldar, Membrane-Active Small Molecules: Designs Inspired by Antimicrobial Peptides, ChemMedChem, 10 (2015) 1606-1624.

[28] R. Domalaon, G. G Zhanel, F. Schweizer, Short antimicrobial peptides and peptide scaffolds as promising antibacterial agents, Current topics in medicinal chemistry, 16 (2016) 1217-1230.

[29] M.B. Strøm, $\varnothing$. Rekdal, J.S. Svendsen, Antimicrobial activity of short arginine-and tryptophan-rich peptides, Journal of Peptide Science, 8 (2002) 431-437.

[30] M. Ahn, P. Gunasekaran, G. Rajasekaran, E.Y. Kim, S.-J. Lee, G. Bang, K. Cho, J.-K. Hyun, H.-J. Lee, Y.H. Jeon, Pyrazole derived ultra-short antimicrobial peptidomimetics with potent anti-biofilm activity, European Journal of Medicinal Chemistry, 125 (2017) 551-564.

[31] S.M. Wales, K.A. Hammer, A.M. King, A.J. Tague, D. Lyras, T.V. Riley, P.A. Keller, S.G. Pyne, Binaphthyl-1, 2, 3triazole peptidomimetics with activity against Clostridium difficile and other pathogenic bacteria, Organic \& biomolecular chemistry, 13 (2015) 5743-5756.

[32] C. Ghosh, G.B. Manjunath, M.M. Konai, D.S. Uppu, K. Paramanandham, B.R. Shome, R. Ravikumar, J. Haldar, Arylalkyl-lysines: Membrane-active small molecules active against murine model of burn infection, ACS Infectious Diseases, 2 (2015) 111-122.

[33] J. Hoque, M.M. Konai, S.S. Sequeira, S. Samaddar, J. Haldar, Antibacterial and Antibiofilm Activity of Cationic Small Molecules with Spatial Positioning of Hydrophobicity: An in Vitro and in Vivo Evaluation, Journal of Medicinal Chemistry, 59 (2016) 10750-10762.

[34] S. Nizalapur, K.K. Ho, Ö. Kimyon, E. Yee, T. Berry, M. Manefield, C.G. Cranfield, M. Willcox, D.S. Black, N. Kumar, Synthesis and biological evaluation of $\mathrm{N}$-naphthoyl-phenylglyoxamide-based small molecular antimicrobial peptide mimics as novel antimicrobial agents and biofilm inhibitors, Organic \& biomolecular chemistry, 14 (2016) 3623-3637. [35] S. Nizalapur, O. Kimyon, E. Yee, K. Ho, T. Berry, M. Manefield, C.G. Cranfield, M. Willcox, D.S. Black, N. Kumar, Amphipathic guanidine-embedded glyoxamide-based peptidomimetics as novel antibacterial agents and biofilm disruptors, Organic \& Biomolecular Chemistry, (2017).

[36] D.A. Horton, G.T. Bourne, M.L. Smythe, The combinatorial synthesis of bicyclic privileged structures or privileged substructures, Chemical Reviews, 103 (2003) 893-930.

[37] M.E. Welsch, S.A. Snyder, B.R. Stockwell, Privileged scaffolds for library design and drug discovery, Current opinion in chemical biology, 14 (2010) 347-361.

[38] H. Aldemir, R. Richarz, T.A. Gulder, The biocatalytic repertoire of natural biaryl formation, Angewandte Chemie International Edition, 53 (2014) 8286-8293.

[39] G. Bringmann, T. Gulder, T.A. Gulder, M. Breuning, Atroposelective total synthesis of axially chiral biaryl natural products, Chemical reviews, 111 (2010) 563-639.

[40] M.C. Kozlowski, B.J. Morgan, E.C. Linton, Total synthesis of chiral biaryl natural products by asymmetric biaryl coupling, Chemical Society reviews, 38 (2009) 3193-3207.

[41] A. Isnansetyo, Y. Kamei, Anti-methicillin-resistant Staphylococcus aureus (MRSA) activity of MC21-B, an antibacterial compound produced by the marine bacterium Pseudoalteromonas phenolica O-BC30 T, International journal of antimicrobial agents, 34 (2009) 131-135.

[42] H. Rahman, B. Austin, W.J. Mitchell, P.C. Morris, D.J. Jamieson, D.R. Adams, A.M. Spragg, M. Schweizer, Novel anti-infective compounds from marine bacteria, Marine drugs, 8 (2010) 498-518.

[43] C.C. CHANG, G.O. MORTON, J.C. JAMES, M.M. SIEGEL, N.A. KUCK, R.T. TESTA, D.B. BORDERS, LL-AF283 antibiotics, cyclic biphenyl peptides, The Journal of antibiotics, 44 (1991) 674-677.

[44] I. UCHIDA, N. SHIGEMATSU, M. EZAKI, M. HASHIMOTO, H. AOKI, H. IMANAKA, Biphenomycins A and B, novel peptide antibiotics. II. Structural elucidation of biphenomycins A and B, The Journal of antibiotics, 38 (1985) 14621468.

[45] K. Pérez-Labrada, M.A. Cruz-Mendoza, A. Chávez-Riveros, E. Hernández-Vázquez, T. Torroba, L.D. Miranda, Diversity-oriented synthesis and cytotoxic activity evaluation of biaryl-containing macrocycles, Organic \& Biomolecular Chemistry, (2017).

[46] D.I. Chan, E.J. Prenner, H.J. Vogel, Tryptophan-and arginine-rich antimicrobial peptides: structures and mechanisms of action, Biochimica et Biophysica Acta (BBA)-Biomembranes, 1758 (2006) 1184-1202.

[47] L. Li, I. Vorobyov, T.W. Allen, The different interactions of lysine and arginine side chains with lipid membranes, The Journal of Physical Chemistry B, 117 (2013) 11906-11920. 
[48] T. Wieprecht, M. Dathe, M. Beyermann, E. Krause, W.L. Maloy, D.L. MacDonald, M. Bienert, Peptide hydrophobicity controls the activity and selectivity of magainin 2 amide in interaction with membranes, Biochemistry, 36 (1997) 6124-6132.

[49] D.-K. Lee, A. Bhunia, S.A. Kotler, A. Ramamoorthy, Detergent-type membrane fragmentation by MSI-78, MSI-367, MSI-594, and MSI-843 antimicrobial peptides and inhibition by cholesterol: a solid-state nuclear magnetic resonance study, Biochemistry, 54 (2015) 1897-1907.

[50] A. Ramamoorthy, S. Thennarasu, D.-K. Lee, A. Tan, L. Maloy, Solid-state NMR investigation of the membranedisrupting mechanism of antimicrobial peptides MSI-78 and MSI-594 derived from magainin 2 and melittin, Biophysical journal, 91 (2006) 206-216.

[51] L.M. Gottler, A. Ramamoorthy, Structure, membrane orientation, mechanism, and function of pexiganan-a highly potent antimicrobial peptide designed from magainin, Biochimica et Biophysica Acta (BBA)-Biomembranes, 1788 (2009) 1680-1686.

[52] A.K. Jepson, J. Schwarz-Linek, L. Ryan, M.G. Ryadnov, W.C. Poon, What Is the 'Minimum Inhibitory Concentration'(MIC) of Pexiganan Acting on Escherichia coli?-A Cautionary Case Study, in: Biophysics of Infection, Springer, 2016, pp. 33-48.

[53] Q.Y. Lau, F.M. Ng, J.W.D. Cheong, Y.Y.A. Yap, Y.Y.F. Tan, R. Jureen, J. Hill, C.S.B. Chia, Discovery of an ultra-short linear antibacterial tetrapeptide with anti-MRSA activity from a structure-activity relationship study, European journal of medicinal chemistry, 105 (2015) 138-144.

[54] J. O'brien, I. Wilson, T. Orton, F. Pognan, Investigation of the Alamar Blue (resazurin) fluorescent dye for the assessment of mammalian cell cytotoxicity, European Journal of Biochemistry, 267 (2000) 5421-5426.

[55] C.G. Cranfield, B.a. Cornell, S.L. Grage, P. Duckworth, S. Carne, A.S. Ulrich, B. Martinac, Transient potential gradients and impedance measures of tethered bilayer lipid membranes: Pore-forming peptide insertion and the effect of electroporation, Biophysical Journal, 106 (2014) 182-189.

[56] C.G. Cranfield, T. Bettler, B. Cornell, Nanoscale ion sequestration to determine the polarity selectivity of ion conductance in carriers and channels, Langmuir, 31 (2015) 292-298.

[57] C. Cranfield, S. Carne, B. Martinac, B. Cornell, The Assembly and Use of Tethered Bilayer Lipid Membranes (tBLMs), in: Methods in Membrane Lipids, Springer New York, 2015, pp. 45-53.

[58] C.G. Cranfield, T. Berry, S.A. Holt, K.R. Hossain, A.P. Le Brun, S. Carne, H. Al Khamici, H. Coster, S.M. Valenzuela, B. Cornell, Evidence of the key role of H3O+ in phospholipid membrane morphology, Langmuir, 32 (2016) 10725-10734.

[59] F.-Y. Chen, M.-T. Lee, H.W. Huang, Evidence for membrane thinning effect as the mechanism for peptide-induced pore formation, Biophysical journal, 84 (2003) 3751-3758.

[60] P. Jorge, D. Grzywacz, W. Kamysz, A. Lourenço, M.O. Pereira, Searching for new strategies against biofilm infections: Colistin-AMP combinations against Pseudomonas aeruginosa and Staphylococcus aureus single-and double-species biofilms, PloS one, 12 (2017) e0174654.

[61] O. Cirioni, C. Silvestri, R. Ghiselli, W. Kamysz, D. Minardi, P. Castelli, F. Orlando, E. Kamysz, M. Provinciali, G. Muzzonigro, In vitro and in vivo effects of sub-MICs of pexiganan and imipenem on Pseudomonas aeruginosa adhesion and biofilm development, Le infezioni in medicina: rivista periodica di eziologia, epidemiologia, diagnostica, clinica e terapia delle patologie infettive, 21 (2013) 287-295.

[62] G. Wang, B. Mishra, R.F. Epand, R.M. Epand, High-quality 3D structures shine light on antibacterial, anti-biofilm and antiviral activities of human cathelicidin LL-37 and its fragments, Biochimica et Biophysica Acta (BBA)Biomembranes, 1838 (2014) 2160-2172.

[63] M.F. Mohamed, A. Abdelkhalek, M.N. Seleem, Evaluation of short synthetic antimicrobial peptides for treatment of drug-resistant and intracellular Staphylococcus aureus, Scientific reports, 6 (2016) 29707.

[64] M.A. Wikler, Methods for dilution antimicrobial susceptibility tests for bacteria that grow aerobically: approved standard, Clinical and Laboratory Standards Institute, 2006.

[65] E. Pasquier, J. Ciccolini, M. Carre, S. Giacometti, R. Fanciullino, C. Pouchy, M.-P. Montero, C. Serdjebi, M. Kavallaris, $\mathrm{N}$. André, Propranolol potentiates the anti-angiogenic effects and anti-tumor efficacy of chemotherapy agents: implication in breast cancer treatment, Oncotarget, 2 (2011) 797.

[66] M. Wu, E. Maier, R. Benz, R.E. Hancock, Mechanism of interaction of different classes of cationic antimicrobial peptides with planar bilayers and with the cytoplasmic membrane of Escherichia coli, Biochemistry, 38 (1999) 72357242.

[67] G.A. O'Toole, Microtiter dish biofilm formation assay, Journal of visualized experiments: JoVE, (2011). 